MARCO ANTONIO SOBRAL FERNANDES

\title{
DIMENSIONAMENTO DE ESFORÇOS RESISTENTES EM BARRAS DE AÇO SOB INCÊNDIO NATURAL COMPARTIMENTADO “ONE ZONE”
}

\author{
Dissertação apresentada à Escola \\ Politécnica da Universidade de São Paulo \\ para obtenção do Título de Mestre em \\ Engenharia.
}

São Paulo 2006 
MARCO ANTONIO SOBRAL FERNANDES

\section{DIMENSIONAMENTO DE ESFORÇOS RESISTENTES EM BARRAS DE AÇO SOB INCÊNDIO NATURAL COMPARTIMENTADO “ONE ZONE”}

Dissertação apresentada à Escola Politécnica da Universidade de São Paulo para obtenção do Título de Mestre em Engenharia.

Área de Concentração:

Engenharia de Estruturas

Orientador:

Prof. Dr. Valdir Pignatta e Silva

São Paulo 2006 
Este exemplar foi revisado e alterado em relação ao original, sob responsabilidade única do autor e com anuência de seu orientador.

São Paulo, 14 de julho de 2006.

Assinatura do autor

Assinatura do orientador

FICHA CATALOGRÁFICA

\section{Fernandes, Marco Antonio Sobral}

Determinação de esforços resistentes em barras de aço sob incêndio natural compartimentado "one zone" / M.A.S. Fernandes. -- São Paulo, 2006.

$165 \mathrm{p}$.

Dissertação (Mestrado) - Escola Politécnica da Universidade de São Paulo. Departamento de Engenharia de Estruturas e Fundações.

1.Estruturas de aço em situação de incêndio 2.Transferência de calor 3.Esforços de barras de aço I.Universidade de São Paulo. Escola Politécnica. Departamento de Engenharia de Estruturas e Fundações II.t. 


\section{AGRADECIMENTOS}

Ao orientador Valdir Pignatta e Silva, pelo empenho, paciência e pela liberdade proporcionada no desenvolvimento do programa de computador e da dissertação.

Ao Dr. Fábio Pannoni e ao Prof. Dr. Ruy Pauletti, pela contribuição à pesquisa bibliográfica e pelos valiosos comentários na etapa de qualificação.

À Projesoft Engenharia por permitir ausentar-me do trabalho por vários dias para a realização deste trabalho e por me ceder componentes imprescindíveis para a elaboração do programa de computador STRESFIRE.

À minha família pelo apoio e enfim aos amigos que fiz durante estes três anos, que tornaram esta empreitada mais agradável. 


\section{RESUMO}

O interesse pelo estudo de estruturas em situação de incêndio vem aumentando dadas as inúmeras ocorrências internacionais, que resultaram em colapso estrutural de edificações. As recentes revisões das normas técnicas brasileiras reforçam a preocupação de organismos públicos e da comunidade técnica.

A contribuição deste trabalho é determinar como os esforços resistentes em perfis isolados de aço são afetados pela ação térmica provenientes do incêndio, ou melhor, em função das variáveis que modelam o incêndio natural.

Para tanto foi desenvolvido o programa de computador STRESFIRE capaz de calcular a ação térmica conforme curvas paramétricas, a transferência de calor para a peça de aço e o esforço resistente em função da temperatura na formulação a ser apresentada na revisão da NBR 14323:1999. 


\begin{abstract}
The interest by study of structures in fire situation has increased due to several international occurrences, which resulted in structural collapse of buildings. The recent revisions of the Brazilian technical standards reinforce the concern of public organisms and technical community.

The contribution of this work is determine how the structural resistance of isolated steel element is affected by fire thermal action, in other words, the variables that model the natural fire.

A software STRESFIRE was developed, which calculates the temperatures in the compartment, the heat transfer to steel member and the fire resistance by analytical methods.
\end{abstract}




\section{SUMÁRIO}

\section{LISTA DE FIGURAS \\ LISTA DE TABELAS \\ LISTA DE ABREVIATURAS E SIGLAS}

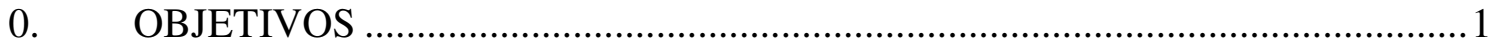

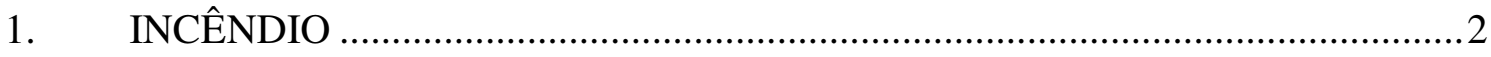

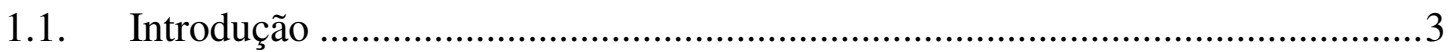

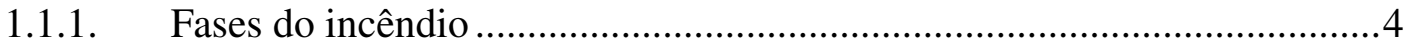

1.1.2. Danos causados às estruturas ......................................................... 7

1.1.3. Segurança contra incêndio ......................................................... 9

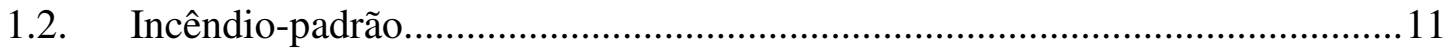

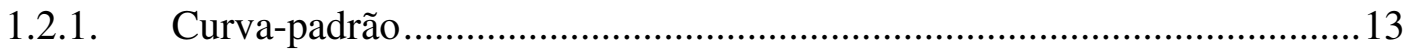

1.2.2. Curva de hidrocarbonetos .............................................................. 14

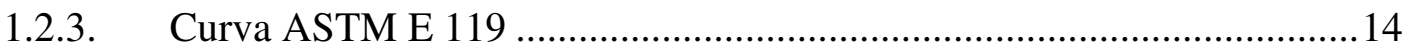

1.2.4. Comparação entre curvas nominais ...................................................... 15

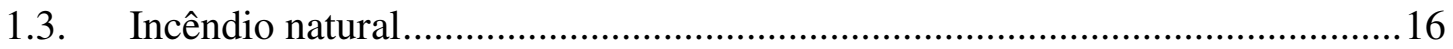

1.3.1. Histórico do modelo de incêndio natural ............................................. 17

1.3.2. Cálculo da curva paramétrica do EC1 (2002) ......................................20

1.3.3. Comparação entre os EC1 (1994 e 2002) ..............................................28

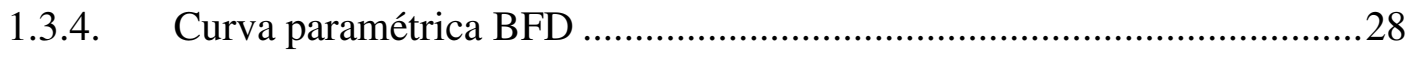

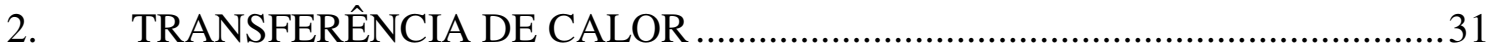

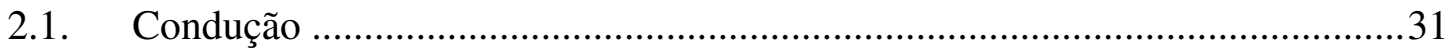

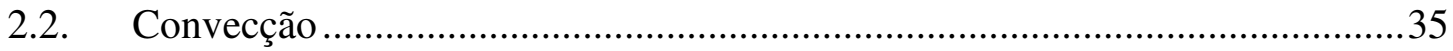


2.3. Radiação

2.4. Transferência de calor em incêndios ..........................................................43

2.4.1. Relação do fluxo de calor com o flashover .......................................47

2.4.2. Ensaios para determinação do fluxo de calor.......................................49

3. TEMPERATURA NOS ELEMENTOS DE AÇO..........................................53

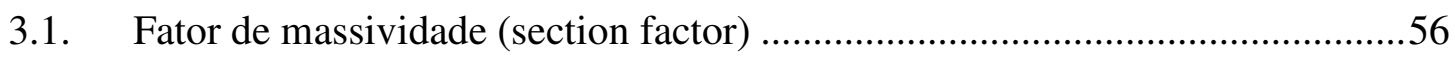

3.2. Distribuição de temperatura em elementos sem proteção...............................60

3.3. Distribuição de temperatura em elementos com revestimento contra fogo .....62

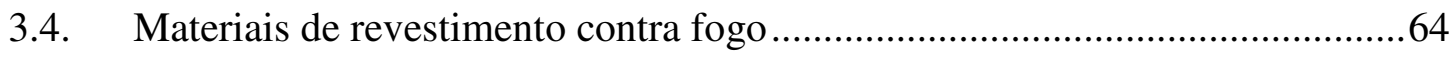

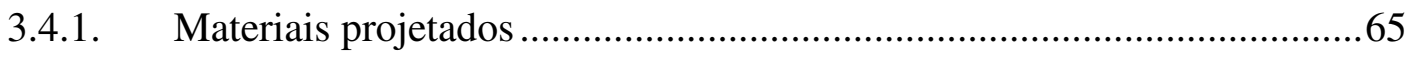

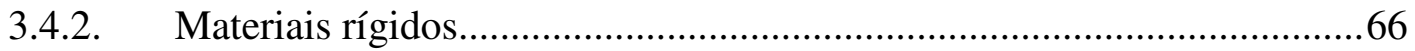

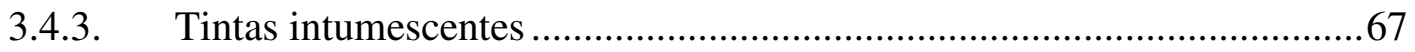

4. MÉTODO SIMPLIFICADO DE DIMENSIONAMENTO .............................6 68

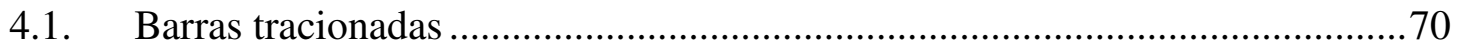

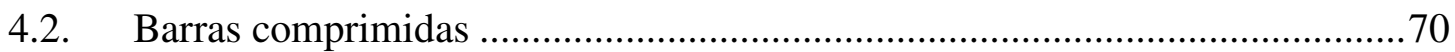

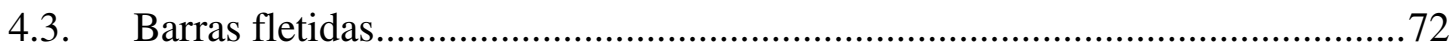

4.4. Verificação de força cortante em incêndio..................................................79

4.5. Combinação de solicitações ................................................................. 80

5. ELABORAÇÃO DO PROGRAMA STRESFIRE ........................................ 83

5.1. Modelos de incêndio compartimentado .................................................. 84

5.2. Entradas e saídas do programa STRESFIRE ............................................ 86

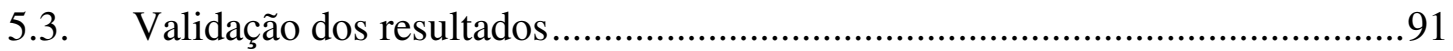

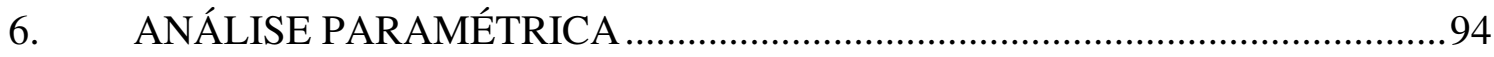




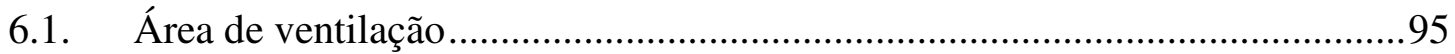

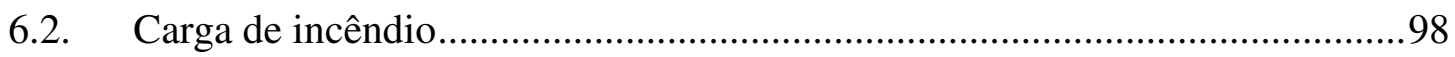

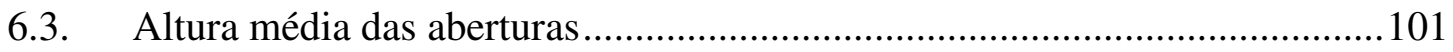

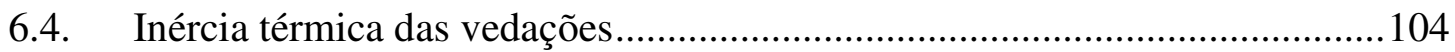

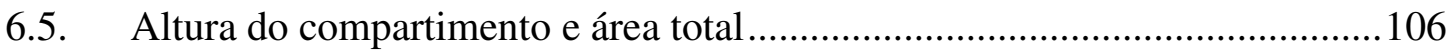

6.6. Fator de massividade ................................................................................. 110

6.7. Espessura do material de revestimento .........................................................112

6.8. Características térmicas do material de revestimento contra fogo...................114

6.8.1. Massa específica...............................................................................114

6.8.2. Calor específico.............................................................................116

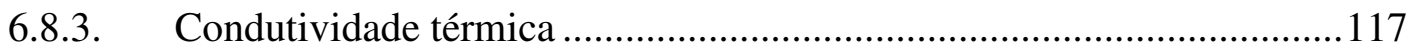

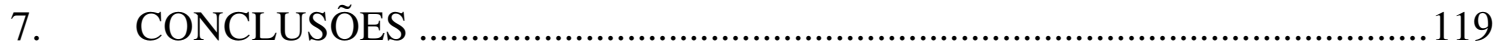

8. SUGESTÕES PARA FUTUROS TRABALHOS ..........................................120

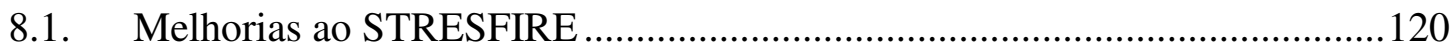

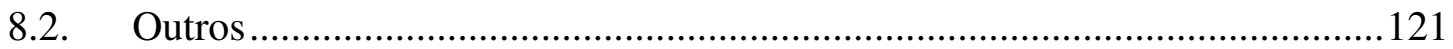

APÊNDICE A - PROPRIEDADES DO AÇO

APÊNDICE B - VALIDAÇÃO DOS ESFORÇOS RESISTENTES (STRESFIRE)

LISTA DE REFERÊNCIAS BIBLIOGRÁFICAS 


\section{LISTA DE FIGURAS}

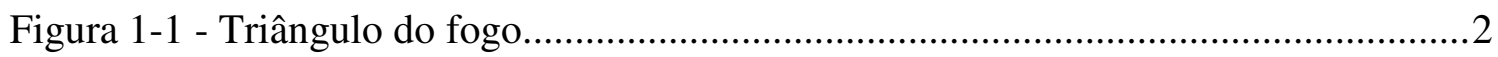

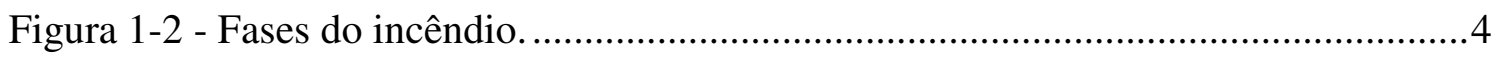

Figura 1-3 - Fase de propagação do incêndio. Fonte: PEACOCK et al, 1999.....................5

Figura 1-4 - Flambagem local no topo do pilar (Ensaio de Cardington, 1996).................8

Figura 1-5 - Deformação de lajes (Ensaio de Cardington, 1996). ...................................... 8

Figura 1-6 - Curva de incêndio padrão (1) x Curva de incêndio natural (2).....................13

Figura 1-7 - Gráfico comparativo entre as curvas nominais tempo-temperatura..............16

Figura 1-8 - Comparação entre testes de Cardington e as curvas BFD. Fonte:

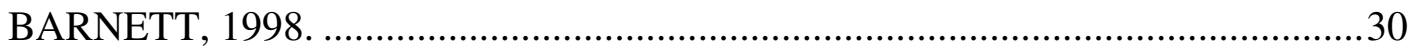

Figura 2-1 - Condução em barra de seção constante (modelo unidimensional)................31

Figura 2-2 - Análise de condução de calor unidimensional ................................................34

Figura 2-3 - Sólido de volume elementar para análise tridimensional de condução de

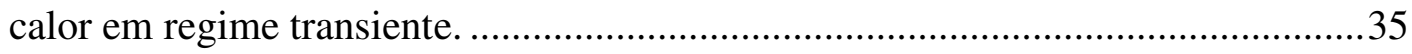

Figura 2-4 -. Influência do escoamento na distribuição de temperatura e velocidade ......37

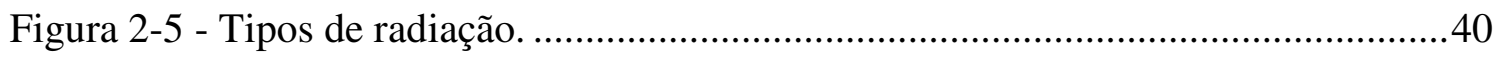

Figura 2-6 - Relação de transmissão de calor com as fases do incêndio. Fonte: KENNEDY; KENNEDY, 2003 .........................................................................4

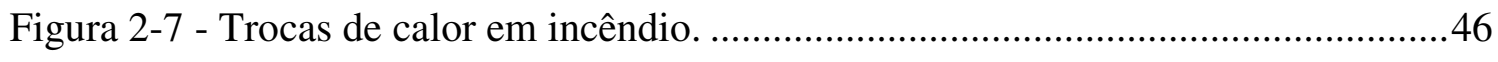

Figura 2-8 - Relação entre o fluxo de calor e o tempo para o flashover. Fonte: BABRAUSKAS; PEACOCK; RENEKE, 2003 .....................................................48

Figura 2-9 - Calorímetro de Cone. Fonte: JANSSENS, 2000 ..........................................51 
Figura 3-1 - Resistência ao escoamento relativo em função da temperatura Fonte: JEANSSON; ANDERBERG, 2001.

Figura 3-2 - Módulo de elasticidade relativo em função da temperatura. Fonte: JEANSSON; ANDERBERG, 2001. .54

Figura 5-1 - Dados para modelagem da curva de incêndio. .87

Figura 5-2 - Definição das características térmicas das vedações. .87

Figura 5-3 - Dados para transferência de calor. .88

Figura 5-4 - Definições para determinação dos esforços resistentes. .88

Figura 5-5 - Gráfico da curva tempo-temperatura dos gases quentes e do perfil de aço de curvas nominais ou paramétricas; 91

Figura 5-6 - Gráfico da curva de esforço resisitente do aço - tempo em incêndio compartimentados para barras tracionadas ou comprimidas ou sob flexão simples;

Figura 6-1 - Temperatura dos gases em função do tempo para diversas área de ventilação

Figura 6-2 - Temperaturas máximas em função do tempo para diversas áreas de ventilação .97

Figura 6-3 - Temperatura do aço em função da área de ventilação .98

Figura 6-4 - Temperatura dos gases do compartimento conforme carga de incêndio por área de piso. 100

Figura 6-5 - Temperaturas máximas dos gases e do aço conforme carga de incêndio. 101 Figura 6-6 - Temperatura dos gases em função da altura média das aberturas. 103

Figura 6-7 - Temperatura máxima doas gases e do aço conforme altura média das aberturas 103

Figura 6-8 - Temperatura dos gases conforme características térmicas das vedações. .105 
Figura 6-9 - Temperatura máxima dos gases e do aço conforme inércia térmica das

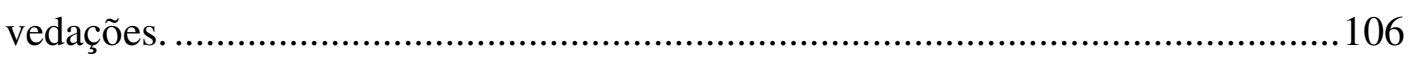

Figura 6-10 - Temperatura dos gases para os itens 6.6 a $6.8 \ldots \ldots \ldots \ldots \ldots \ldots \ldots \ldots \ldots \ldots \ldots \ldots \ldots \ldots \ldots . . . .109$

Figura 6-11 - Temperatura do aço conforme fator de massividade .................................111

Figura 6-12 - Temperatura máxima do aço conforme fator de massividade ..................111

Figura 6-13 - Temperatura do elemento de aço conforme espessura do revestimento contra fogo

Figura 6-14 - Temperaturas máximas do aço conforme massa específica do revestimento

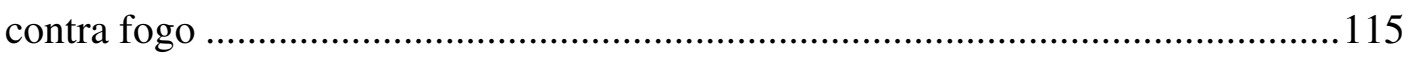

Figura 6-15 - Temperaturas máximas do aço conforme calor específico do revestimento contra fogo

Figura 6-16 - Temperaturas máximas do aço conforme condutividade térmica do

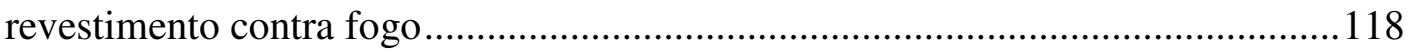




\section{LISTA DE TABELAS}

Tabela 1-1 - Contabilidade de fatalidades por incêndio em cidades americanas. Fonte: NFIRS - National Fire Incident Reporting System.......................................... 10

Tabela 1-2 - Valores de Tempo-Temperatura da ASTM ........................................... 15

Tabela 1-3 - Parâmetros obtidos por Barnett em diversos ensaios. Fonte: BARNETT

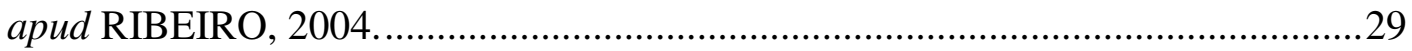

Tabela 2-1 Valores de condutividade térmica a $0{ }^{\circ} \mathrm{C}$. Fonte: LIENHARD, 2005..........32

Tabela 2-2 Valores de emissividade dada uma temperatura. Fonte: LIENHARD, 2005.42 Tabela 3-1 - Fator de massividade de elementos não revestidos. Fonte: NBR 14323:1999

Tabela 3-2 - Fator de massividade de elementos revestidos. Fonte: NBR 14323:1999. .59

Tabela 4-1-Fatores de redução da resistência ao escoamento para aços submetidos a ação térmica. FONTE: NBR 14323:1999

Tabela 4-2 - Expressões para cálculo dos parâmetros $\lambda, \lambda_{p}, \lambda_{r}$ de acordo o caso de flambagem. Expressões válidas para perfis com seção transversal em forma de "I" ou "H" com dois eixos de simetria fletidos em torno do eixo de maior inércia Fonte: NBR 8800 (em revisão)

Tabela 4-3. Expressões para cálculo do parâmetros $\lambda, \lambda_{\mathrm{p}}, \lambda_{\mathrm{r}}$ para força cortante. Fonte: NBR 8800 (em revisão) .79

Tabela 5-1 - Tabela comparativa de temperatura de perfis desprotegidos, conforme a curva ISO. Parâmetros: $\mathrm{F}=100 \mathrm{~m}^{-1} / \varepsilon=0,7$.

Tabela 5-2 - Tabela comparativa de temperatura de perfis desprotegidos, conforme a curva ISO. Parâmetros: $\mathrm{F}=200 \mathrm{~m}^{-1} / \varepsilon=0,5$.

Tabela 5-3- Tabela comparativa de temperatura de perfis protegidos, conforme a curva ISO. Parâmetros: $\mathrm{F}=106,67 \mathrm{~m}^{-1}, \lambda_{\mathrm{m}}=0,15 \mathrm{~W} / \mathrm{m}^{\circ} \mathrm{C}, \mathrm{t}_{\mathrm{m}}=0,02 \mathrm{~m}, \varepsilon=0,7$. 
Tabela 6-1 - Temperaturas máximas dos gases e do aço conforme área de ventilação...96

Tabela 6-2 - Esforços resistentes conforme área de ventilação do compartimento. ........98

Tabela 6-3 - Temperatura máximas dos gases e do aço conforme carga de incêndio.....99

Tabela 6-4 - Esforços resistentes conforme carga de incêndio ....................................101

Tabela 6-5 - Temperaturas máximas dos gases e do aço conforme altura média das

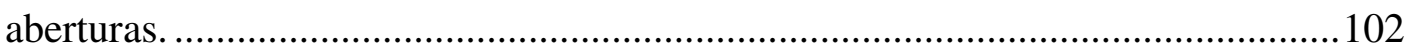

Tabela 6-6 - Esforços resistentes conforme altura média das aberturas. ....................... 104

Tabela 6-7 - Temperaturas máximas dos gases e do aço conforme inércia térmica das

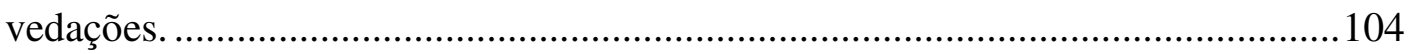

Tabela 6-8 - Esforços resistentes conforme inércia térmica das vedações ....................106

Tabela 6-9 - Correlação entre altura e área total do compartimento ..............................107

Tabela 6-10 - Temperaturas máximas dos gases e do aço conforme altura do

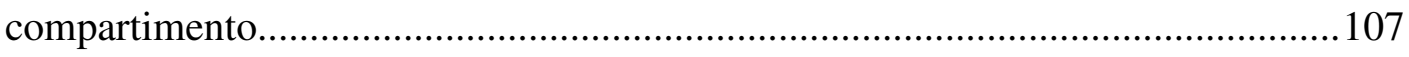

Tabela 6-11 - Esforços resistentes conforme altura do compartimento ........................107

Tabela 6-12 - Correlação entre altura e área total do compartimento...........................108

Tabela 6-13 - Temperaturas máximas dos gases e do aço conforme altura do

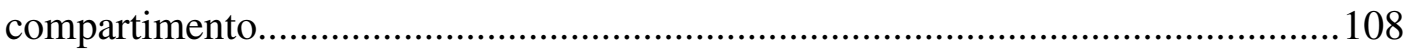

Tabela 6-14- Temperatura dos gases conforme Figura 6-10. ..................................109

Tabela 6-15 - Temperaturas máximas do aço conforme fator de massividade..............110

Tabela 6-16 - Esforços resistentes conforme fator de massividade. ...........................112

Tabela 6-17 - Temperaturas máximas do aço conforme espessura do material de

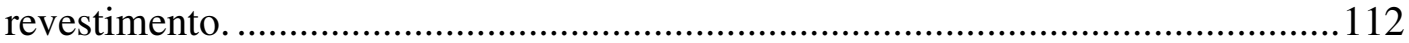

Tabela 6-18- Variação de temperatura conforme espessura do revestimento................113

Tabela 6-19 - Esforços resistentes conforme espessura do revestimento contra fogo...114 
Tabela 6-20 - Temperaturas máximas do aço conforme massa específica do revestimento

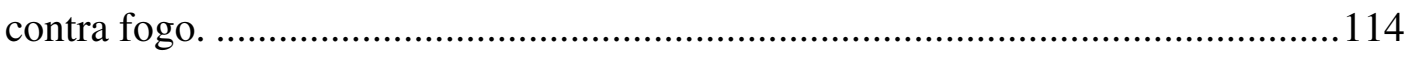

Tabela 6-21 - Esforços resistentes conforme massa específica do material de

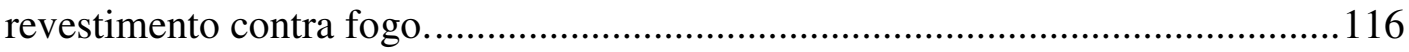

Tabela 6-22 - Temperaturas máximas do aço conforme calor específico do revestimento contra fogo.

Tabela 6-23 - Esforços resistentes conforme calor específico do material de revestimento contra fogo 117

Tabela 6-24 - Temperaturas máximas do aço conforme condutividade térmica do revestimento contra fogo 118

Tabela 6-25 - Esforços resistentes conforme condutividade térmica de revestimento contra fogo ...............................................................................................119 


\section{LISTA DE ABREVIATURAS E SIGLAS}

$\begin{array}{ll}\text { ASTM } & \text { American Standards and Testing Materials } \\ \text { BFD } & \text { Barnett Fire Design } \\ \text { BS } & \text { British Standards } \\ \text { HRR } & \text { Heat Release Rate } \\ \text { EC } & \text { Eurocode } \\ \text { FSD } & \text { Fire Safety Design } \\ \text { ISO } & \text { International of Standardization Organization } \\ \text { NBS } & \text { National Bureau of Standards } \\ \text { NFPA } & \text { National Fire Prevention Association } \\ \text { NFIRS } & \text { National Fire Incident Reporting System } \\ \text { NBR } & \text { Norma Brasileira } \\ \text { OSU } & \text { Ohio State University } \\ \text { SBN } & \text { Swedish Building Regulations } \\ \text { SIA } & \text { Societé Suisse des Ingénieurs et des Architectes } \\ \text { STRESFIRE } & \text { Steel Resistance in Fire } \\ \text { TRRF } & \text { Tempo requerido de resistência ao fogo } \\ \text { UL } & \text { Underwriter's Laboratory }\end{array}$




\section{LISTA DE SÍMBOLOS}

\section{Letras maiúsculas}

A área da seção transversal infinitesimal através da qual o calor flui $\mathrm{m}^{2}$ (cap. 2)

A área líquida da seção transversal da peça estrutural $\mathrm{m}^{2}$

$A_{f}$ área de piso $\mathrm{m}^{2}$

$A_{g} \quad$ área bruta da seção transversal da barra $\mathrm{m}^{2}$

$A_{t} \quad$ área total do compartimento (teto, piso e paredes) $\mathrm{m}^{2}$

$A_{v} \quad$ área total de aberturas verticais / área de ventilação $\mathrm{m}^{2}$

$A_{j} \quad$ área de cada superfície (aberturas não incluídas) $\quad \mathrm{m}^{2}$

$A_{w} \quad$ área da seção transversal da alma $\mathrm{m}^{2}$

$C_{b} \quad$ fator de equivalência de momentos na flexão

$C_{w} \quad$ constante de empenamento da seção $\quad \mathrm{m}^{6}$

$E$ energia irradiada do corpo real (cap. 2) $\mathrm{W} / \mathrm{m}^{2}$

E módulo de elasticidade do aço (cap. 4) $\quad \mathrm{kN} / \mathrm{m}^{2}$

$E_{b} \quad$ energia irradiada do corpo ideal $\quad \mathrm{W} / \mathrm{m}^{2}$

$F \quad$ fator de massividade para elementos estruturais de aço $\mathrm{m}^{-1}$

$F_{v}$ grau de ventilação $\quad \mathrm{m}^{1 / 2}$

$F_{v, \text { lim }}$ grau de ventilação limite para incêndios controlados pelo combustível

$G$ módulo de deformação transversal do aço $\quad \mathrm{kN} / \mathrm{m}^{2}$

Iy momento de inércia à flexão em relação ao eixo de maior inércia $\mathrm{m}^{4}$

$I_{t}$ momento de inércia à torção $\quad \mathrm{m}^{4}$

L comprimento característico que descreve o sistema m

$\begin{array}{lll}M_{c r} & \text { momento fletor de flambagem elástica } \quad \text { kN.m }\end{array}$ 
$M_{p l} \quad$ momento de plastificação da seção transversal para projeto em kN.m temperatura ambiente

$M_{f i, R d}$ momento resistente de cálculo de uma barra em situação de kN.m incêndio

$M_{r} \quad$ momento fletor correspondente ao início do escoamento da seção $\quad$ kN.m transversal para projeto em temperatura ambiente

$N_{f i, R d}$ resistência de cálculo de uma barra axialmente tracionada ou $\mathrm{kN}$ comprimida em situação de incêndio

$N_{u} \quad$ número de Nusselt

Pr número de Prandtl

$Q_{f o} \quad$ calor liberado crítico para ocorrência de flashover MW

$\dot{Q}$ calor proveniente da combustão $\quad$ W

$\dot{Q}_{b} \quad$ calor absorvido pelos gases do compartimento

$\dot{Q} \quad$ calor gerado durante a combustão $\quad$ W

$\dot{Q}_{l} \quad$ perda de calor por fluxo convectivo através de aberturas $\quad$ W

$\dot{Q}$ calor dissipado por radiação através das aberturas W

$\dot{Q}$ calor dissipado por meio dos elementos de vedação $\quad$ W

Re número de Reynolds

$R_{f i d}$ resistência de cálculo correspondente do elemento estrutural para o estado limite último em consideração, em situação de incêndio

$S_{f i, d} \quad$ solicitação de cálculo em situação de incêndio

$V_{f i, R d} \quad$ valor de cálculo da força cortante resistente em situação de $\quad \mathrm{kN}$ 
$V_{p l} \quad$ força cortante correspondente à plastificação da alma por $\quad \mathrm{kN}$ cisalhamento

W módulo resistente elástico $\mathrm{m}^{3}$

Z módulo resistente plástico $\mathrm{m}^{3}$

\section{Letras minúsculas}

$b \quad$ propriedade térmica das vedações do compartimento $\quad \mathrm{J} / \mathrm{m}^{2} \mathrm{~s}^{1 / 2}{ }^{\circ} \mathrm{C}$

$b_{\mathrm{j}} \quad$ propriedade térmica de cada superfície $\quad \mathrm{J} / \mathrm{m}^{2} \mathrm{~s}^{1 / 2}{ }^{\circ} \mathrm{C}$

c calor específico do material de vedação (cap. 1) $\quad \mathrm{J} / \mathrm{kg}{ }^{\circ} \mathrm{C}$

c velocidade da luz (cap. 2) $\mathrm{m} / \mathrm{s}$

$\begin{array}{lll}c_{a} \quad \text { calor específico do aço } & \mathrm{J} / \mathrm{kg}{ }^{\circ} \mathrm{C}\end{array}$

$c_{m} \quad$ calor específico do material de revestimento contra fogo $\quad \mathrm{J} / \mathrm{kg}^{\circ} \mathrm{C}$

$f$ freqüência de onda $\mathrm{s}^{-1}$

$f_{y} \quad$ valor característico de resistência de escoamento do aço $\quad \mathrm{kN} / \mathrm{m}^{2}$

$h$ altura interna do perfil de aço $\mathrm{m}$

$\dot{h}$ fluxo de calor absorvido pelas peças estruturais $\mathrm{W} / \mathrm{m}^{2}$

$\dot{h}_{c} \quad$ fluxo de calor convectivo $\mathrm{W} / \mathrm{m}^{2}$

$\dot{h}_{r} \quad$ fluxo de calor radiativo $\quad \mathrm{W} / \mathrm{m}^{2}$

$h_{e q}$ altura média das aberturas $\mathrm{m}$

$k_{E, \theta}$ fator de redução do módulo de elasticidade do aço à temperatura $\theta_{a}$

$k_{y, \theta} \quad$ fator de redução do limite de escoamento do aço à temperatura $\theta_{a} \quad$ -

$\begin{array}{lll}l_{b} & \text { distância entre travamentos } & \mathrm{m}\end{array}$

$l_{f l} \quad$ comprimento de flambagem determinado à temperatura ambiente $\mathrm{m}$

- $\quad$ taxa de perda de massa ou taxa de pirólise $\mathrm{kg} / \mathrm{s}$

$k_{f} \quad$ condutividade térmica do fluido $\quad \mathrm{W} / \mathrm{m}{ }^{\circ} \mathrm{C}$ 
$\dot{q}_{c} \quad$ taxa de calor convectivo que permeia a área perpendicular ao $\quad \mathrm{W} / \mathrm{m}^{2}$

$q_{c} \quad$ fluxo convectivo

- calor gerado no interior do elemento

$q_{\text {ger }}$

$\begin{array}{ll}\text { - fluxo de calor radiativo } & \mathrm{W} / \mathrm{m}^{2}\end{array}$

$q_{r}$

- fluxo de calor condutivo na direção 'x' $\quad \mathrm{W} / \mathrm{m}^{2}$

$q_{x}$

$q_{t, d} \quad$ valor de cálculo da carga de incêndio específica relacionada à área $\mathrm{MJ} / \mathrm{m}^{2}$ total do compartimento

$q_{f, d} \quad$ valor de cálculo da carga de incêndio específica relacionada à área $\quad \mathrm{MJ} / \mathrm{m} 2$ de piso

$r$ raio de giração $\mathrm{m}$

$s_{c} \quad$ fator de forma da curva de incêndio

$s_{\text {lim }}$ espessura limite da camada m

$t$ tempo $\mathrm{h}, \mathrm{min}$

$t^{*} \quad$ tempo fictício $\quad \mathrm{h}$

$t_{\text {lim }}$ tempo limite $\mathrm{h}$

$t_{m} \quad$ espessura do material de revestimento contra fogo $\mathrm{m}$

$t_{\max }$ instante em que ocorre a temperatura máxima $\quad \mathrm{h}$

$t_{\text {max }}^{*}$ tempo fictício de temperatura máxima $\quad \mathrm{h}$

$t_{w}$ espessura da alma do perfil de aço $\mathrm{m}$

$u \quad$ perímetro exposto ao fogo $\mathrm{m}$

$v_{m} \quad$ velocidade média do fluido $\mathrm{m} / \mathrm{s}$

\section{Letras gregas minúsculas}

$\alpha$ difusividade térmica do fluido (cap. 2) $\mathrm{m}^{2} / \mathrm{s}$

$\alpha \quad$ somatório do coeficiente de transferência de calor radiativo e $\quad \mathrm{W} / \mathrm{m}^{2 \mathrm{o}} \mathrm{C}$

$\alpha \quad$ coeficiente relacionado à curva de dimensionamento a compressão (cap. 4)

$\alpha_{c} \quad$ coeficiente de transmissão de calor por convecção $\quad \mathrm{W} / \mathrm{m}^{20} \mathrm{C}$ 
$\alpha_{r} \quad$ coeficiente de transferência de calor por radiação $\quad \mathrm{W} / \mathrm{m}^{20} \mathrm{C}$

$\varepsilon_{1-2} \quad$ emissividade entre dois corpos

$\varepsilon_{r} \quad$ emissividade resultante envolvendo chamas, gases em combustão e superfície do aço exposta às chamas.

$\phi \quad$ diâmetro do sistema $\mathrm{m}$

$\rho$ massa específica do material de vedação $\quad \mathrm{kg} / \mathrm{m}^{3}$

$\rho_{a}$ massa específica do aço $\quad \mathrm{kg} / \mathrm{m}^{3}$

$\rho_{m} \quad$ massa específica do material de revestimento contra fogo $\mathrm{kg} / \mathrm{m}^{3}$

$\rho_{\theta} \quad$ fator de redução da resistência à compressão em situação de incêndio

$\delta$ altura da camada limite $\mathrm{m}$

$\delta$ altura da camada limite térmica m

$\lambda \quad$ condutividade térmica do material de revestimento das superfícies $\mathrm{W} / \mathrm{m}{ }^{\circ} \mathrm{C}$ de vedação do compartimento (cap. 1)

$\lambda \quad$ condutividade térmica do material (cap. 2) $\quad \mathrm{W} / \mathrm{m}^{\circ} \mathrm{C}$

$\lambda$ comprimento de onda (cap. 2) m

$\lambda \quad$ parâmetro de esbeltez (cap. 4) -

$\lambda_{m} \quad$ condutividade térmica do material de revestimento contra fogo $\quad \mathrm{W} / \mathrm{m}^{\circ} \mathrm{C}$

$\lambda_{o, f i} \quad$ parâmetro de esbeltez para barras comprimidas à temperatura $\theta_{a} \quad$ -

$\lambda_{p} \quad$ parâmetro de esbeltez correspondente à plastificação

$\lambda_{p, f i} \quad$ parâmetro de esbeltez, à temperatura $\theta a$, correspondente à plastificação

$\lambda_{r} \quad$ parâmetro de esbeltez correspondente ao início do escoamento

$\lambda_{r, f i} \quad$ parâmetro de esbeltez, à temperatura $\theta a$, correspondente ao início do escoamento

$\sigma \quad$ constante proporcionalidade de Stefan-Boltzmann $\quad \mathrm{W} / \mathrm{m}^{2}{ }^{\circ} \mathrm{C}^{4}$

$\begin{array}{lll}\sigma_{r} & \text { tensão residual do aço } \quad \mathrm{kN} / \mathrm{m}^{2}\end{array}$

$\theta$ temperatura do irradiador $\quad{ }^{\circ} \mathrm{C}$ 
$\begin{array}{lll}\theta_{a} & \text { temperatura superficial do elemento estrutural de aço } & { }^{\circ} \mathrm{C}\end{array}$

$\theta_{c}$ temperatura da superfície que receberá o calor por convecção $\quad{ }^{\circ} \mathrm{C}$

$\theta_{g}$ temperatura dos gases $\quad{ }^{\circ} \mathrm{C}$

$\theta_{m} \quad$ incremento máximo de temperatura no incêndio para a curva BFD ${ }^{\circ} \mathrm{C}$

$\theta_{\max }$ temperatura máxima da curva de incêndio natural $\quad{ }^{\circ} \mathrm{C}$

$\begin{array}{lll}\theta_{0} & \text { temperatura ambiente } & { }^{\circ} \mathrm{C}\end{array}$

$\begin{array}{lll}\theta_{\infty} & \text { temperatura do fluido } & { }^{\circ} \mathrm{C}\end{array}$

$\theta_{\mathrm{w}}$ temperatura do fluido em contato com a superfície $\quad{ }^{\circ} \mathrm{C}$

$v \quad$ viscosidade cinemática $\mathrm{m}^{2} / \mathrm{s}$

$\chi \quad$ fator de correção para o ramo descendente da curva EC1 -

\section{Letras gregas maiúsculas}

$\Delta E_{\text {int }} \quad$ variação de energia interna

$\Delta \theta_{a, t}$ elevação de temperatura no elemento estrutural de aço $\quad{ }^{\circ} \mathrm{C}$

$\Delta t$ intervalo de tempo s 


\section{OBJETIVOS}

O objetivo deste trabalho é estudar o efeito do incêndio nos esforços resistentes de elementos estruturais de aço. Para esse fim será desenvolvido um programa de computador em linguagem Visual Basic, considerando os modelos de incêndio-padrão e natural, aplicados na formulação a ser apresentada na revisão da NBR 14323:1999. Essa ferramenta computacional será utilizada para realizar uma análise da influência de cada parâmetro interveniente no cálculo dos esforços resistentes. 


\section{INCÊNDIO}

O fogo é uma reação química exotérmica acompanhada pela intensa liberação de calor. Ocorre somente quando três elementos estão reunidos: material combustível, oxigênio e uma fonte de calor. Esses três elementos formam o "triângulo do fogo" (Figura 1-1). Caso um dos três elementos estiver ausente em um cenário não existirão condições para o início de incêndio ou, caso esteja em progresso, o incêndio se extinguirá.

Combustíveis podem entrar em combustão se aplicada uma fonte de ignição capaz de iniciar uma reação em cadeia. A substância combustível reaciona com o oxigênio liberando energia (calor) e gerando produtos de combustão, alguns dos quais podem ser tóxicos" (DRYSDALE, 1999).

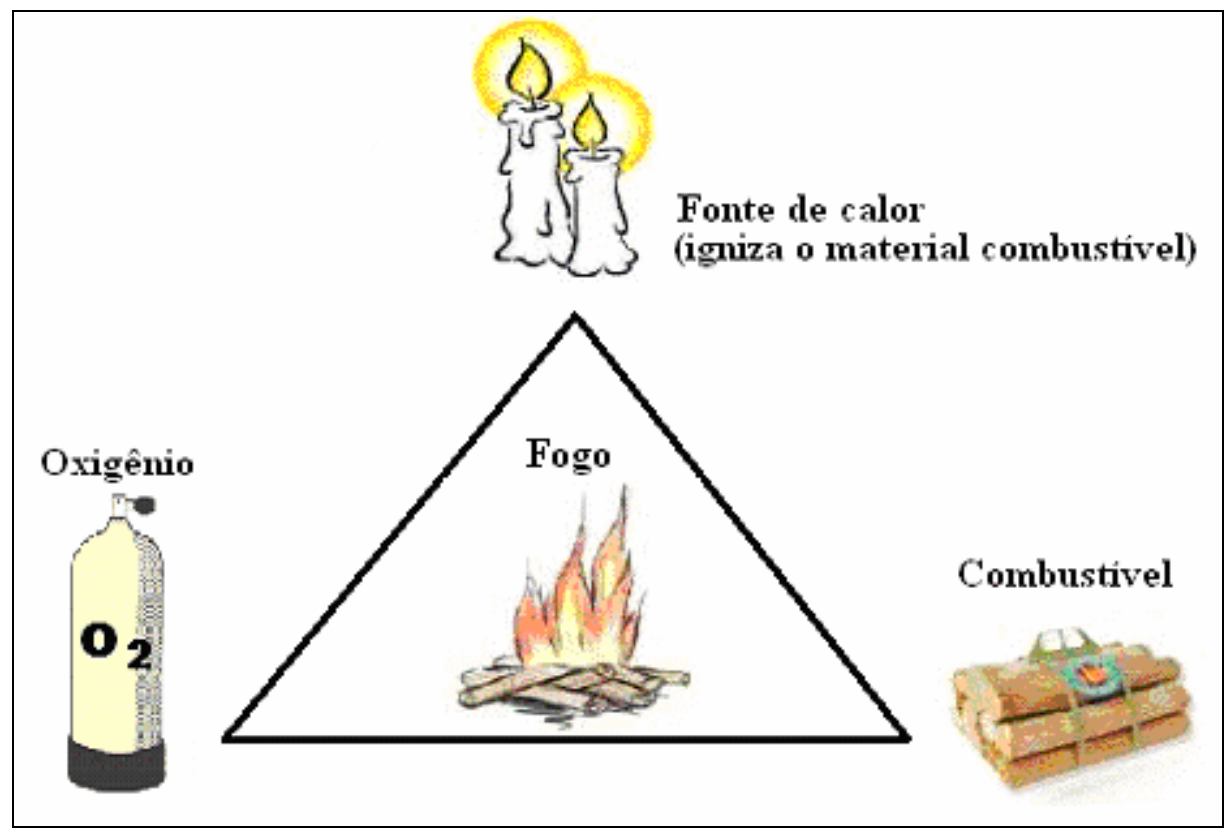

Figura 1-1 - Triângulo do fogo

O incêndio é o fogo sem controle, que causa danos e prejuízos à vida, ao meio ambiente e ao patrimônio. 


\subsection{INTRODUÇÃO}

Segundo Hall ${ }^{1}$ (2003), o maior número de casos de incêndio acontecem em residências com poucos pavimentos. Entretanto, mais de dez mil ocorrências de incêndio em grandes edifícios são reportadas por ano nos Estados Unidos. Os fatores que devem ser considerados na probabilidade de ocorrência e propagação de incêndio são:

- Atividade e o conteúdo de combustíveis (carga de incêndio) na edificação. Os riscos são maiores em edificações cuja atividade envolva fontes de calor, por exemplo, fornos ou atividades que utilizem ou estoquem material combustível;

- Tipo de edificação. Edificações sem compartimentação ou vedação nãoresistente ao fogo, possibilitam o alastramento de pequenos focos;

- Prevenção ativa do incêndio. As chances de desenvolvimento de um incêndio são fortemente reduzidas se forem instalados detectores de fumaça e chuveiros automáticos.

A intensidade e duração de um incêndio no compartimento em chamas estão relacionadas com as características listadas abaixo:

- Carga de incêndio. A carga de incêndio é determinada pela quantidade e tipo de materiais;

- Distribuição da carga de incêndio. Materiais podem ser armazenados de maneira que o oxigênio tenha fácil acesso a eles, facilitando a combustão.

- Características da ventilação do compartimento. Influencia a intensidade e a duração do incêndio. Compartimentos com maior ventilação propiciam incêndios mais intensos e, por conseqüência, de duração menor;

\footnotetext{
1 John Hall Jr é pesquisador do National Fire Prevention Association (NFPA). A organização mais reconhecida nos Estados Unidos para compilação de estatísticas de incêndio.
} 
- Propriedades térmicas e espessura dos pisos e paredes que envolvem o compartimento. Materiais com características isolantes reduzem a possibilidade de propagação de fogo para outros ambientes, entretanto, mais severo será o incêndio no interior do compartimento, e assim, mais rápido.

\subsubsection{FASES DO INCÊNDIO}

O incêndio é dividido em três fases. São elas: propagação, fase de aquecimento, fase de resfriamento representados na Figura 1-2.

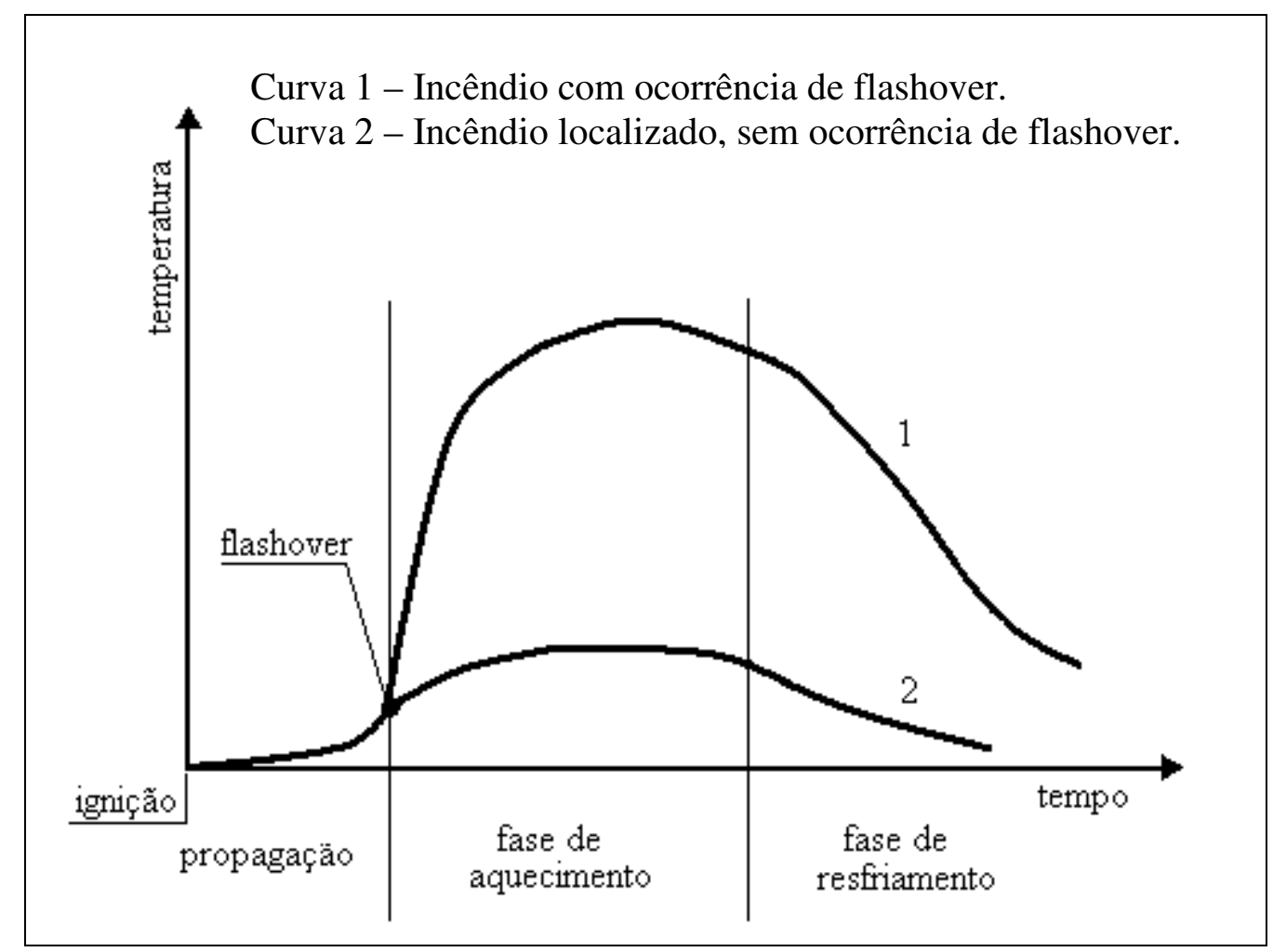

Figura 1-2 - Fases do incêndio.

A fase da propagação inicia-se com a ignição, geralmente iniciada em uma pequena região do compartimento. Para materiais celulósicos como a madeira, a ignição ocorre em temperaturas entre $200^{\circ} \mathrm{C}$ a $400^{\circ} \mathrm{C}$. (SPEARPOINT; QUINTIERE, 2000) 
Essa primeira fase caracteriza-se pelo alastramento das chamas. $\mathrm{O}$ alastramento das chamas acontece em diferentes configurações que são organizadas por orientação do combustível e direção do fluxo de gases. (WHITE; DIETENBERGER, 1999) Uma pluma de fogo é formada sobre o foco de incêndio (Figura 1-3). Há geração de fumaça concentrando-se na parte superior do compartimento. À medida que os gases quentes encontram as paredes do compartimento forma-se uma camada de fumaça quente abaixo do teto (ceiling jet), irradiando calor para a porção inferior do compartimento, portanto, ao combustível. O calor radiativo realimenta a produção de fumaça e a ignição de outros materiais combustíveis no compartimento.(LAMONT et al, 2001)

Para situações de combustível escasso, a chama queimará todo o combustível disponível e se extinguirá. Para situações de ventilação insuficiente, a chama se extinguirá com o fim do oxigênio. Em ambos os casos, o incêndio é localizado.(ver Figura 1-2) Caso haja material combustível e ventilação suficiente, a temperatura aumentará intensamente e alastrará o fogo por todo o compartimento - está deflagrado o flashover.

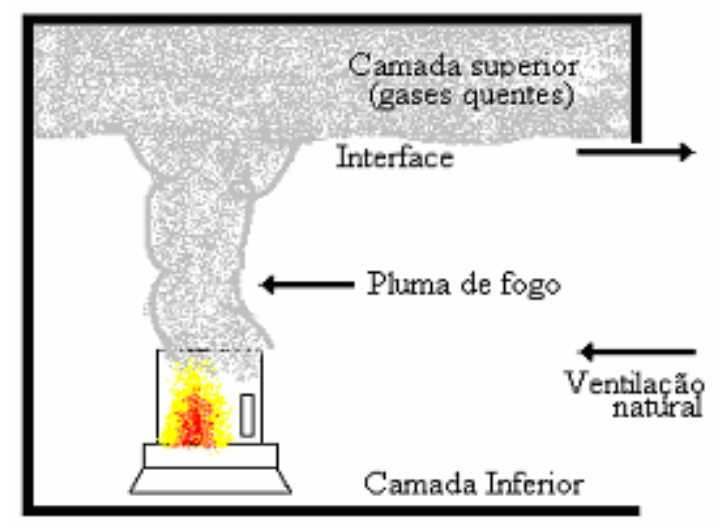

Figura 1-3 - Fase de propagação do incêndio. Fonte: PEACOCK et al, 1999

A inflamação generalizada ou flashover segundo Drysdale (1999), é a transição de um incêndio localizado para uma conflagração generalizada dentro de um compartimento onde toda a superfície combustível está em chamas. 
Uma compilação de resultados feita por Peacock (et al, 1999) de ensaios realizados por inúmeros pesquisadores ${ }^{2}$ mostra que os valores de temperatura atingidos durante o fenômeno do flashover estão no intervalo entre $450^{\circ} \mathrm{C}$ e $800^{\circ} \mathrm{C}$, porém concentrados entre $600^{\circ} \mathrm{C}$ e $700^{\circ} \mathrm{C}$. O fluxo de calor por unidade de área encontrado está entre 15 e 33 $\mathrm{kW} / \mathrm{m}^{2}$. Embora com variação considerável de dados experimentais, caracterizações de flashover consistentes com as práticas comuns também são consistentes com uma ampla faixa de dados experimentais: temperatura de gás da camada superior maior ou igual a $600^{\circ} \mathrm{C}$ ou fluxo de calor por unidade de área ao nível do piso maior ou igual a 20 $\mathrm{kW} / \mathrm{m}^{2}$. Também é evidente que existe considerável incerteza nessa caracterização dependendo de materiais e configurações de compartimentos envolvidos. Muito dessa incerteza é compreensível, dada a natureza do flashover como uma transição do incêndio localizado até envolvimento completo do compartimento. (PEACOCK et al, 1999)

$\mathrm{Na}$ fase de aquecimento, o incêndio é totalmente desenvolvido e atinge um taxa de pirólise ${ }^{3}$ constante. As temperaturas altas são sustentadas até que o combustível seja quase completamente consumido.

A última fase é a de resfriamento. O período de resfriamento inicia-se após a redução da temperatura média para "80\% do valor máximo" (DRYSDALE, 1999), contudo, a temperatura pode-se manter alta por um longo período.

\footnotetext{
${ }^{2}$ Richard Peacock é pesquisador do Building and Fire Research Laboratory, NIST. A pesquisa de Peacock incluem ensaios de Häggland (1974), Fang (1975), Bundick \& Klein (1979), Lee \& Breese (1979), Babrauskas (1977), Fang \& Breese (1980), Quintiere \& McCaffrey (1980), Thomas (1981) e Parker \& Lee (1974).

${ }^{3}$ A taxa de pirólise $(\dot{m})$ é a quantidade de massa de combustível sólido que é transformada em gases combustíveis por unidade de tempo. A unidade de medida (SI) é kg/s.
} 


\subsubsection{DANOS CAUSADOS ÀS ESTRUTURAS}

Uma pesquisa internacional conduzida pelo National Institute of Standards and Technology (EUA) e compilada por Beitel e Iwankin (2002) revelou a ocorrência de 22 incêndios de grandes proporções em edifícios de múltiplos andares entre 1970 e 2002 envolvendo diversos materiais de construção (concreto, aço, madeira e alvenaria). A pesquisa confirmou o baixo número de colapsos induzidos por incêndio em edifícios de múltiplos andares, contudo, as conseqüências podem ser enormes. Os danos mais comuns observados em estruturas deterioradas por incêndio, listados no EC1 (2002) são as expansões e deformações impostas causadas por aumento de temperatura. São exemplos dessas expansões e deformações:

- Expansão térmica restringida dos elementos das estruturas afetados, por exemplo, pilares envolvidos por paredes rígidas;

- Expansão térmica diferencial em elementos hiperestáticos, como em lajes contínuas;

- Gradientes térmicos dentro das seções transversais produzindo tensões internas;

- Expansão térmica de elementos adjacentes, por exemplo, deslocamento de um pilar devido à expansão da laje de piso;

- Expansão térmica de elementos afetando outros elementos exteriores ao compartimento em chamas. 


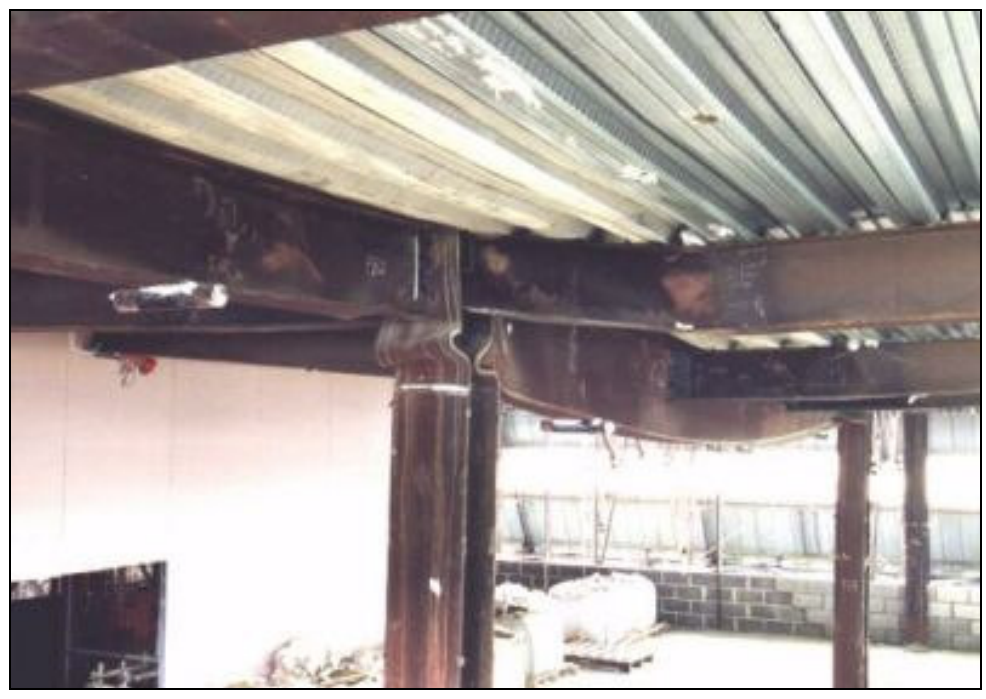

Figura 1-4 - Flambagem local no topo do pilar (Ensaio de Cardington ${ }^{4}$, 1996).

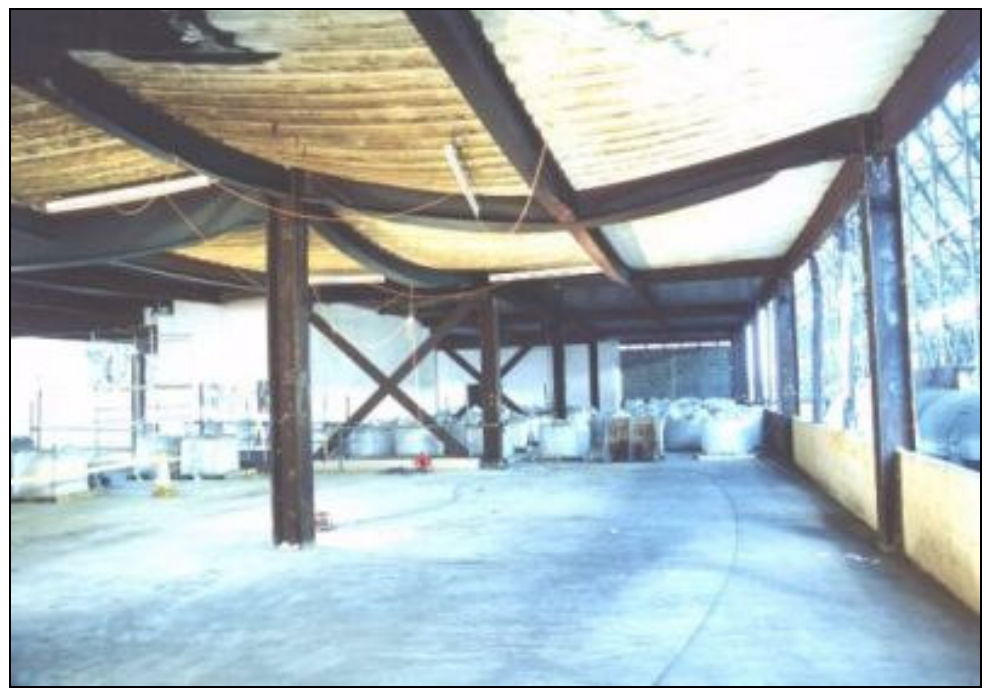

Figura 1-5 - Deformação de lajes (Ensaio de Cardington, 1996).

${ }^{4}$ Os ensaios realizados em Cardington (Figura 1-4 e Figura 1-5) foram parte de um programa de ensaios de incêndio nos laboratórios do Building Research Estabilishment's Cardington no Reino Unido realizado entre 1995 e 1996. Os ensaios foram realizados em um edifício construído para esse propósito, com área de piso igual a $945 \mathrm{~m}^{2}$ e $33 \mathrm{~m}$ de altura. (VARGAS; SILVA, 2003) 
A severidade do incêndio é influenciada pela fase em que o incêndio é combatido e extinguido. Antes do flashover, normalmente não há risco de falha estrutural, apesar de poder ocorrer algum dano localizado no conteúdo do compartimento em chamas. As interações estruturais em estruturas hiperestáticas sofrem intensas redistribuições de cargas durante o incêndio. Este fenômeno cria capacidade de reserva suficiente para permitir a maioria de estruturas suportar pequenos danos estruturais.

Em edifícios de múltiplos andares, a resistência ao fogo ${ }^{5}$ dos elementos estruturais é mais importante, pois pode evitar danos no conteúdo de partes do prédio que estão distantes do local do incêndio. Falhas nos elementos estruturais em edificações térreas têm pouca influência nas perdas do conteúdo do prédio, que provavelmente estará danificado antes do flashover. (INTERNATIONAL IRON AND STEEL INSTITUTE, 1993)

"São aceitáveis plastificações e ruínas localizadas que não determinem colapso além do local. Nesse caso, depois de um incêndio, a estrutura só pode ser reutilizada após verificação. Essa verificação pode eventualmente concluir que não existe necessidade de recuperação da estrutura, se o incêndio foi de pequena severidade ou se a estrutura tinha proteção adequada. Em caso contrário, deve ser projetada e executada a sua recuperação. Tal recuperação pressupõe que a estrutura volte a ter as características que apresentava antes do incêndio, recuperando todas as capacidades últimas e de serviço exigidas".(VARGAS; SILVA, 2003)

\subsubsection{SEGURANÇA CONTRA INCÊNDIO}

O propósito global da segurança contra incêndio em edificações é a redução do risco a vidas e danos à propriedade. Ocorrências de ferimentos ou óbitos são usualmente

\footnotetext{
5 A resistência ao incêndio é a habilidade do elemento estrutural de impedir ou retardar a passagem de calor excessivo, gases quentes, ou chamas enquanto suporta as cargas estruturais. A resistência ao incêndio é normalmente obtida a partir de testes de incêndio-padrão (item 1.2).
} 
provocadas por fumaça, calor e desabamento de partes da edificação. "O maior perigo da fumaça é a redução de visibilidade, que retarda a desocupação, e prolonga a exposição ao calor e aos gases tóxicos".(LIE, s.d.) De $75 \%$ a $80 \%$ de vítimas de fogo não são atingidos pelas chamas, porém morrem como resultado de exposição a fumaça, exposição aos gases tóxicos, ou falta de oxigênio. (WHITE; DIETENBERGER, 1999) É incomum ocupantes sobreviverem no interior de um compartimento após o flashover, já que as chamas envolvem todo o compartimento e as temperaturas são extremamente altas.

"O Serviço de Combate a Incêndio da Nova Zelândia coletou dados que mostram que 99\% de todas mortes por incêndio acontecem em propriedades residenciais. Embora somente $1 \%$ das mortes ocorram em edifícios não-residenciais, uma grande parcela do esforço nacional concentra-se em transformar edifícios não-residenciais, seguros ao incêndio”. (BARNETT, 1998)

Uma pesquisa de incêndios em edifícios altos ${ }^{6}$ em cidades americanas, realizada entre os anos de 1994 e 1996, contabilizou o número de fatalidades em incêndios. Os resultados estão apresentados na Tabela 1-1.

Tabela 1-1 - Contabilidade de fatalidades por incêndio em cidades americanas. Fonte: NFIRS National Fire Incident Reporting System.

\begin{tabular}{|l|l|l|l|}
\hline Cidade & Incêndios & Mortes de civis & $\begin{array}{l}\text { Mortes a cada 1000 } \\
\text { incêndios }\end{array}$ \\
\hline Chicago & 1396 & 25 & 17,9 \\
\hline Washington, D. C. & 239 & 4 & 16,7 \\
\hline Boston & 362 & 2 & 5,5 \\
\hline Detroit & 293 & 0 & 0 \\
\hline Média americana & 33500 & 170 & 5,1 \\
\hline
\end{tabular}

${ }^{6}$ Segundo definição da NFPA edifícios altos são aqueles superiores a sete pavimentos. Para efeito estatístico, os edifícios são subdivididos em quatro categorias: 7-12 pavimentos, 13-24 pavimentos, 25-49 pavimentos e 50 ou mais pavimentos. 
"O incêndio é uma ação controlável” (SILVA, 2001), portanto, a fim de minimizar perdas patrimoniais e majorar a segurança dos ocupantes das edificações, é conveniente prever em projeto, a instalação de dispositivos e a otimização da arquitetura. São fatores que influenciam na segurança e reduzem o tempo de evacuação:

- Detecção e alarme de incêndio: Início imediato das operações de evacuação e combate ao incêndio;

- Rotas de escape seguras: Asseguram a evacuação e a proteção dos ocupantes. São protegidas por portas corta-fogo, dutos de ventilação e/ou pressurização que mantém as rotas de escape livres de níveis elevados de temperaturas, de gases tóxicos e fumaça;

- Chuveiros automáticos: Limitam a propagação de incêndios e a geração de fumaça e gases perigosos; Os chuveiros automáticos ou sprinklers são altamente eficientes no combate ao fogo. Segundo Janicak, (s.d.) aproximadamente $91 \%$ das mortes ocorridas em arranha-céus em situação de incêndio na cidade de Chicago (EUA) entre 1985 e 1994, aconteceram em edifício sem chuveiros automáticos;

- Compartimentação resistente ao fogo: este fator tem pequeno efeito na segurança das vidas nas edificações com menores alturas, mas é essencial nos edifícios altos com muitos andares. Neste caso permite maior tempo para evacuação segura dos ocupantes e contribui para o trabalho seguro dos bombeiros;

- Disponibilidade de brigada de bombeiros na localidade e de extintores de incêndio: o imediato combate aumenta a probabilidade de extinção rápida do incêndio e limitam perdas patrimoniais.

\subsection{INCÊNDIO-PADRÃO}

As curvas de incêndio-padrão ou curvas nominais foram desenvolvidas para uniformizar ensaios em elementos como portas corta-fogo, paredes, divisórias, forros e de partes 
isoladas de uma estrutura (vigas, pilares, conexões, etc.) e assim, classificá-los de acordo com o tempo resistente a ação térmica associada à curva de incêndio-padrão.

Os testes de incêndio-padrão foram requisitados pelas companhias de seguro, pois precisavam avaliar comparativamente os diferentes tipos de construção. Os testes mais antigos foram registrados no Reino Unido, Alemanha e EUA. (LAMONT et al, 2001)

A resistência ao incêndio-padrão segundo o EC1(2002) é a habilidade de uma estrutura ou parte dela (normalmente elementos isolados) de preencher os requisitos funcionais (suporte e/ou isolamento), para exposição ao aquecimento de acordo com a curva temperatura-tempo padrão para uma combinação específica de carregamento por um período de tempo preestabelecido.

Essas curvas são pouco representativas de um incêndio real, já que desconsideram aspectos como compartimentação, ventilação, carga de incêndio, etc. São geradas a partir de equações cuja única variável é o tempo. O valor de resistência ao fogo obtido por meio dessas curvas não indica, portanto, o tempo real que a estrutura resistirá ao incêndio. "É usual em normas nacionais e internacionais, ao invés de exigir segurança à temperatura, exigir-se segurança por um determinado tempo associado à curvapadrão".(VARGAS; SILVA, 2003) Segundo a NBR 14432:2000, esse tempo é conhecido como tempo requerido de resistência ao fogo (TRRF), ou seja, o tempo mínimo de resistência ao fogo de um elemento construtivo, quando sujeito ao incêndio padrão.

A Figura 1-6 apresenta a curva de incêndio-padrão e uma curva representativa de incêndio (incêndio natural). Nota-se que as curvas nominais não simulam a fase de resfriamento. 


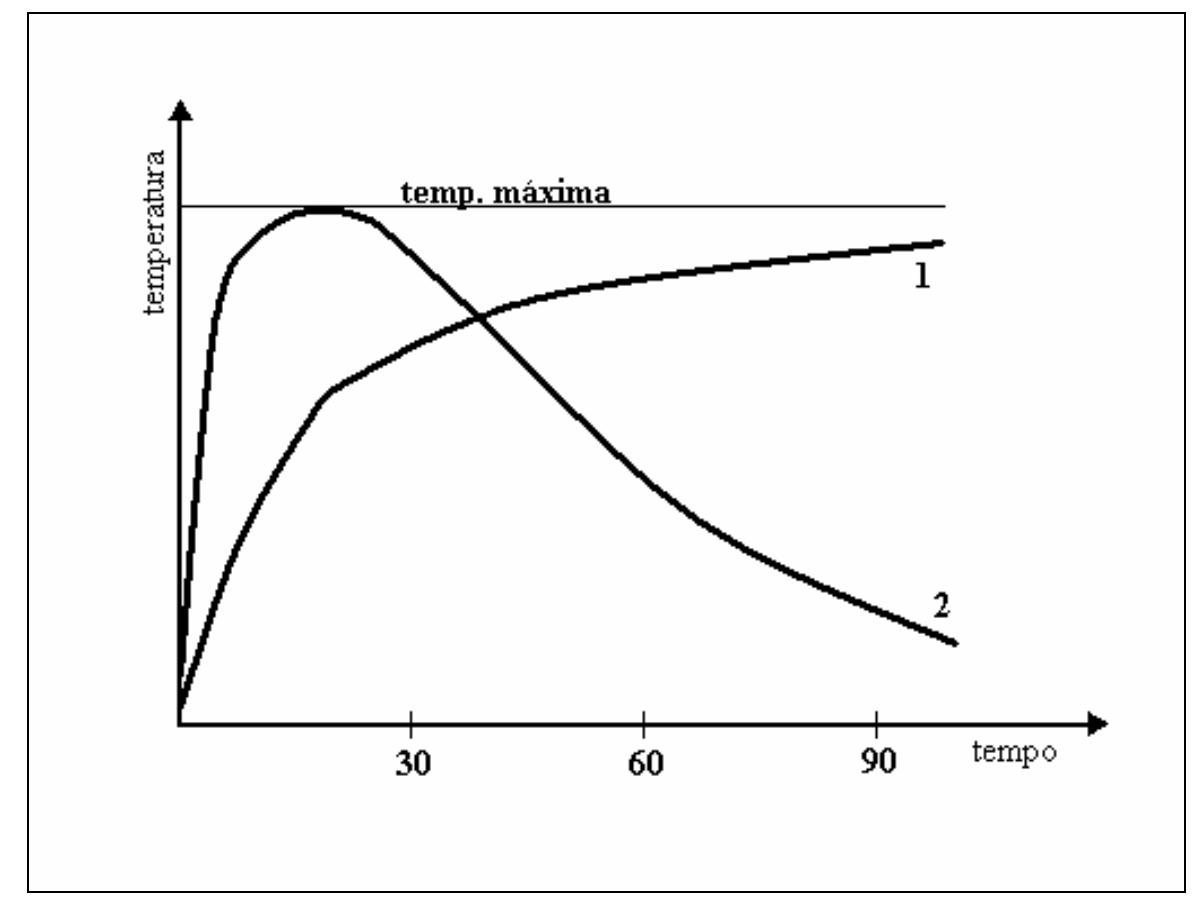

Figura 1-6 - Curva de incêndio padrão (1) x Curva de incêndio natural (2)

A seguir serão apresentadas as formulações e as curvas de incêndio padrão advindas do EC1 (2002) e da norma americana ASTM E119 (2000). Em todas as equações, a temperatura ambiente é fixada em $20^{\circ} \mathrm{C}$.

\subsubsection{CURVA-PADRÃO}

A curva-padrão é empregada em incêndios à base de materiais celulósicos. Ela é caracterizada pelo aumento contínuo da temperatura ao longo do tempo numa velocidade preestabelecida, expressa pela exp. 1.1. Essa curva é também padronizada pela ISO 834 (1975) e NBR 5628:1980.

$$
\theta_{g}=345 \log (8 t+1)+20
$$

Onde:

$\theta_{g}$ é a temperatura dos gases, em ${ }^{\circ} \mathrm{C}$; 
$t$ é o tempo em minutos.

A ISO 834 tem por base hipóteses e condições do cenário de incêndio (grau de ventilação $v=0,04 \mathrm{~m}^{1 / 2}$, inércia térmica de compartimentação $\left.\sqrt{\rho \cdot \mathrm{c} \cdot \lambda}=1160 \mathrm{~J} /\left(\mathrm{m}^{2} \cdot \mathrm{s}^{1 / 2} \cdot{ }^{\circ} \mathrm{C}\right)\right)$ similares àquelas que deram origem ao ramo ascendente da curva (para o tempo $t \leq 120$ minutos) recomendada pela norma sueca de 1967 — SBN/1967. (SILVA (1997)

\subsubsection{CURVA DE HIDROCARBONETOS}

Há casos em que os materiais combustíveis no compartimento são hidrocarbonetos que provocam um incêndio de maior intensidade do que incêndio-padrão. Nesse caso, utilizase a curva de incêndio chamada de curva " $\mathrm{H}$ ".

$$
\theta_{g}=1080\left(1-0,325 e^{-0,167 t}-0,675 e^{-2,5 t}\right)+20
$$

Onde:

$$
\begin{aligned}
& \theta_{g} \text { é a temperatura dos gases, em }{ }^{\circ} \mathrm{C} \text {; } \\
& t \text { é o tempo em minutos. }
\end{aligned}
$$

De acordo com o anexo E do EC1 (2002), os materiais celulósicos (lã, papel, algodão, etc) possuem potencial calorífico específico em torno de $20 \mathrm{MJ} / \mathrm{kg}$. Os hidrocarbonetos (polipropileno, poliestireno, polietileno, etc) possuem potencial calorífico específico em torno de $40 \mathrm{MJ} / \mathrm{kg}$.

\subsubsection{CURVA ASTM E 119}

Essa curva foi adotada em 1918 pela ASTM baseada na proposta do UL - Underwriter's Laboratory de Chicago de 1916 para curva-padrão na fase de aquecimento em ensaios de pilares (LIE, 1972; SILVA apud 1997). 
A curva de incêndio ASTM E119 (2000) é apresentada na forma tabular (ver Tabela 1-2), ou seja, a norma americana retrata por meio de uma tabela, o valor correspondente de temperatura ao tempo associada (intervalo de 5 minutos) para materiais celulósicos.

Tabela 1-2 - Valores de Tempo-Temperatura da ASTM

\begin{tabular}{|l|l|l|l|}
\hline Tempo $[\mathrm{min}]$ & Temperatura $\left[{ }^{\circ} \mathrm{C}\right]$ & Tempo $[\mathrm{min}]$ & Temperatura $\left[{ }^{\circ} \mathrm{C}\right]$ \\
\hline 0 & 20 & 45 & 892 \\
\hline 5 & 538 & 50 & 905 \\
\hline 10 & 704 & 55 & 916 \\
\hline 15 & 760 & 60 & 927 \\
\hline 20 & 795 & 75 & 955 \\
\hline 25 & 821 & 90 & 978 \\
\hline 30 & 843 & 105 & 996 \\
\hline 35 & 862 & 120 & 1010 \\
\hline 40 & 878 & 180 & 1052 \\
\hline
\end{tabular}

\subsubsection{COMPARAÇÃO ENTRE CURVAS NOMINAIS}

O EC denomina as curvas de incêndio-padrão como curvas nominais. O desenvolvimento das curvas citadas em 1.2.1 a 1.2.3 está explicitado na Figura 1-7. 


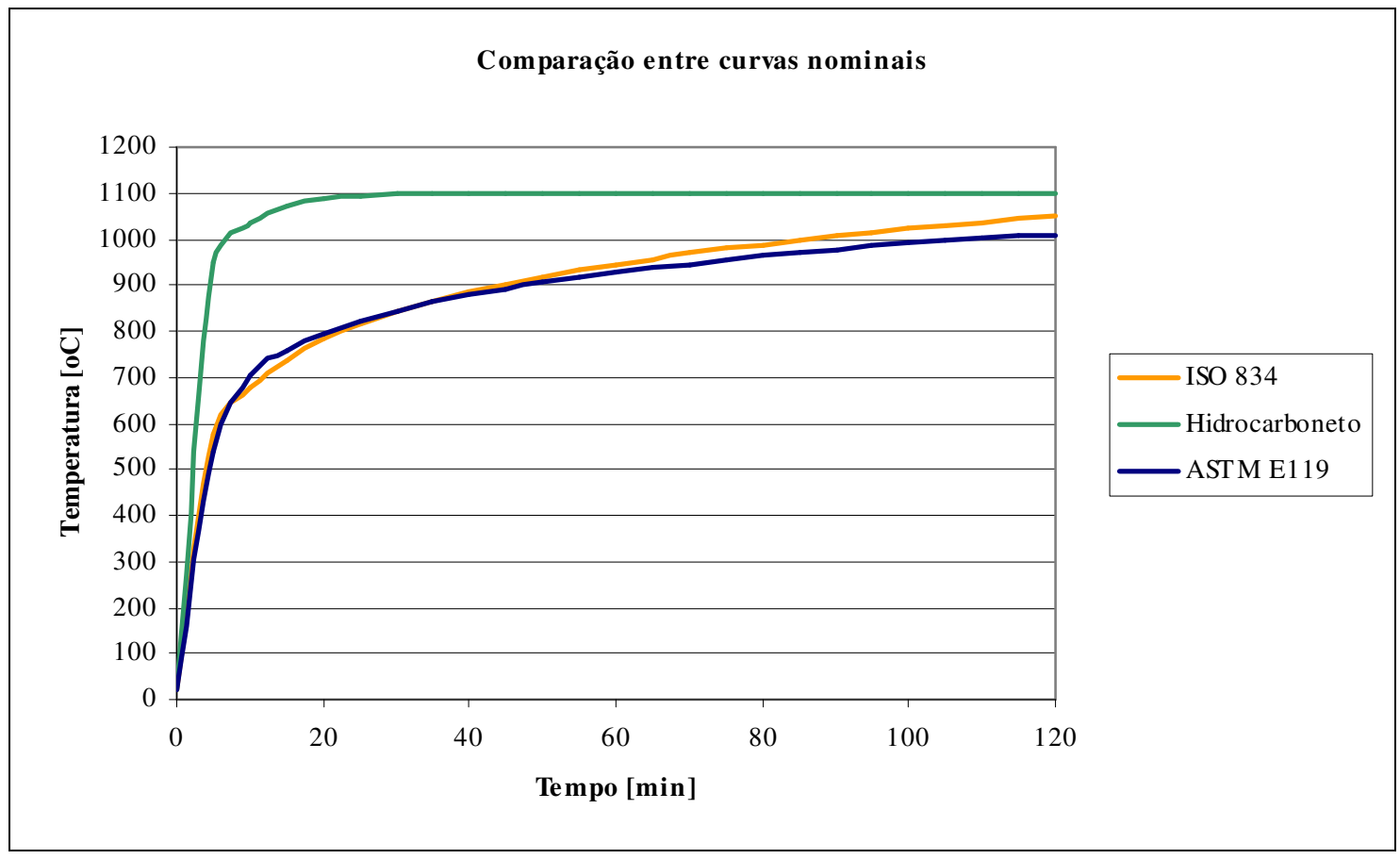

Figura 1-7 - Gráfico comparativo entre as curvas nominais tempo-temperatura.

A curva de hidrocarboneto converge para um patamar de temperatura, já a curva ISO 834 de 1975 e a ASTM E119 (2000) são indefinidamente crescentes. A curva ISO 834 é derivada de uma uniformização entre a curva americana ASTM E119 de 1918 e a curva britânica BS 476 de 1932. (COSTA; SILVA, 2002)

\subsection{INCÊNDIO NATURAL}

O modelo de incêndio natural compartimentado é um método mais preciso de determinação da temperatura dos gases no interior de um compartimento em chamas.

O incêndio natural compartimentado pode ser modelado por curvas paramétricas. As curvas paramétricas são determinadas em "base de modelos de incêndio e parâmetros físicos específicos definindo as condições do incêndio compartimentado".(COMITÉ EUROPÉEN DE NORMALISATION, 2002) Este modelo é aferido por ensaios, cujos 
resultados demonstram que a curva temperatura-tempo de um incêndio natural compartimentado depende dos seguintes parâmetros:

- Carga de incêndio;

- Grau de ventilação;

- Características do material componente da vedação;

São hipóteses do incêndio natural compartimentado:

- Distribuição de temperatura dos gases é uniforme em todo o volume do compartimento. $^{7}$

- O incêndio é restrito a uma área compartimentada, sem possibilidade de se propagar para fora dela;

- O material combustível é formado por madeira ${ }^{8}$;

\subsubsection{HISTÓRICO DO MODELO DE INCÊNDIO NATURAL}

O modelo de incêndio natural foi originado a partir das curvas temperatura-tempo. A primeira curva temperatura-tempo foi desenvolvida por Kawagoe em 1958, pesquisador do Building Research Institute do Japão e por Odeën do Royal Institute of Technology da Suécia, em trabalhos independentes, constando somente de um ramo ascendente. Kawagoe descobriu que a taxa de pirólise e a taxa de calor liberado pelo incêndio eram independentes da quantidade de combustível, porém proporcionais à ventilação,

\footnotetext{
${ }^{7} \mathrm{O}$ movimento turbulento dos gases, durante um incêndio, contribui para uniformizar a temperatura em volumes;

${ }^{8}$ No anexo F do EC1 informa que caso a carga de incêndio não possua um comportamento específico descrito, então se deve limitar o incêndio no compartimento a materiais celulósicos, no caso a madeira é relacionado na literatura com maior freqüência.
} 
particularmente da altura das aberturas (correlação de Kawagoe). Esse método era limitado ao incêndio controlado pela ventilação com uma taxa de calor liberado constante. A correlação de Kawagoe foi deduzida semi empiricamente, dada pela exp. 1.3. O modelo de Kawagoe foi refinado em 1963 e 1967. (LAMONT et al, 2001) (KAEFER; SILVA, 2003)

$$
\dot{m}=0,092 \cdot A_{v} \cdot h_{e q}^{\frac{1}{2}}
$$

Onde:

m é a taxa de pirólise, em $\mathrm{kg} / \mathrm{s}$;

$A_{v}$ é a área de ventilação em $\mathrm{m}^{2}$;

$h_{e q}$ é a altura média das aberturas em $\mathrm{m}$.

Em 1970, a curva temperatura-tempo recebeu um ramo descendente proposto por Magnusson e Thelandersson. O fluxo de calor liberado pelo incêndio era relacionado com o tempo de incêndio, porém limitado ao valor máximo encontrado pela correlação de Kawagoe (eq. 1.3). Este modelo é usualmente citado na literatura especializada como “método sueco". Em 1976, Petterson publicou uma série de curvas tempo-temperatura, em seu trabalho, para uma variedade de cargas de incêndio, ventilação e propriedades térmicas das superfícies de vedação do compartimento tendo por base o método sueco.

Aproveitando a crescente capacidade computacional da época, pesquisadores propuseram várias expressões paramétricas entre elas: Lie de 1974 e 1996, Harmathy de 1972 e 1976, Babrauskas de 1978 e 1981, Thomas e Heselden de 1972 e Law de 1983, entre outras.

Em 1985, a partir das hipóteses adotadas por Petterson, Wickström propõe uma expressão única para determinação do ramo ascendente da curva tempo-temperatura dos gases quentes em função do grau de ventilação e das características dos materiais de vedação. A curva temperatura-tempo de Wickström foi publicada no EC1 de 1994 com a 
designação de curva parametrizada. (SILVA, 1997) A partir, dos trabalhos apresentados por Franssen (2000), NFSC1 de 1999 e ARBED de 2001 a curva paramétrica do EC1 (2002) recebeu modificações como possibilidade de consideração de camadas com propriedades térmicas distintas nas superfícies de vedação ${ }^{9}$, introdução do incêndio controlado pelo combustível pelo estabelecimento da duração mínima do incêndio e modificações na fase de resfriamento. Recentemente, novas curvas paramétricas foram apresentadas nos trabalhos Ma e Mäkeläinen de 2000, Barnett (2002) e Cadorin e Franssen (2003), entre outros. (CADORIN; FRANSSEN, 2003)

A curva parametrizada estudada neste trabalho é a curva publicada no EC1 (2002). A curva tempo-temperatura do EC1 é válida para compartimentos com área de piso inferior a $500 \mathrm{~m}^{2}$, pé-direito máximo de $4 \mathrm{~m}$ e sem aberturas no teto (ou telhado). Assume-se a hipótese que todo material combustível do compartimento está em chamas (fase pós-flashover).

Segundo observações feitas por Cadorin e Franssen (2003) o EC1 (2002) tem por base desenvolvimentos teóricos, porém muitos são primordialmente empíricos. Como conseqüência a método é questionável pelos motivos listados abaixo:

- Não retrata uma fase de pré-flashover;

- Não há relação direta com a taxa de calor liberada (HRR). Como conseqüência o método deve ser aplicado para cargas de incêndio essencialmente celulósicas.

- A temperatura máxima obtida pelo método tende a $1350^{\circ} \mathrm{C}$. O valor da temperatura deveria depender do fluxo de calor liberado (HRR) e das características do compartimento;

\footnotetext{
${ }^{9}$ O EC1 (1994) permitia a consideração com propriedades térmicas distintas, entretanto, havia dois pontos questionáveis: $1^{\circ}$. A importância da camada exposta ao fogo é a mesma da camada subseqüente, porém, a camada exposta ao fogo tem maior influência na transferência de calor dos gases às superfícies. $2^{\circ}$. As espessuras das camadas tinham o mesmo peso no cálculo da inércia térmica equivalente $\left(b_{\mathrm{eq}}\right)$ (FRANSSEN, 2000).
} 
- A duração da fase de resfriamento não é a mesma da fase de aquecimento. É inconsistente com o fato que a fase de resfriamento inicia-se quando $2 / 3$ da carga de incêndio foi queimada, o que levaria a períodos idênticos entre as fases;

- A abordagem dos incêndios controlados pelo combustível é insatisfatória. Em incêndios controlados pelo combustível, não existe conexão entre a taxa de calor liberado, a temperatura do compartimento ou a duração do incêndio. Além do mais, o grau de ventilação não é relevante em incêndios controlados pelo combustível;

- Ainda sobre os incêndios controlados pelo combustível, a duração da fase de aquecimento $\left(t_{\text {lim }}\right)$ é ligada à taxa de crescimento do incêndio (característica préflashover), entretanto, a curva paramétrica do EC1 é um método de análise pósflashover;

- O método não confere bons resultados para múltiplas aberturas de alturas muito desiguais ou quando estão algumas estão localizadas na parte inferior do compartimento e outras na parte superior.

\subsubsection{CÁlCULO DA CURVA PARAMÉTRICA DO EC1 (2002)}

No intuito de facilitar o entendimento a seqüência de cálculo para traçado da curva paramétrica será dividida em quatro tópicos: cálculo da temperatura máxima (item 1.3.2.1), cálculo das características térmicas e físicas dos materiais de vedação do compartimento (item 1.3.2.2), cálculo do ramo ascendente (fase de aquecimento, item 1.3.2.3) e cálculo do ramo descendente (fase de resfriamento, item 1.3.2.4).

\subsubsection{CÁLCULO DA TEMPERATURA MÁXIMA}

Para o cálculo da temperatura máxima da curva é preciso previamente calcular o instante $t_{\max }$, utilizando a exp. 1.4. Evidentemente, o instante em que ocorre a temperatura 
máxima, é o divisor entre o ramo ascendente e o ramo descendente da curva parametrizada.

$$
t_{\max }=\max \left\lfloor\left(0,2 \cdot 10^{-3} \cdot q_{t, d} / F_{v}\right), t_{\lim }\right\rfloor
$$

Onde:

$t_{\text {max }}$ é instante de temperatura máxima em horas;

$F_{v}$ é o grau de ventilação em $\mathrm{m}^{1 / 2}$;

$t_{\text {lim }}$ é o tempo limite em horas. Segundo Kaefer e Silva (2003) a determinação do $\mathrm{t}_{\lim }$ tem por base as curvas HRR (heat release rate) de Buchanan e Feasey (2002), ou seja, a taxa de combustão de acordo com o material combustível e com a ventilação do ambiente compartimentado. De acordo com o EC1 (2002) o valor de $t_{\text {lim }}$ é escolhido de acordo com a velocidade de desenvolvimento do incêndio:

- Lento desenvolvimento, considerar $t_{\text {lim }}=25 \mathrm{~min}$;

- Médio desenvolvimento, considerar $t_{\text {lim }}=20 \mathrm{~min}$;

- Rápido desenvolvimento, considerar $t_{\text {lim }}=15 \mathrm{~min}$;

$q_{t, d}$ é o valor de cálculo da carga de incêndio específica relacionada à área total do compartimento $\left(A_{t}\right)$ conforme exp. 1.5 , observando os limites $50 \mathrm{MJ} / \mathrm{m}^{2} \leq q_{t, d} \leq 1000$ $\mathrm{MJ} / \mathrm{m}^{2}$.

$$
q_{t, d}=q_{f, d} \frac{A_{f}}{A_{t}}
$$

Onde:

$q_{f, d}$ é o valor de cálculo da carga de incêndio específica relacionada à área de piso $\left(A_{f}\right)$.É especificada no anexo E do EC1 (2002) ou na NBR 14432:2000 tendo por base a norma suíça SIA81. 
$A_{f}$ é a área de piso em $\mathrm{m}^{2}$;

$A_{t}$ é a área total em m²;

Para calcular o grau de ventilação $\left(F_{v}\right)$ utilizar a exp. 1.6, com os seguintes limites 0,02 $\mathrm{m}^{1 / 2} \leq F_{v} \leq 0,20 \mathrm{~m}^{1 / 2}$

$$
F_{v}=\frac{A_{v} \cdot \sqrt{h_{e q}}}{A_{t}}
$$

Onde:

$F_{v}$ é o grau de ventilação em $\mathrm{m}^{1 / 2}$;

$A_{v}$ é a área total de aberturas verticais $\mathrm{em}^{2}$;

$A_{t}$ é a área total do compartimento (teto, piso e paredes) $\mathrm{em} \mathrm{m}^{2}$;

$h_{e q}$ é a altura média das aberturas em $\mathrm{m}$.

Há duas possibilidades de incêndio: o incêndio ser controlado pelo combustível ou ser controlado pela ventilação. É conhecido que incêndios controlados pelo combustível são normalmente menos severos, já que o ar em excesso que adentra o compartimento acarreta em um efeito refrigerante. (THOMAS; HESELDEN, 1972 apud LAMONT et $a l, 2001)$ As experiências concluem que compartimentos com carga de incêndio entre 40 $\mathrm{kg} / \mathrm{m}^{2}$ e $100 \mathrm{~kg} / \mathrm{m}^{2}$, normalmente são incêndios controlados pela ventilação. (WALTON et al, 1995)

Possibilidade 1. Para $t_{\max }=0,2 \cdot 10^{-3} \cdot q_{t, d} / F_{v}$, significa que o incêndio é controlado pela ventilação. O incêndio é dito "controlado pela ventilação" porque a taxa de aquecimento no compartimento depende principalmente de quantidade de oxigênio disponível e, 
portanto, das condições de ventilação. Neste caso, o fator $\Gamma$, é calculado a partir da exp. 1.7. O fator $\Gamma$ será usado para calcular o ramo ascendente da curva.

$$
\Gamma=\frac{\left(F_{v} / 0,04\right)^{2}}{(b / 1160)^{2}}
$$

Onde:

$F_{v}$ é o grau de ventilação em $\mathrm{m}^{1 / 2}$

$b$ é uma propriedade térmica das vedações do compartimento em $\mathrm{J} / \mathrm{m}^{2} \mathrm{~s}^{1 / 2}{ }^{\circ} \mathrm{C}$ (item 1.3.2.2);

Em muitos casos, as temperaturas encontradas no EC1 (2002) são muito baixas, deste modo, Feasey e Buchanan (2002) propuseram uma modificação à equação 1.7 do EC1 fundamentados em dados experimentais e computacionais.

$$
\Gamma=\frac{\left[F_{v} / b\right]^{2}}{(0,04 / 1900)^{2}}
$$

Possibilidade 2. Para $t_{\max }=t_{\lim }$, significa que o incêndio é controlado pelo combustível. O incêndio é dito, "controlado pelo combustível" por que o aquecimento liberado no compartimento depende principalmente das características e da quantidade de material em combustão. A ventilação é grande o suficiente para não ter influência sobre o incêndio. O oxigênio disponível é suficiente para a combustão. Neste caso, para calcular o grau de ventilação $\left(F_{v, l i m}\right)$ e o fator $\Gamma_{\text {lim }}$, utilizar as expressões 1.8 e 1.9 . O fator $\Gamma_{\text {lim }}$ será usado para calcular o ramo ascendente da curva.

$$
F_{v, \lim }=0,1 \cdot 10^{-3} \cdot \frac{q_{t, d}}{t_{\lim }}
$$

Onde: 
$F_{v, l i m}$ é o grau de ventilação limite para incêndios controlados pelo combustível;

$q_{t, d}$ é o valor de cálculo da carga de incêndio específica em $\mathrm{MJ} / \mathrm{m}^{2}$;

$t_{\text {lim }}$ é o tempo limite em horas.

$$
\Gamma_{\lim }=\frac{\left[F_{v, \lim } / b\right]^{2}}{(0,04 / 1160)^{2}}
$$

Onde:

$F_{v, \text { lim }}$ é o grau de ventilação limite para incêndios controlados pelo combustível;

$b$ é a propriedade térmica das vedações do compartimento em $\mathrm{J} / \mathrm{m}^{2} \mathrm{~s}^{1 / 2}{ }^{\circ} \mathrm{C}$ (item 1.3.2.2);

No caso das variáveis $F_{v}>0,04, q_{t, d}<75$ e $b<1160, \Gamma_{\lim }$ em deve ser multiplicado por $k$. A eq. 1.10 é derivada de uma normalização de curva e não de considerações teóricas.

$$
k=1+\left(\frac{F_{v}-0,04}{0,04}\right)\left(\frac{q_{t, d}-75}{75}\right)\left(\frac{1160-b}{1160}\right)
$$

Com o valor do tempo em que ocorre a temperatura máxima ( $\left.t_{\max }\right)$, é calculado o tempo fictício máximo $\left(t^{*}{ }_{\max }\right)$ com a exp. $1.11 \mathrm{e}$ admitido $t^{*}=t^{*}{ }_{\max }$ na exp. 1.16 (item 1.3.2.3) para o cálculo da temperatura máxima.

$$
t_{\max }^{*}=t_{\max } \Gamma \quad \text { ou } \quad t_{\max }^{*}=t_{\max } \Gamma_{\text {lim }}
$$

\subsubsection{CÁLCULO DAS CARACTERÍSTICAS TÉRMICAS}

As características térmicas do material de vedação influenciam o fluxo de calor entre os gases quentes do ambiente compartimentado e as superfícies de vedação. Quanto mais 
isolante for o material de vedação, mais severo será o incêndio no interior do compartimento. $\mathrm{O}$ valor de $b$, associado às características térmicas e físicas dos materiais de vedação é calculado por meio da exp. 1.12, com os seguintes limites: $100 \mathrm{~J} / \mathrm{m}^{2} \mathrm{~s}^{1 / 2}{ }^{\circ} \mathrm{C}$ $\leq b \leq 2200 \mathrm{~J} / \mathrm{m}^{2} \mathrm{~s}^{1 / 2}{ }^{\circ} \mathrm{C}$.

$$
b=\sqrt{\rho \cdot c \cdot \lambda}
$$

Onde:

$b$ é uma propriedade térmica das vedações do compartimento em $\mathrm{J} / \mathrm{m}^{2} \mathrm{~s}^{1 / 2}{ }^{\circ} \mathrm{C}$;

$\rho$ é a massa específica do material de vedação em $\mathrm{kg} / \mathrm{m}^{3}$;

$c$ é o calor específico do material de vedação em $\mathrm{J} / \mathrm{kg}{ }^{\circ} \mathrm{C}$;

$\lambda$ é a condutividade térmica do material de revestimento das superfícies de vedação do compartimento em $\mathrm{W} / \mathrm{m}{ }^{\circ} \mathrm{C}$;

Para compartimentos onde os materiais de vedação são distintos entre as superfícies, deve-se utilizar a exp. 1.13.

$$
b=\frac{\sum b_{j} A_{j}}{A_{t}-A_{v}}
$$

Onde:

$b_{\mathrm{j}}$ é a propriedade térmica de cada superfície calculada de acordo com a exp. 1.12 $\mathrm{em} \mathrm{J} / \mathrm{m}^{2} \mathrm{~s}^{1 / 2} \mathrm{C}$;

$A_{j}$ é a área de cada superfície (aberturas não incluídas) em $\mathrm{m}^{2}$;

$A_{t}$ é a área total das superfícies do compartimento em $\mathrm{m}^{2}$;

$A_{v}$ é a área de ventilação em $\mathrm{m}^{2}$;

Para superfícies compostas por camadas de materiais com propriedades térmicas e físicas distintas adotar uma das possibilidades: 
- Caso $b_{1}<b_{2}$, então assumir a propriedade $b$ da camada 1 como a propriedade térmica da superfície $\left(b=b_{1}\right)$. O índice 1 representa a camada exposta ao fogo, a camada 2 a camada seguinte.

- Caso $b_{1}>b_{2}$, a espessura limite $s_{\text {lim }}$ é calculada para o material exposto de acordo com as exp. 1.14 e 1.15:

$$
s_{\lim }=\sqrt{\frac{3600 \cdot t_{\max } \cdot \lambda_{1}}{c_{1} \rho_{1}}}
$$

Onde:

$s_{\text {lim }}$ é a espessura limite em metros;

$t_{\text {max }}$ é o tempo para atingir a temperatura máxima (ver exp. 1.4) em horas;

$\lambda_{l}, c_{l}$ e $\rho_{l}$ são as características térmicas da camada exposta ao fogo.

para $s_{1}>$ Slim então, adotar $b=b_{1}$;

para $s_{1}<$ Slim então utilizar a exp. 1.15;

$$
b=\frac{s_{1}}{s_{\lim }} b_{1}+\left(\frac{1-s_{1}}{s_{\lim }}\right) b_{2}
$$

Onde:

$s_{1}$ é a espessura da camada 1 (exposta ao fogo) em metros;

$s_{\text {lim }}$ é a espessura limite em metros;

$b_{\mathrm{j}}$ é a propriedade térmica de cada superfície calculada de acordo com a exp. 1.12 .

\subsubsection{RAMO ASCENDENTE DA CURVA PARAMETRIZADA}

O ramo ascendente da curva parametrizada é determinado por meio da exp. 1.16. 


$$
\theta_{g}=20+1325\left(1-0,324 e^{-0,2 t^{*}}-0,204 e^{-1,7 t^{*}}-0,472 e^{-19 t^{*}}\right)
$$

Onde:

$\theta_{\mathrm{g}}$ é a temperatura dos gases em ${ }^{\circ} \mathrm{C}$;

$t^{*}$ é o tempo fictício em horas. É calculado de acordo com a exp.1.17 conforme o tipo de incêndio (item 1.3.2.1).

$$
t^{*}=t \Gamma \quad \text { ou } \quad t^{*}=t \Gamma_{\lim }
$$

\subsubsection{RAMO DESCENDENTE DA CURVA PARAMETRIZADA}

O ramo descendente da curva parametrizada proposto pelo EC1 é linear, comandado por uma expressão conforme o tempo $t_{\text {max }}^{*}$, ou seja, o tempo $t^{*}$ em que ocorre a temperatura máxima na fase de aquecimento. Estão listadas as equações 1.18 a 1.20 relativas ao ramo descendente da curva parametrizada.

$$
\begin{array}{ll}
\theta_{g}=\theta_{\text {max }}-625\left(t^{*}-t_{\text {max }}^{*} x\right) & \text { para } t_{\text {max }}^{*} \leq 0,5 \\
\theta_{g}=\theta_{\text {max }}-250\left(3-t_{\text {max }}^{*}\right)\left(t^{*}-t_{\text {max }}^{*} x\right) & \text { para } 0,5<t_{\text {max }}^{*}<2,0 \\
\theta_{g}=\theta_{\text {max }}-250\left(t^{*}-t_{\text {max }}^{*} x\right) & \text { para } t_{\text {max }}^{*} \geq 2,0
\end{array}
$$

Onde:

$\theta_{g}$ é a temperatura dos gases quentes em ${ }^{\circ} \mathrm{C}$;

$\theta_{\max }$ é a temperatura máxima da curva de incêndio natural em ${ }^{\circ} \mathrm{C}$;

$t^{*}$ é o tempo fictício dado pela exp. 1.17 em horas;

$\chi$ é um fator de correção, onde

- $\chi=1$ para incêndio controlado pela ventilação e

- $\chi=t_{\text {lim }} \cdot \Gamma / t_{\text {max }}^{*}$ para incêndio controlado pelo combustível. 


\subsubsection{COMPARAÇÃO ENTRE OS EC1 (1994 E 2002)}

O EC1 de 2002 apresenta novidades listadas em 1.3 em relação ao EC1 de 1994. De acordo com Kaefer e Silva (2003) a curva parametrizada apresentada no EC1 de 1994 resulta em valores conservadores de temperatura dos gases quentes em relação ao EC1 de 2002 para incêndios controlados pela ventilação em ambiente compartimentado. O EC1 versão 1994 não apresentava incêndio controlado pelo combustível.

\subsubsection{CURVA PARAMÉTRICA BFD}

Uma nova curva paramétrica proposta em 2002 por Barnett vem ganhando destaque, dada sua simplicidade, pequeno número de parâmetros e o uso de uma expressão única.

$$
\theta_{g}=\theta_{o}+\theta_{m} e^{-z}
$$

Onde:

$$
\begin{aligned}
& \theta_{g} \text { é a temperatura dos gases quentes em }{ }^{\circ} \mathrm{C} ; \\
& \theta_{0} \text { é a temperatura ambiente em }{ }^{\circ} \mathrm{C} ; \\
& \theta_{m} \text { é o incremento máximo de temperatura no incêndio em }{ }^{\circ} \mathrm{C} \text {; } \\
& z \text { é calculado conforme exp. } 1.22 \\
& z=\frac{\left(\ln t-\ln t_{\max }\right)^{2}}{s_{c}}
\end{aligned}
$$

Onde:

$t$ é o instante do incêndio em minutos;

$t_{\text {max }}$ é o tempo em que ocorre a temperatura máxima em minutos; 
$s_{c}$ é o fator de forma da curva de incêndio. O fator de forma é um número adimensional que pode ser obtido em correlação com a taxa de pirólise $(\dot{m})$ e grau de abertura $\left(F_{v}\right)$ do compartimento.

Barnett utilizou 142 ensaios de incêndio para modelar a sua expressão. Os ensaios englobam temperaturas máximas entre $500{ }^{\circ} \mathrm{C}$ e $1200{ }^{\circ} \mathrm{C}$ com ampla gama de massa e tipo de combustível (RIBEIRO, 2004).

Tabela 1-3 - Parâmetros obtidos por Barnett em diversos ensaios. Fonte: BARNETT apud RIBEIRO, 2004.

\begin{tabular}{|l|l|l|l|}
\hline \multicolumn{1}{|c|}{ Ensaio publicado } & \multicolumn{1}{c|}{$\theta_{m}\left({ }^{\circ} \mathrm{C}\right)$} & $t_{\max }(\mathrm{min})$ & $S_{c}$ \\
\hline Odden test & 860 & 48 & 0.7 \\
\hline Car test & 590 & 13 & 1.0 \\
\hline Swedish test 22 & 850 & 21 & 1.6 \\
\hline EBS test 22 & 930 & 18 & 1.8 \\
\hline JFRO test R & 800 & 10 & 1.8 \\
\hline EBS test 9 & 1125 & 19 & 1.3 \\
\hline EBS test 16 & 1030 & 11 & 1.2 \\
\hline CIB / W14(a) & 960 & 15 & 0.3 \\
\hline CIB / W14(b) & 980 & 20 & 1.2 \\
\hline CTICM test 35 & 1120 & 14 & 1.7 \\
\hline CTICM test 63 & 1242 & 9 & 1.6 \\
\hline Cardington test 2 & 1100 & 29 & 0.8 \\
\hline Cardington test 5 & 1160 & 39 & 1.6 \\
\hline Cardington test 6 & 740 & 115 & 4.5 \\
\hline Cardington test 7 & 1260 & 19 & 1.9 \\
\hline
\end{tabular}




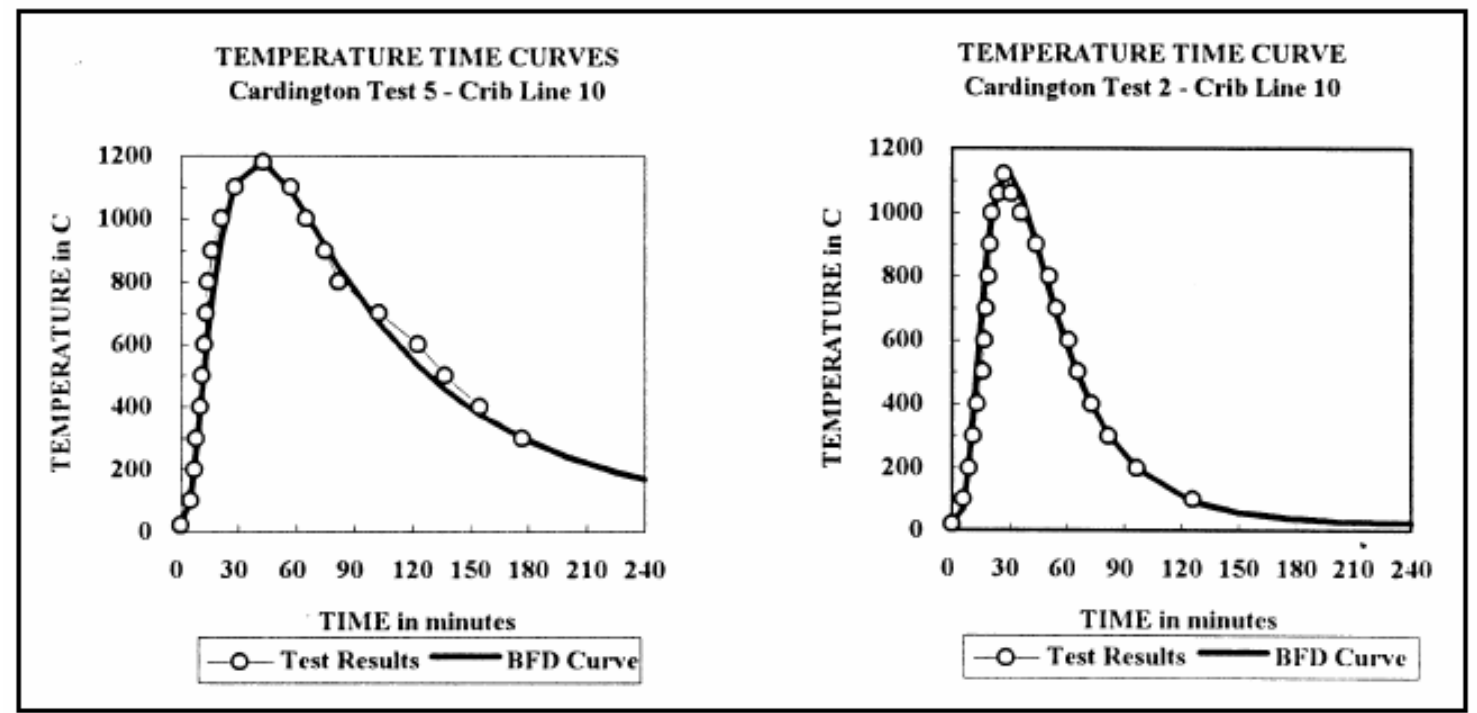

Figura 1-8 - Comparação entre testes de Cardington e as curvas BFD. Fonte: BARNETT, 1998. 


\section{TRANSFERÊNCIA DE CALOR}

Ao existir um gradiente de temperatura no interior de um sistema ou que sistemas em diferentes temperaturas forem colocados em contato, haverá transferência de energia térmica (calor). A literatura especializada reconhece três modos distintos de transmissão de calor: condução, convecção e radiação.

A compreensão dos processos de transferência de calor é chave para o entendimento do fenômeno do incêndio. Neste capítulo serão apresentados os modelos de transferência de calor e como esses efeitos influenciam o equilíbrio térmico no interior do compartimento em chamas.

\subsection{CONDUÇÃo}

O processo de transferência de calor ocorre devido à interação entre as moléculas que constituem os materiais. Ocorre nos três estados da matéria, contudo, é mais expressivo nos materiais sólidos. É o processo no qual a energia (calor) flui de uma região à alta temperatura, para outra à baixa temperatura, num mesmo meio.

O estudo do processo da condução é importante para determinar a distribuição de calor em um volume e o fluxo de calor. Um exemplo prático de condução é o da barra (modelo unidimensional) entre duas fontes de calor $\theta_{A}$ e $\theta_{B}$, e área de seção transversal "A" conforme Figura 2-1.

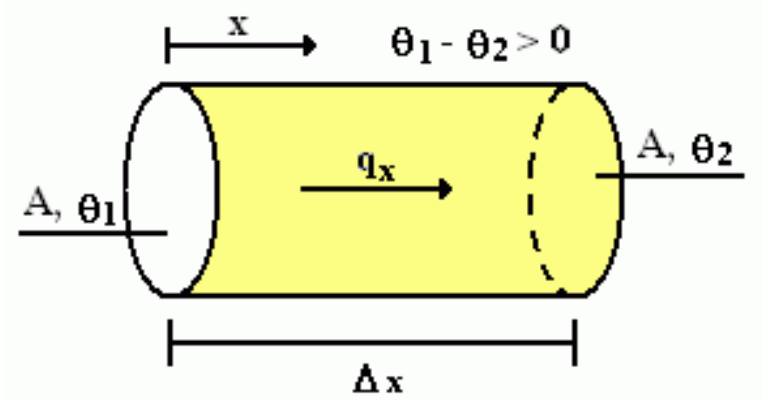

Figura 2-1 - Condução em barra de seção constante (modelo unidimensional). 
A lei fundamental que rege o fenômeno da condução é a lei de Fourier determinada em 1822. Fourier observou que a taxa de transferência de calor entre as faces de uma barra é proporcional ao gradiente de temperatura entre as extremidades da barra e inversamente proporcional a área transversal da barra. A lei de Fourier expressa na eq. 2.1 está na forma unidimensional (Figura 2-2) em regime permanente (não depende do tempo).

$$
\dot{q}_{x}=-\lambda \cdot A \cdot \frac{\partial \theta}{\partial x}
$$

Onde:

$\dot{q}_{x}$ é o fluxo de calor condutivo na direção "x" em W/m²;

$\lambda$ é a condutividade térmica do material em $\mathrm{W} / \mathrm{m} .{ }^{\circ} \mathrm{C}$;

$A$ é a área da seção transversal infinitesimal através da qual o calor flui em $\mathrm{m}^{2}$;

$\frac{\partial \theta}{\partial x}$ é o gradiente de temperatura na direção do fluxo de calor em ${ }^{\circ} \mathrm{C} / \mathrm{m}$.

A constante positiva " $\lambda$ " é uma propriedade física do material que depende da estruturas física e atômica relacionadas ao estado da matéria. "O sinal negativo da exp. 2.1 é inserido para satisfazer o segundo princípio da termodinâmica, ou seja, o calor deve fluir no sentido da temperatura decrescente." (HOLMAN, 1983) A Tabela 2-1 apresenta alguns valores de condutividade térmica " $\lambda$ " para temperatura ambiente.

Tabela 2-1 Valores de condutividade térmica a $0^{\circ} \mathrm{C}$. Fonte: LIENHARD, 2005.

\begin{tabular}{|l|l|}
\hline Material & $\lambda\left(\mathrm{W} / \mathrm{m} .{ }^{\circ} \mathrm{C}\right)$ \\
\hline Cobre (puro) & 401 \\
\hline Alumínio (puro) & 236 \\
\hline Ferro & 84 \\
\hline Aço (1\% de carbono) & 43 \\
\hline
\end{tabular}




\begin{tabular}{|l|l|}
\hline Água & 0,55 \\
\hline Madeira & 0,20 \\
\hline
\end{tabular}

Para situações em que a temperatura do corpo varia com o tempo ou existem fontes ou dissipadores de calor no interior do corpo é necessário estabelecer o equilíbrio térmico. (HOLMAN, 1983). Para o elemento de espessura $d x$, o balanço de energia é dado pela equação 2.2 .

$$
\dot{q}_{x}+\dot{q}_{g e r}=\Delta E_{\mathrm{int}}+\dot{q}_{x+d x}
$$

As expressões deduzidas por Holman (1983) e descritas neste trabalho sob os índices 2.3 a 2.6, explica cada uma das parcelas da exp. 2.2 e considera os dois primeiros termos da série da expansão da série de Taylor.

Energia conduzida para dentro pela face esquerda:

$$
\dot{q}_{x}=-\lambda \cdot A \frac{\partial \theta}{\partial x}
$$

Calor gerado no interior do elemento:

$$
\dot{q}_{g e r}=\dot{q} \cdot A \cdot d x
$$

Variação de energia interna:

$$
\Delta E_{\mathrm{int}}=\rho \cdot c \cdot A \frac{\partial \theta}{\partial t} d x
$$

Energia conduzida pela face direita: 


$$
\dot{q}_{x+d x}=-\left.\lambda \cdot A \frac{\partial \theta}{\partial x}\right|_{x+d x}=-A\left[\lambda \frac{\partial \theta}{\partial x}+\frac{\partial}{\partial x}\left(\lambda \frac{\partial \theta}{\partial x}\right) d x\right]
$$

Onde:

$q$ é a energia gerada por unidade de volume em $\mathrm{J} / \mathrm{m}^{3}$;

$c$ é o calor específico do material em $\mathrm{J} / \mathrm{kg} .{ }^{\circ} \mathrm{C}$;

$\rho$ é a massa específica em $\mathrm{kg} / \mathrm{m}^{3}$.

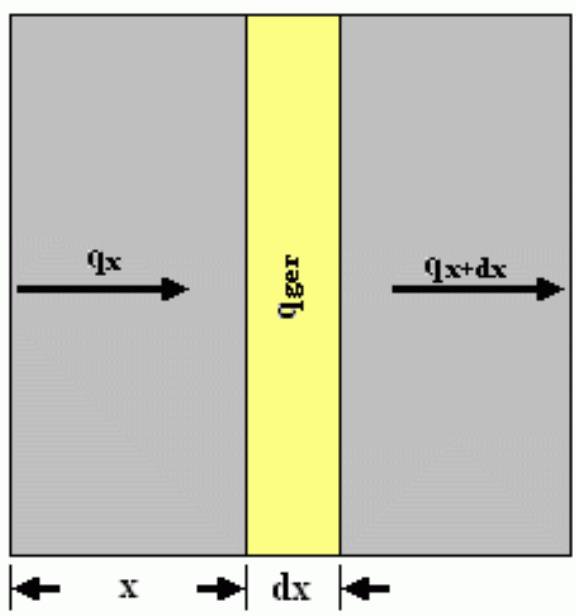

Figura 2-2 - Análise de condução de calor unidimensional

Para tratar o fluxo de calor em mais de uma dimensão (Figura 2-3) deve-se considerar o calor conduzido para dentro e para fora do volume elementar nas três direções $\mathrm{x}, \mathrm{y}, \mathrm{z}$, conforme a exp. 2.7 .

$\dot{q}_{x}+\dot{q}_{y}+\dot{q}_{z}+\dot{q}_{g e r}=\frac{\partial E}{\partial \theta}+\dot{q}_{x+d x}+\dot{q}_{y+d y}+\dot{q}_{z+d z}$ 


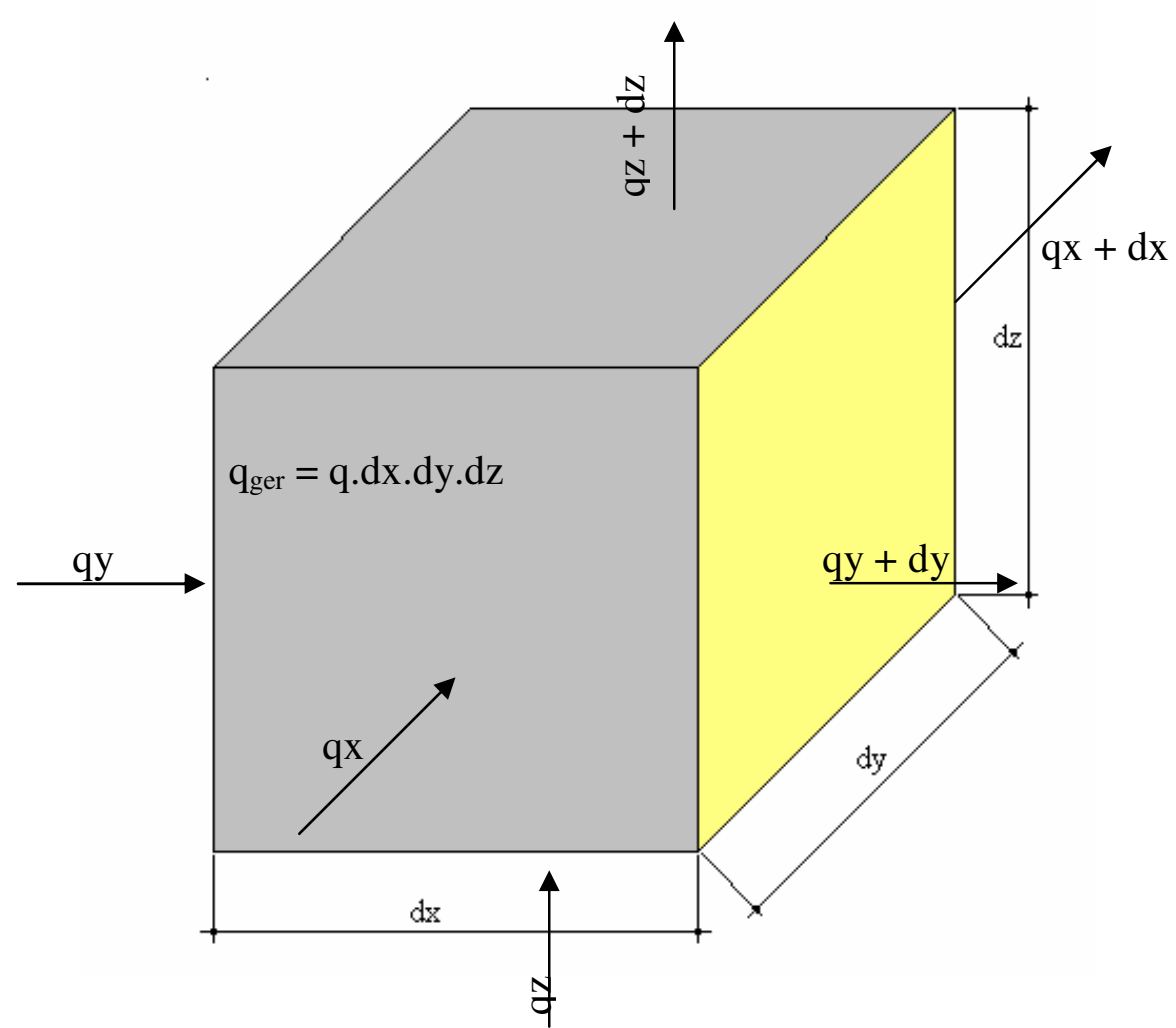

Figura 2-3 - Sólido de volume elementar para análise tridimensional de condução de calor em regime transiente ${ }^{10}$.

\subsection{CONVECÇÃO}

A convecção é o processo de transferência de energia (calor) devido a fluidos em movimento. Newton propôs em 1701, a expressão que relaciona o fluxo de calor convectivo à temperatura dos gases.

$$
\dot{q}_{c}=\alpha_{c}\left(\theta_{c}-\theta_{g}\right)
$$

Onde:

\footnotetext{
${ }^{10}$ Regime transiente ou transitório ocorre quando pelo menos uma variável se altera em relação ao tempo.
} 
$\dot{q}_{c}$ é a taxa de calor convectivo que permeia a área perpendicular ao fluxo convectivo, de interface sólido-fluido em $\mathrm{W} / \mathrm{m}^{2}$;

$\alpha_{c}$ é o coeficiente de transmissão de calor por convecção em $\mathrm{W} / \mathrm{m}^{20} \mathrm{C}$;

$\theta_{g}$ é a temperatura dos gases em ${ }^{\circ} \mathrm{C}$;

$\theta_{c}$ é a temperatura da superfície que receberá o calor por convecção em ${ }^{\circ} \mathrm{C}$.

O problema central de avaliação da convecção é a determinação das condições de contorno de uma superfície exposta ao fluido em movimento, essencial para determinar o coeficiente de transmissão de calor por convecção, $\alpha_{c}$. Para grande parte dos casos, a determinação de $\alpha_{c}$ é feita por meio de modelos em escala reduzida. O EC1 (2002) adota por simplificação $\alpha_{c}=25 \mathrm{~W} / \mathrm{m}^{2}{ }^{\circ} \mathrm{C}$ para a curva padrão ISO $834, \alpha_{c}=50 \mathrm{~W} / \mathrm{m}^{2}{ }^{\circ} \mathrm{C}$ para a curva de hidrocarbonetos e $\alpha_{c}=35 \mathrm{~W} / \mathrm{m}^{2}{ }^{\circ} \mathrm{C}$ para a curva de incêndio natural. $\mathrm{O}$ coeficiente de transmissão de calor por convecção $\alpha_{c}$ é, na realidade, uma função complexa do escoamento do fluido, das propriedades térmicas do meio fluido e da geometria do sistema. Seu valor numérico não é, em geral, uniforme sobre a superfície e depende também do local onde a temperatura do fluido $\theta_{\infty}$ é medida. (KREITH, 1977)

As partículas do fluido ao entrar em contato com uma superfície ${ }^{11}$, tendem à velocidade zero e reduzem a velocidade da camada adjacente (ver Figura 2-4) devido à ação da viscosidade do fluido. Esse efeito se propaga até uma altura $\delta$, conhecida como altura da camada limite. Da mesma forma que na camada limite fluidodinâmica ocorre uma influência da parede de distribuição de velocidades acima da superfície, se houver uma diferença de temperatura entre o fluido não-pertubado (afastamento superior a $\delta$ ) e a superfície, haverá uma região de influência na temperatura do fluido. (KRIEGER, 2001)

\footnotetext{
${ }^{11}$ Por motivo de simplificação a superfície apresentada na Figura 2-4 é uma placa plana e o fluxo do fluido é paralelo à placa.
} 
O fluido a uma temperatura $\theta_{\infty}$ encontra a placa que está a uma temperatura $\theta_{\mathrm{w}}$. As partículas junto à placa, por terem velocidade relativa nula, entram em equilíbrio térmico com a placa e atingem, portanto, a temperatura $\theta_{\mathrm{w}}$. Esta influência de temperatura da parede se estende até uma altura $\delta$ ' que é chamada de camada de limite térmica.
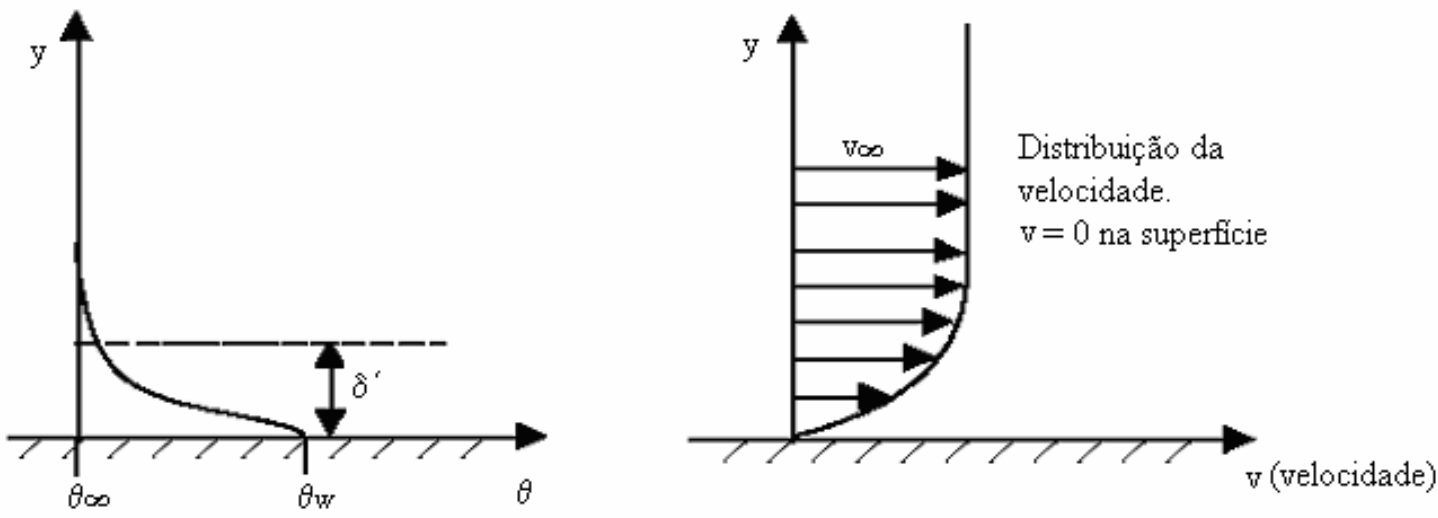

Figura 2-4 -. Influência do escoamento na distribuição de temperatura e velocidade

A relação entre as alturas da camada limite $(\delta)$ e da camada limite térmica $\left(\delta^{\prime}\right)$ é dada pelo número de Prandtl (Pr). A exp. 2.9 só “é válida para fluidos com número de Prandtl maiores que 0,7 (maioria dos gases e líquidos)".(HOLMAN, 1983)

$$
\frac{\delta}{\delta}=\frac{1}{1,026} \operatorname{Pr}^{-\frac{1}{3}}
$$

$$
\operatorname{Pr}=\frac{v}{\alpha}
$$

Onde:

$\operatorname{Pr}$ é o numero de Prandtl (adimensional). Para $\operatorname{Pr}=1$ a distribuição da velocidade é igual à distribuição de temperatura;

$\alpha$ é a difusividade térmica do fluido $\mathrm{em}^{2} / \mathrm{s}$;

$v$ é viscosidade cinemática do fluido $\mathrm{em} \mathrm{m}^{2} / \mathrm{s}$. 
A convecção é classificada em natural ou forçada de acordo com a fonte de movimentação do fluido. "Para a engenharia de segurança contra incêndios um regime de convecção importante é o de convecção natural". (KRIEGER, 2001)

"Na convecção natural, ou livre, o movimento do fluido é devido a diferenças de densidades provocadas pelo processo de aquecimento. O movimento do fluido na convecção natural seja um gás ou um líquido resulta das forças de empuxo impostas ao fluido quando a sua densidade diminui nas proximidades da superfície de transferência de calor como resultado do processo de aquecimento". (HOLMAN, 1983)

Kreith (1983) descreve a obtenção do coeficiente de convecção natural do fluido por meio do número de Nusselt $\left(N_{u}\right)$, dado pela exp. 2.11:

$$
\alpha_{c}=N_{u} \frac{k_{f}}{L}
$$

Onde:

$N_{u}$ é o número de Nusselt (adimensional);

$k_{\mathrm{f}}$ é a condutividade térmica do fluido em $\mathrm{W} / \mathrm{m}{ }^{\circ} \mathrm{C}$;

$L$ é o comprimento característico que descreve o sistema em metros.

O número de Nusselt é função dos adimensionais de Reynolds (exp. 2.13) e de Prandtl (exp. 2.10). Para uma placa plana e de escoamento laminar ${ }^{12}$ é obtido por meio da exp. 2.12 .

$$
N u=0,35 \cdot R e^{\frac{1}{2}} \cdot \operatorname{Pr}^{\frac{1}{3}}
$$

Onde:

\footnotetext{
${ }^{12}$ Consultar bibliografia para outras configurações.
} 
Re é o número de Reynolds (adimensional);

Pr é o número de Prandtl (adimensional).

O número de Reynolds é obtido por meio da exp. 2.13

$$
R e=\frac{v_{m} \phi}{v}
$$

Onde:

$$
\begin{aligned}
& R e \text { é o número de Reynolds (adimensional); } \\
& v_{m} \text { é a velocidade média do fluido } \mathrm{em} \mathrm{m} / \mathrm{s} ; \\
& \phi \text { é o diâmetro em metros; } \\
& v \text { é a viscosidade cinemática do fluido } \mathrm{em}^{2} / \mathrm{s} \text {. }
\end{aligned}
$$

Na convecção forçada, o movimento do fluido é induzido por algum agente externo, tal como uma bomba ou um ventilador.

\subsection{RADIAÇÃO}

A radiação é o processo pelo qual o calor flui na forma de propagação de ondas de um corpo à alta temperatura para outro à temperatura mais baixa. A radiação térmica assim como qualquer radiação eletromagnética propaga-se à velocidade da luz.

Este fenômeno é distinto dos anteriores, pois não necessita de um meio material interveniente entre duas superfícies ou a dependência de posição entre elas. Todos os corpos cuja temperatura é superior ao zero absoluto, emitem radiação proporcional a sua temperatura superficial (KRIEGER, 2001). 
A transferência de calor por radiação é realizada por fótons. Quando um fóton é irradiado para uma superfície (Figura 2-5), eles podem ser absorvidos $(\alpha)$, refletidos $(\rho)$ ou transmitidos $(\tau)$. É evidente que a soma das frações irradiadas é igual a radiação total ou incidente, ou seja, $\alpha+\rho+\tau=1$.

Um irradiador perfeito ou ideal é aquele cuja fração de radiação incidente absorvida $(\alpha)$ é igual a 1. É comum encontrar na literatura a expressão "corpo negro" para designar um irradiador perfeito.

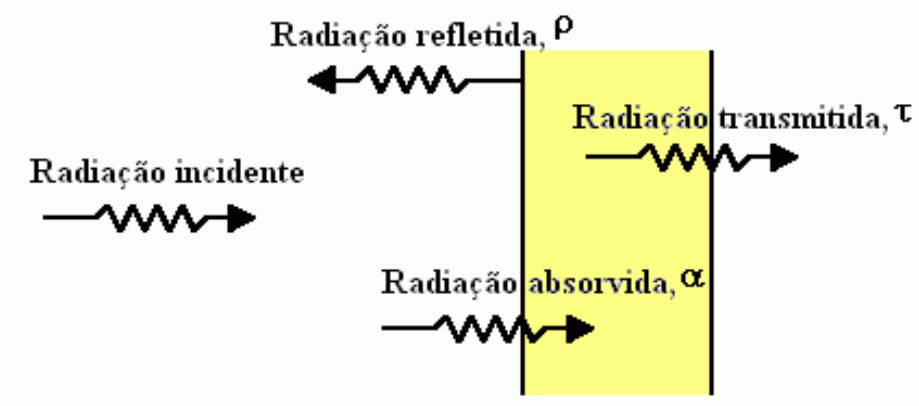

Figura 2-5 - Tipos de radiação.

A expressão para o cálculo do fluxo de calor emitido por um irradiador perfeito foi encontrada experimentalmente por J. Stefan em 1879 e deduzida teoricamente por L. Boltzmann em 1884. A exp. 2.14 só é valida para radiação térmica, outros tipos de radiação eletromagnética precisam de tratamento mais complexo.

$$
\dot{q}_{r}=\sigma(\theta+273,15)^{4}
$$

Onde:

$\dot{q}_{r}$ é o fluxo de calor radiativo em $\mathrm{W} / \mathrm{m}^{2}$;

$\sigma$ é a constante proporcionalidade de Stefan-Boltzmann $=5,669.10^{-8} \mathrm{~W} / \mathrm{m}^{2}{ }^{\circ} \mathrm{C}^{4}$;

$\theta$ é a temperatura do irradiador em ${ }^{\circ} \mathrm{C}$. 
Corpos reais ou corpos "cinzentos" irradiam efetivamente menos que corpos ideais. No caso de troca de calor por radiação entre dois corpos reais tem-se:

$\dot{q}_{r}=\sigma \varepsilon_{1-2}\left[\left(\theta_{1}+273,15\right)^{4}-\left(\theta_{2}+273,15\right)^{4}\right]$

Onde:

$\dot{q}_{r}$ é o fluxo de calor radiativo em $\mathrm{W} / \mathrm{m}^{2}$

$\varepsilon_{1-2}$ é a emissividade, fator dependente das características térmicas e geométricas dos dois corpos (adimensional).

$\sigma$ é a constante proporcionalidade de Stefan-Boltzmann

$\theta_{1}$ e $\theta_{2}$ são as temperaturas dos dois corpos em ${ }^{\circ} \mathrm{C}$.

Alterando a forma da exp. 2.15 para uma similar a da convecção, obtém-se:

$\dot{q}_{r}=\alpha_{r}\left(\theta_{g}-\theta_{a}\right)$

e

$$
\alpha_{r}=\frac{\sigma \varepsilon_{r}\left\lfloor\left(\theta_{g}+273,15\right)^{4}-\left(\theta_{a}+273,15\right)^{4}\right\rfloor}{\left(\theta_{g}-\theta_{a}\right)}
$$

Onde:

$\alpha_{r}$ é o coeficiente de transferência de calor por radiação em $\mathrm{W} / \mathrm{m}^{2}{ }^{\circ} \mathrm{C}$;

$\theta_{\mathrm{g}}$ é a temperatura dos gases quentes em ${ }^{\circ} \mathrm{C}$;

$\theta_{a}$ é a temperatura do elemento estrutural em ${ }^{\circ} \mathrm{C}$;

$\mathcal{E}_{r}$ é a emissividade resultante envolvendo chamas, gases em combustão e superfície do aço exposta às chamas. 
A emissividade é entendida como a razão entre a energia irradiada do corpo real e a energia irradiada do corpo ideal para uma mesma temperatura $\theta$. Portanto, a emissividade varia no intervalo $0<\varepsilon_{r}<1$, cuja expressão está representada em 2.18.

$$
\varepsilon_{r}=\frac{E}{E_{b}}
$$

Onde:

$E$ é a energia irradiada do corpo real em $\mathrm{W} / \mathrm{m}^{2}$;

$E_{b}$ é a energia irradiada do corpo ideal $\mathrm{em} \mathrm{W} / \mathrm{m}^{2}$.

Tabela 2-2 Valores de emissividade dada uma temperatura. Fonte: LIENHARD, 2005.

\begin{tabular}{|l|l|l|}
\hline Material & Temperatura $\left[{ }^{\circ} \mathrm{C}\right]$ & Emissividade \\
\hline Aço oxidado & 40 & 0,8 \\
\hline Aço polido & $40-260$ & $0,07-0,1$ \\
\hline Aço inoxidável polido & 40 & $0,07-0,17$ \\
\hline Alumínio Polido & $200-600$ & $0,04-0,06$ \\
\hline Alumínio muito oxidado & $90-540$ & $0,2-0,33$ \\
\hline Cobre polido & 90 & 0,02 \\
\hline Cobre oxidado (preto) & 40 & 0,76 \\
\hline Gelo & 0 & $0,97-0,98$ \\
\hline Madeira & 40 & $0,8-0,9$ \\
\hline Ouro & $90-600$ & $0,02-0,035$ \\
\hline
\end{tabular}

O valor de $\varepsilon_{r}$ depende da forma de exposição ao fogo do elemento estrutural e pode variar entre 0,3 e 0,7 (PETTERSSON et al, 1976 apud SILVA, 1997). Recomenda-se por simplificação $\varepsilon_{r}=0,5$ conforme recomendação do EC3 (2003) e da NBR 14323:1999.

A energia de um corpo negro, $E_{b}$ é distribuída ao longo da faixa de comprimento de onda. Quando a temperatura aumenta, o comprimento de onda para máxima energia emitida muda para valores menores. A freqüência de onda dada pela exp. 2.19 mostra 
que energia mais alta significa comprimentos de onda menores, portanto, mais próximos da zona visível do espectro.

$$
f=\frac{c}{\lambda}
$$

Onde:

$f$ é a freqüência de onda em $\mathrm{s}^{-1}$;

$c$ é a velocidade da luz, $\mathrm{c}=3 \cdot 10^{8} \mathrm{~m} / \mathrm{s}$

$\lambda$ é o comprimento de onda em metros.

"A faixa visível do espectro estende-se por uma faixa muito estreita do espectro entre $0,4 \mu \mathrm{m}$ e $0,7 \mu \mathrm{m}$. Apenas uma pequena parte da energia total cai nessa faixa do comprimento de onda, em temperaturas abaixo de $650^{\circ} \mathrm{C}$. Em temperaturas mais elevadas, a quantidade de energia visível aumenta, e o olho humano começa a detectar a radiação. A cerca de $700^{\circ} \mathrm{C}$, uma quantidade de energia radiante suficiente a ser observada, é emitida em comprimentos de onda entre $0,6 \mu \mathrm{m}$ e $0,7 \mu \mathrm{m}$, e um objeto a essa temperatura brilha com uma cor avermelhada. À medida que a temperatura cresce a cor muda para vermelho-vivo e amarela, tornando-se branca a cerca de $1300^{\circ} \mathrm{C}$ “ $(\mathrm{KREITH}$, 1977).

\subsection{TRANSFERÊNCIA DE CALOR EM INCÊNDIOS}

Embora os três processos de transferência de calor (condução, convecção e radiação) atuem no incêndio, é observado que apenas um deles é predominante durante um certo estágio do aquecimento ou em um certo local do compartimento, conforme apontado na Figura 2-6. A condução determina a velocidade do fluxo de calor dentro do material das estruturas; a convecção comparece em todos os estágios do incêndio, sendo a sua ação predominante no início do incêndio, quando os níveis de radiação térmica são baixos; a 
radiação é emitida na maioria do incêndio como conseqüência da difusão das chamas (DRYSDALE, 1999; apud COSTA; SILVA, 2002).

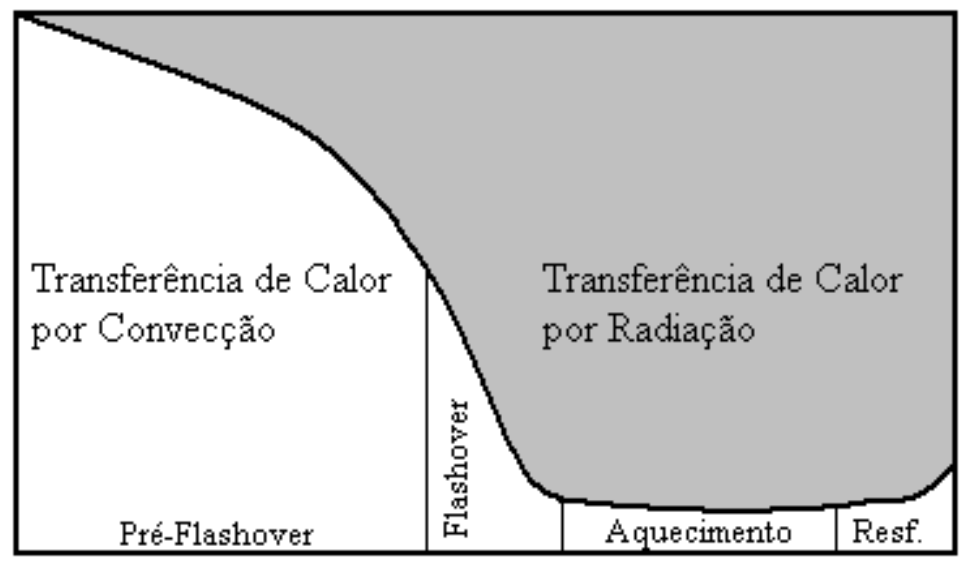

Figura 2-6 - Relação de transmissão de calor com as fases do incêndio. Fonte: KENNEDY; KENNEDY, 2003

"A diferença de temperatura entre as chamas de um incêndio e os elementos estruturais gera um fluxo de calor que, via radiação e convecção, (exp. 2.20) transfere-se para a estrutura provocando aumento de temperatura. $\mathrm{O}$ acréscimo de temperatura na peça estrutural é determinado considerando-se o equilíbrio térmico envolvendo o calor emitido pelo fogo e o calor absorvido pela peça de aço”. (SILVA, 1997)

$$
\dot{h}=\dot{h}_{c}+\dot{h}_{r}
$$

Onde:

$\dot{h}$ é o fluxo de calor absorvido pelas peças estruturais em $\mathrm{W} / \mathrm{m}^{2}$;

$\dot{h}_{c}$ é o fluxo de calor convectivo em $\mathrm{W} / \mathrm{m}^{2}$;

$\dot{h}_{r}$ é o fluxo de calor radiativo em $\mathrm{W} / \mathrm{m}^{2}$; 
O calor proveniente da combustão é dado pelo fluxo de calor absorvido em uma área dado pela exp. 2.21 .

$$
\dot{Q}=\dot{h} \cdot A
$$

Onde:

$\dot{Q}$ é o calor proveniente da combustão em $\mathrm{W}$;

$\dot{h}$ é o somatório dos fluxos de calor convectivo e irradiado em $\mathrm{W} / \mathrm{m}^{2}$;

$A$ é a área da seção através da qual o calor flui em $\mathrm{m}^{2}$.

Num compartimento em chamas, o fluxo de calor gerado pela queima dos materiais combustíveis é dissipado pelos elementos de vedação (paredes e pisos) e aberturas e, além disso, uma parcela do calor de combustão é dissipado devido à troca de calor entre os ambientes interno e externo (Figura 2-7). O equilíbrio térmico do fluxo de calor num incêndio compartimentado é descrito por Petterson (et al, 1976) por meio da eq. 2.22.

$$
\dot{Q}_{c}=\dot{Q}_{w}+\dot{Q}_{r}+\dot{Q}_{l}+\dot{Q}_{b}
$$

Onde:

$\dot{Q}_{c}$ é o calor gerado durante a combustão em W. O calor gerado pela combustão corresponde a queima de madeira, cujo potencial calorífico foi definido por Petterson em seus ensaios, é de 18,84 MJ/kg.

$\dot{Q}_{w}$ é o calor dissipado por meio dos elementos de vedação em W. Para calcular a dissipação de calor pelos elementos de vedação as equações de condução têm que ser resolvidas numericamente considerando as propriedades térmicas do material das vedações variando conforme o aumento de temperatura. Os elementos de vedação do compartimento são divididos em $n$ camadas de espessura $\Delta x$. Uma série de equações diferenciais de primeira ordem descrevendo 
o fenômeno da condução, é empregada para resolver cada camada, em intervalos de tempo $\Delta t$;

$\dot{Q}_{r}$ é o calor dissipado por radiação através das aberturas em W. Pode ser calculado pela lei de Stefan-Boltzman;

$\dot{Q}_{l}$ é a perda de calor por fluxo convectivo através de aberturas em W. Esta perda deve-se a distribuição de pressão linear na (direção) vertical sobre as aberturas e uma camada neutra onde não existe diferença entre a pressão estática interna e externa. Assumindo a camada neutra e a distribuição uniforme em todo o compartimento, a quantidade de gases fluindo para o exterior e a quantidade de gases adentrando o compartimento pode ser calculado usando o teorema de Bernoulli;

$\dot{Q}_{b}$ é o calor absorvido pelos gases do compartimento em W. Este termo pode ser ignorado, uma vez que, é insignificante comparado aos outros termos. (PETTERSON et al, 1976)

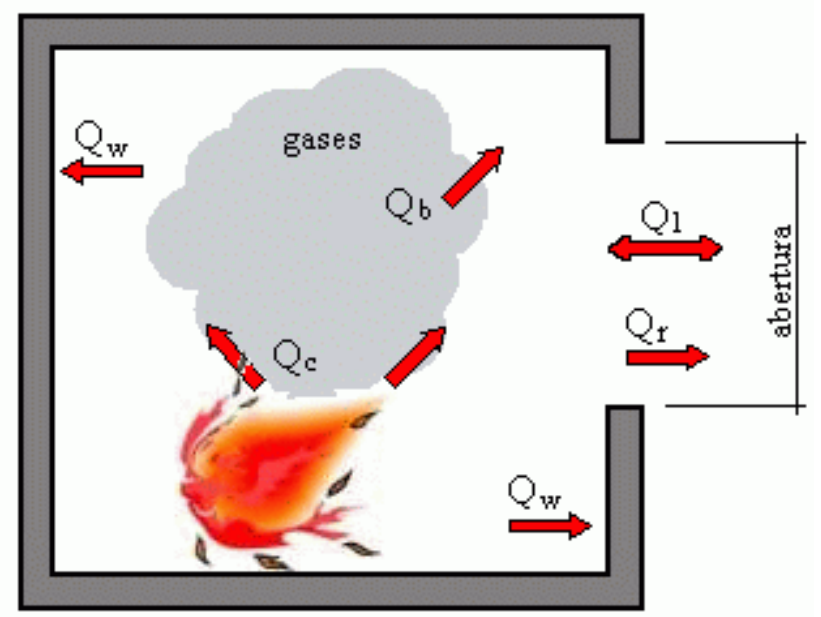

Figura 2-7 - Trocas de calor em incêndio. 
Uma série de hipóteses foi feita por Petterson (et al, 1976) para resolver o equilíbrio térmico.

- A combustão é completa e acontece exclusivamente no interior do compartimento;

- A temperatura é uniforme no compartimento em qualquer instante;

- O coeficiente de transmissão de calor por convecção das superfícies é uniforme;

- O fluxo de calor é unidimensional, e com exceção das aberturas e portas, é uniformemente distribuído em cada tipo de estrutura.

\subsubsection{RELAÇÃO DO FLUXO DE CALOR COM O FLASHOVER}

O termo "fluxo de calor liberado" ou $\mathrm{HRR}^{13}$ (Heat Release Rate) é freqüentemente empregado na engenharia de segurança contra incêndio, cujo significado é calor liberado por um produto combustível como uma função de tempo. É descrito como a "variável simples mais importante na indicação do risco à vida e a propriedade"..(BABRAUSKAS; PEACOCK, 1992), já que os materiais que liberam sua energia química potencial (e também a fumaça e gases tóxicos) relativamente rápido são mais perigosos que aqueles que liberam a energia lentamente.

O HRR está correlacionado com a ocorrência de flashover. Thomas (WALTON; THOMAS, 1995) desenvolveu um critério para a ocorrência de flashover, relacionado com as características físicas do compartimento. Após a análise de diversos compartimentos, Thomas concluiu que o flashover somente acontece caso o compartimento atinja um valor crítico de calor liberado.

$$
Q_{f o}=0,0078 A_{t}+0,378 A_{v} \sqrt{h_{e q}}
$$

Onde:

$13 \mathrm{Na}$ literatura especializada também é encontrado a expressão RHR (Rate of Heat Release) 
$Q_{f o}$ é o calor liberado crítico para ocorrência de flashover em MW;

$A_{t}$ é a área total do compartimento em $\mathrm{m}^{2}$;

$A_{v}$ é a área de ventilação em $\mathrm{m}^{2}$;

$h_{e q}$ é a altura média das aberturas em $\mathrm{m}$.

O HRR médio estimado para a ocorrência de flashover é $1975 \pm 1060 \mathrm{~kW}$, entretanto se aceita o valor característico de $1700 \mathrm{~kW}$. A

Figura 2-8 relaciona o fluxo de calor com o tempo para ocorrência do flashover. Nota-se que para ocorrência de flashover em tempos inferiores a 120 segundos são necessários altos valores de fluxo de calor. (BABRAUSKAS; PEACOCK; RENEKE, 2003) "A HRR depende da quantidade de combustível presente no compartimento, das condições de ventilação e da fase do incêndio". (CADORIN; FRANSSEN, 2003)

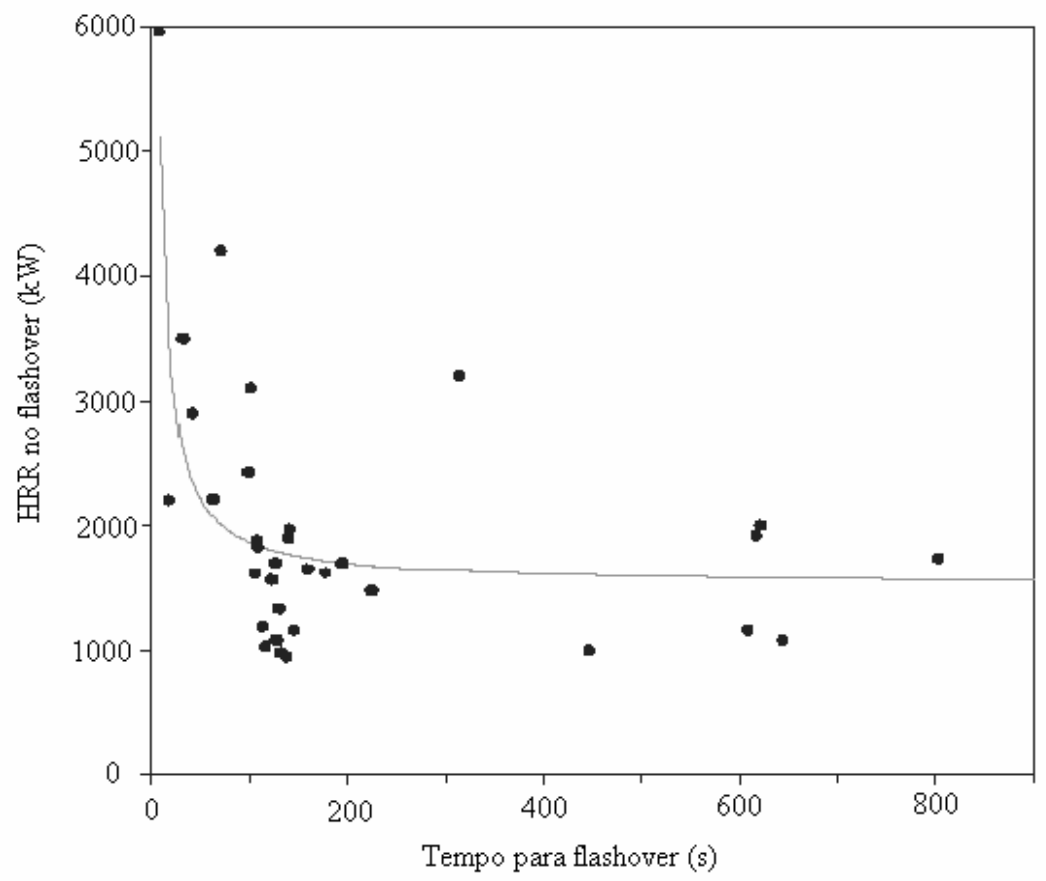

Figura 2-8 - Relação entre o fluxo de calor e o tempo para o flashover. Fonte: BABRAUSKAS; PEACOCK; RENEKE, 2003. 


\subsubsection{ENSAIOS PARA DETERMINAÇÃO DO FLUXO DE CALOR}

O fluxo de calor liberado é entrada essencial para modelos de incêndio, conseqüentemente, são realizados muitos ensaios para aferição do fluxo de calor e estimar correlações com o incêndio real. Os ensaios aplicados para determinação do fluxo de calor liberado são realizados em modelos de escala reduzida ou em escala real, aplicado em diferentes materiais como móveis (colchões, sofás e camas), químicos por meio de pool-fires ${ }^{14}$, televisores, etc. O primeiro aparato em que o fluxo de calor liberado foi quantitativamente medido, nas unidades corretas, foi o calorímetro de materiais de construção da Factory Mutual. Foi desenvolvido por Thompson e Cousins no Factory Mutual Research Laboratories em 1959 para testar roof decks em escala reduzida. Este calorímetro utilizava o método da substituição, onde um espécime era inserido no aparato e sujeito a uma exposição prescrita por um queimador de óleo. Um segundo teste era então realizado, substituindo o espécime por uma amostra nãocombustível. Com a adição de um queimador de propano ao experimento, o queimador era regulado para que a temperatura captada pelos termopares fosse dobrada. A massa restante de propano era medida e o fluxo de calor liberado era estimado multiplicando a massa perdida de combustível pelo calor de combustão do combustível (BABRAUSKAS; GRAYSON, 1992) (THOMPSON, 1959; apud BABRAUSKAS; PEACOCK, 1992) Este método também foi utilizado por Brenden do FPL (Forest Product Laboratories) As desvantagens do método da substituição são a duplicidade de testes a serem realizadas e o complexo sistema de controle.(JANSSENS, 2000)

\footnotetext{
${ }^{14}$ Segundo Hamins, Kashiwagi e Burch (1996) um pool fire é um incêndio de difusão turbulenta sob uma "piscina" horizontal de vaporização de hidrocarbonetos (combustível) onde o combustível possui impulso inicial baixo ou zero. Embora o nome sugira que o combustível esteja na forma líquida, ele pode estar na forma de gás ou mesmo sólido. A "piscina" por motivos de simplificação normalmente é de geometria circular, para que a configuração seja relacionada a apenas uma única dimensão, o diâmetro.
} 
Em 1972, foi desenvolvido na NBS por Parker ${ }^{15}$ e Long um calorímetro (NBS-I) que utilizava além do espécime a ser testado (pequena escala), um queimador auxiliar abastecido de propano. Avaliava-se a temperatura em diversas posições por termopares, e mantinha-se a temperatura constante regulando o queimador auxiliar (método da compensação). A energia de combustão representada pelo propano é tomada com o fluxo de calor liberado. (BABRAUSKAS; GRAYSON, 1992)

Tanto o método da substituição quanto o da compensação apresentava erros, devido "a variação da fração de calor liberado pela radiação de acordo com o tipo de material testado, e porque nem toda energia radiante contribui para o aumento da temperatura do ar" (STECKLER, s.d.), e assim, não obtiveram ampla aceitação.

Uma outra linha de pesquisa desenvolvida por Parker, e provada por Huggett ${ }^{16}$ explorou a possibilidade de aferir o fluxo de calor liberado (HRR) por meio da redução da concentração de oxigênio nos gases expelidos pela combustão, já que "o fluxo de calor liberado por volume de unidade de oxigênio consumido é aproximadamente o mesmo para uma série de materiais utilizados na construção de edifícios e mobiliário". (STECKLER, s.d.) A técnica é a base para os testes em pequena escala (bench scale) e grande escala (room scale) atualmente, apesar da complexa instrumentação.

Tornou-se prática aceita em todos os testes de fluxo de calor liberado utilizar aparatos baseados na técnica do consumo de oxigênio. A ISO adotou o "calorímetro de cone" como o seu método para medição do HRR em bench-scale (ISO DIS 5660), assim como, a ASTM (E 1354). O “calorímetro de cone” foi projetado pela NBS por Babrauskas,

\footnotetext{
${ }^{15}$ William Parker, pesquisador da NBS (National Bureau of Standards), apresentou a técnica de medição do fluxo de calor por oxigênio consumido. Pesquisou incêndios em túneis (ASTM E 84).

${ }^{16}$ Clayton Huggett foi pesquisador do NBS (National Bureau os Standards) na década de 70 e 80 , publicou o trabalho que assegura a comunidade científica de que a técnica de consumo de oxigênio é precisa para pesquisas de fluxo de calor. Também apresentou trabalhos na propulsão de foguetes e desenvolvimento de combustíveis para mísseis.
} 
Parker e Swanson após experiência adquirida na operação dos calorímetros NBS-I, NBS-II e OSU (Ohio State University).

O calorímetro de cone é capaz de medir simultaneamente, não apenas o HRR, mas também ignitabilidade, produção de fumaça e a produção de várias espécies de gases tóxicos. (BABRAUSKAS, PEACOCK, 1992)

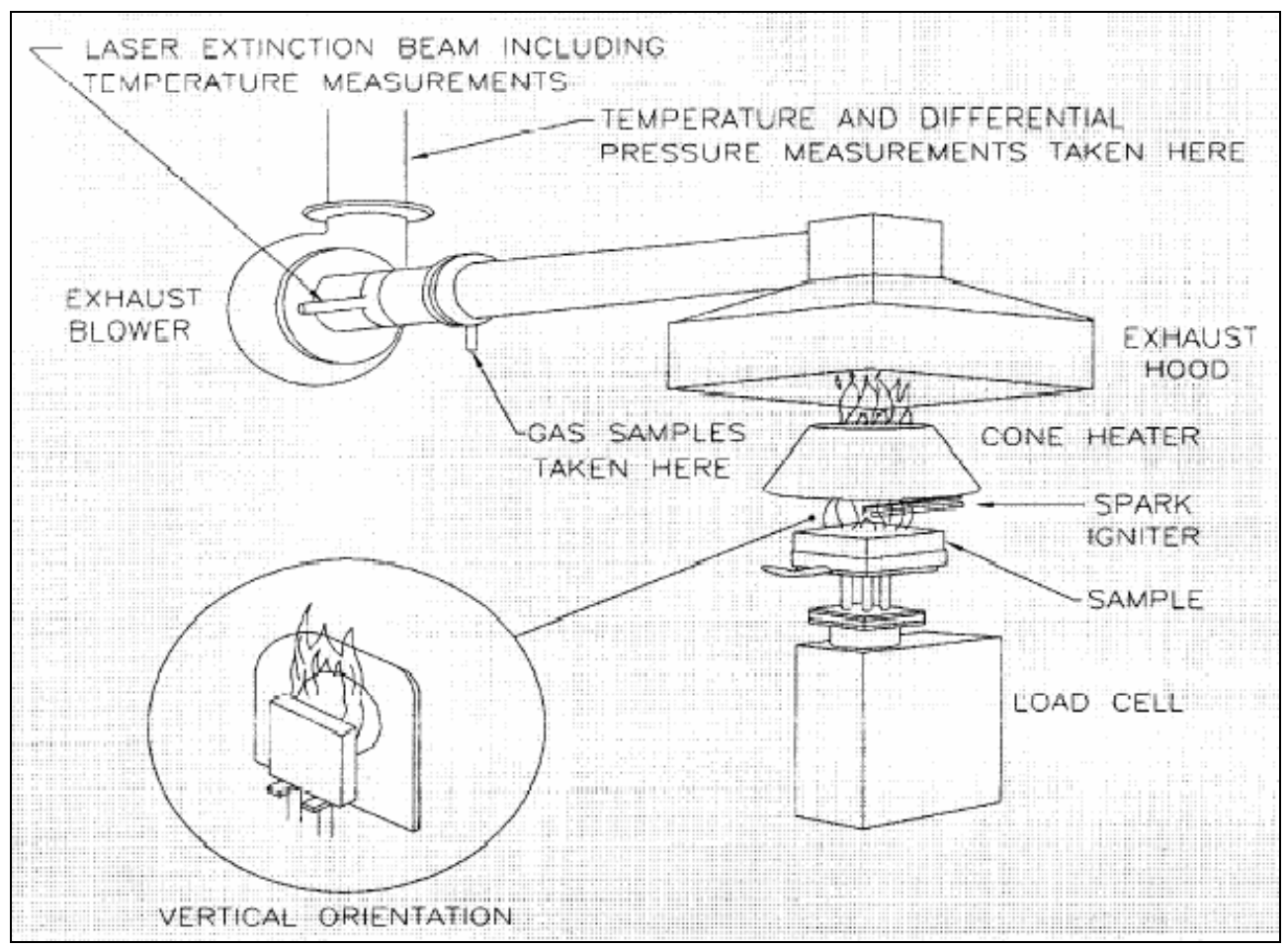

Figura 2-9 - Calorímetro de Cone. Fonte: JANSSENS, 2000

A primeira tentativa para desenvolver uma técnica para medição do fluxo de calor liberado em grande escala foi 1978 por Warren Fitzgerald (Monsanto Chemical). O calorímetro da Monsanto Chemical avaliava a temperatura em diversas posições por termopares, e computava o fluxo de calor liberado. O método valia-se de premissas computacionais incertas e de capacidade limitada de medição. O primeiro teste roomscale aceito pela comunidade científica foi divulgado pela ASTM em 1982. (BABRAUSKAS; PEACOCK, 1992) 
As incertezas decorrentes dos métodos de medição da HRR são referentes à "variabilidade das amostras, variabilidade da operação, variabilidade do fluxo de calor (em teste de pequena escala), efeitos aleatórios do crescimento do incêndio (em testes em grande escala) e erros dinâmicos".(JANSSENS, 2000) 


\section{TEMPERATURA NOS ELEMENTOS DE AÇO}

Os elementos estruturais de aço atingem altas temperaturas, em intervalos pequenos de tempo, por serem esbeltos e bons condutores. As propriedades térmicas (calor específico e condutividade térmica) e mecânicas (resistência e rigidez) do aço são afetadas pelo aumento de temperatura, e assim, "devem ser consideradas no dimensionamento das estruturas em situação de incêndio, para a garantia da segurança requerida" (VARGAS; SILVA, 2003).

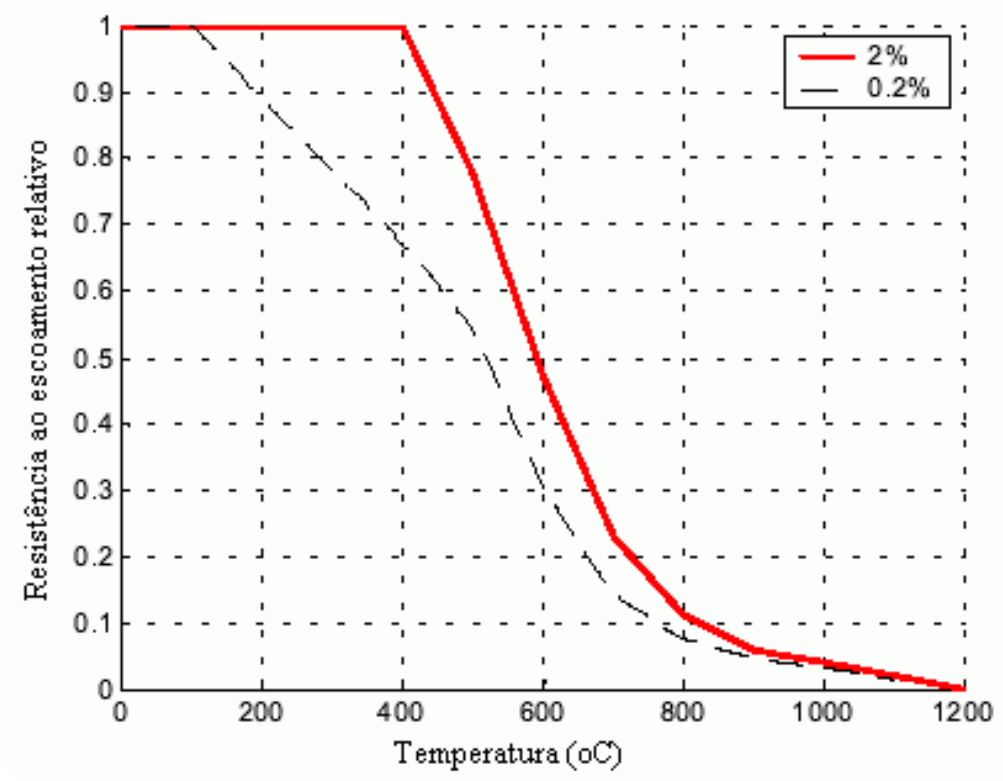

Figura 3-1 - Resistência ao escoamento relativo em função da temperatura Fonte: JEANSSON; ANDERBERG, 2001.

Perfis formados a frio permitem deformação crítica do aço $(0,2 \%)$ inferior aos perfis formados a quente (2\%), já que por serem muito esbeltos, não admitem plastificação. A flambagem local ocorrerá antes da plastificação da seção transversal.

Observando a Figura 3-1, conclui-se que para aços com deformação crítica de $2 \%$ a redução da resistência inicia-se em $400^{\circ} \mathrm{C}$. Caso a deformação crítica seja de $0,2 \%$ a redução inicia-se em torno de $100^{\circ} \mathrm{C}$. Já a redução do módulo de elasticidade dos aços é notada a partir dos $100^{\circ} \mathrm{C}$, como apresentado na Figura 3-2. 


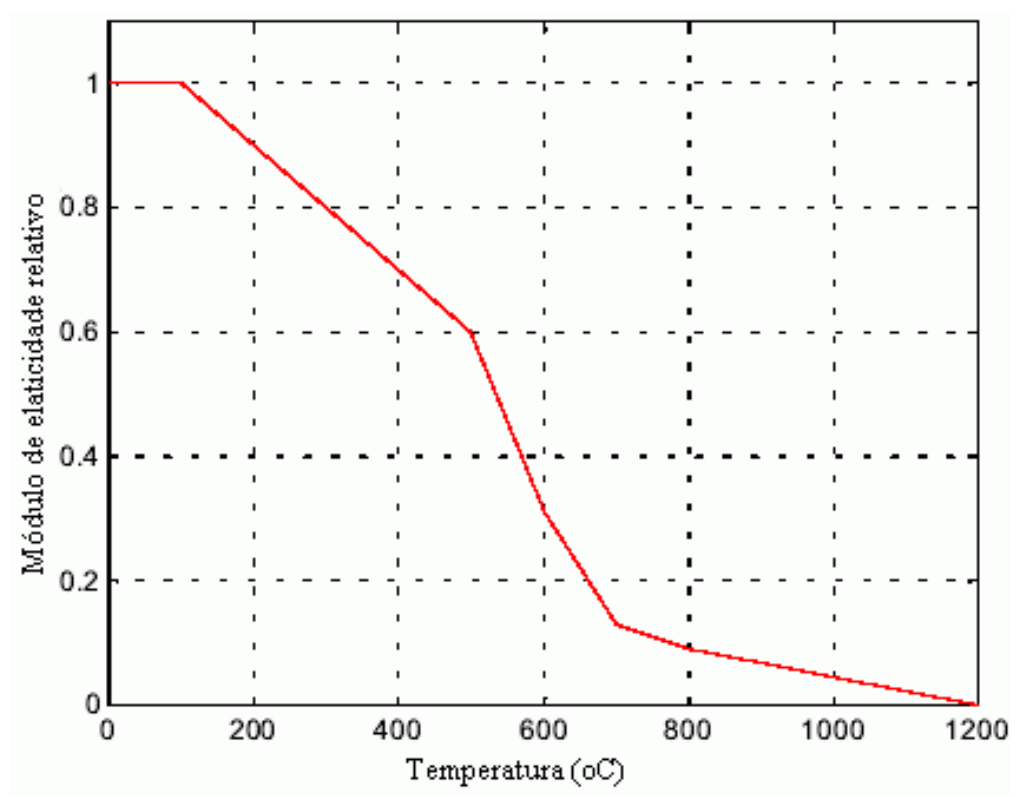

Figura 3-2 - Módulo de elasticidade relativo em função da temperatura. Fonte: JEANSSON; ANDERBERG, 2001.

A engenharia estrutural costumava enxergar a redução da capacidade suporte em termos de temperatura crítica. A temperatura crítica é a temperatura que causa colapso estrutural em uma situação de incêndio. "Um limite de temperatura crítica média comum é $550^{\circ} \mathrm{C}$, mas o limite pode subir tão alto quanto $800^{\circ} \mathrm{C}$, ou tão baixo quanto $400^{\circ} \mathrm{C}$, dependendo do comprimento, vínculo, excentricidade e carregamentos na viga ou no pilar" (BARNETT, 1998).

O fato é que o aço perde aproximadamente $40 \%$ de sua resistência a $550^{\circ} \mathrm{C}$ em relação à temperatura ambiente. A fim de retardar as temperaturas críticas, os códigos de edificações ${ }^{17}$ acenando para a possibilidade das medidas de proteção ativa de combate

${ }^{17}$ Os códigos de edificações impõem requisitos estatuários em relação à segurança contra incêndio. Esses requisitos são divididos em duas categorias: os requisitos de materiais e requisitos de construção. Os requisitos materiais incluem características como combustibilidade, alastramento da chama e resistência 
ao fogo (item 1.1.3) não serem suficientes ou confiáveis para extinção do incêndio no estágio inicial, quando as temperaturas são relativamente baixas, exigem que as estruturas sejam resguardadas por integração com outros elementos construtivos, como concreto e alvenaria ou por barreiras por intermédio da aplicação de revestimentos de proteção contra fogo (caixa ou contorno). Existe a possibilidade de dimensionar a estrutura sem nenhuma proteção, entretanto, é uma opção onerosa.

Em geral, os efeitos do incêndio sobre o aço estrutural são predominantemente temporários, duram somente enquanto o aço está aquecido, já que os aços comuns possuem relativamente baixa composição de carbono. Portanto, para aços aquecidos até por volta de $700^{\circ} \mathrm{C}$ por menos de 20 minutos, readquirem suas propriedades préincêndio. Para aços aquecidos além dos $700^{\circ} \mathrm{C}$, por motivos práticos considera-se uma pequena perda de resistência e dureza do aço, menos de $20 \%$ do valor da resistência à temperatura ambiente. Além dos $870^{\circ} \mathrm{C}$, a microestrutura do aço submete-se a uma transformação permanente devido a uma alteração na composição química e reordenamento dos grãos, que com o subseqüente resfriamento, afetará suas propriedades mecânicas (por exemplo, a ductilidade). (GEWAIN; IWANKIW; ALFAWAKHIRI, 2003)

Hoje, por meio dos métodos analíticos é possível calcular o incremento de temperatura na peça estrutural em função do tempo, mesmo que simplificadamente, obtendo economia e segurança nos projetos. Os mesmos modelos são empregados para calcular as espessuras dos revestimentos contra fogo. As hipóteses adotadas para distribuição de temperatura de elementos revestidos por material antitérmico ou não-revestidos são:

- $\quad$ O elemento estrutural se encontra totalmente imerso no ambiente em chamas;

- A distribuição da temperatura no elemento estrutural é uniforme, já que "a difusividade térmica do aço é muito alta" (WICKSTRÖM, 1985);

ao fogo. Os requisitos construtivos incluem área e limitações de altura, portas e outras saídas, sprinklers e detectores de fogo. (WHITE; DIETENBERGER, 1999) 
- O fluxo de calor é unidimensional ${ }^{18}$ para o elemento estrutural. "A temperatura em uma estrutura de aço, exposta ao incêndio, pode ser estimada por análise unidimensional se a exposição e o isolamento são iguais em todas as superfícies e os efeitos de canto ${ }^{19}$ são negligenciados" (WICKSTRÖM, 1985).

\subsection{FATOR DE MASSIVIDADE (SECTION FACTOR)}

A taxa de aquecimento de uma seção de aço em situação de incêndio depende do fator de massividade. $\mathrm{O}$ fator de massividade é a relação entre a área exposta ao fogo $(A)$ e o volume aquecido de uma peça estrutural de aço $(V)$. "Quanto maior for à área superficial exposta ao calor em relação ao volume do perfil, mais rápida será a elevação da temperatura, pois o fluxo de calor penetrará por uma superfície relativamente grande para aquecer uma massa de aço relativamente pequena”.(KAEFER; SILVA, 2003)

Para barras prismáticas, o fator de massividade pode ser expresso, também, como a relação entre o perímetro exposto ao fogo e a área da seção transversal da peça, conforme a exp. 3.1 .

$$
F=\frac{u}{A}
$$

Onde:

$F$ é o fator de massividade para elementos estruturais de aço em $\mathrm{m}^{-1}$. Consultar Tabela 3-1 para elementos não revestidos e Tabela 3-2 para elementos revestidos por material térmico;

${ }^{18}$ O fluxo de calor unidimensional, neste caso, significa que todo o elemento metálico é submetido à mesma temperatura instantaneamente após o seu contorno ser submetido à ação térmica.

${ }^{19}$ O fluxo de calor absorvido é superior nos cantos do elemento, já que, a superfície contribuinte é a de duas faces. 
$u$ é o perímetro exposto ao fogo em metro. O perímetro $(u)$ varia de acordo com o tamanho do elemento e onde ele é localizado no edifício. Para elementos revestidos, corresponde ao perímetro efetivo $\left(u_{m}\right)$ do material térmico;

$A$ é a área líquida da seção transversal da peça estrutural $\mathrm{em}^{2}$.

O fator de massividade foi formulado para elementos isolados e imersos em chamas (expostos ao incêndio por quatro lados). Silva (2005b) com o auxílio de um programa de computador de análise térmica (Super-TempCalc ${ }^{20}$ ), confirmou que a exp. 3.1 é empregada somente para elementos esbeltos e sem contato com elementos mais robustos como lajes e alvenarias. Caso contrário, a face do elemento em contato com elementos pesados, por meio do mecanismo de condução (item 2.1), transmitiria calor, assim sendo, a temperatura seria dispare entre as faces imersas no incêndio. Assim, a hipótese de adoção do fluxo de calor unidimensional não seria aceita.

A NBR 14323:1999 e o EC3(2003) permitem situações em que o elemento de aço está em contato com outros elementos (porém expostos ao incêndio por três lados) como os exemplos apresentados nas Tabela 3-1 e Tabela 3-2, já que são próximos ao resultados reais e estão a favor da segurança.

Tabela 3-1 - Fator de massividade de elementos não revestidos. Fonte: NBR 14323:1999

\begin{tabular}{|l|l|}
$\begin{array}{l}\text { Seção aberta exposta ao incêndio por } \\
\text { todos os lados: }\end{array}$ & $\begin{array}{l}\text { Seção tubular de forma circular exposta } \\
\text { ao incêndio por todos os lados: }\end{array}$ \\
$F=\frac{\text { perímetro da seção da peça de aço }}{\text { área da seção da peça de aço }}$ & $F=\frac{\mathrm{d}}{\mathrm{t}(\mathrm{d}-\mathrm{t})}$ \\
\hline
\end{tabular}

${ }^{20}$ O Super-TempCalc é um programa de computador de elementos finitos bidimensional adaptado para incêndios desenvolvido pela FSD (Fire Safety Design, Sweden) por Yngve Anderberg. 
Seção aberta exposta ao incêndio por três lados:

$F=\frac{\text { perímetro da seção da peça de aço }}{\text { área da seção da peça de aço }}$

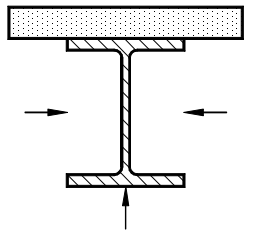

Seção tubular de forma retangular (ou seção caixão soldada de espessura uniforme) exposta ao incêndio por todos os lados:

$$
F=\frac{\mathrm{b}+\mathrm{d}}{\mathrm{t}(\mathrm{b}+\mathrm{d}-2 \mathrm{t})}
$$

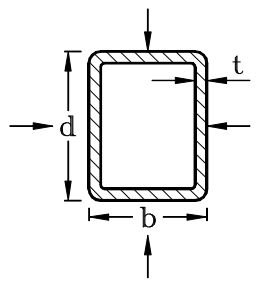

Seção caixão soldada exposta ao incêndio por todos os lados:

$$
F=\frac{2(\mathrm{~b}+\mathrm{d})}{\text { área da seção transversal }}
$$

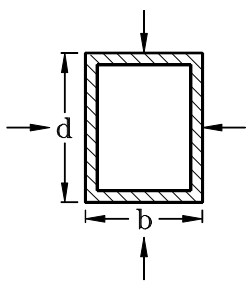

Cantoneira (ou qualquer seção aberta de espessura uniforme) exposta ao incêndio por todos os lados:

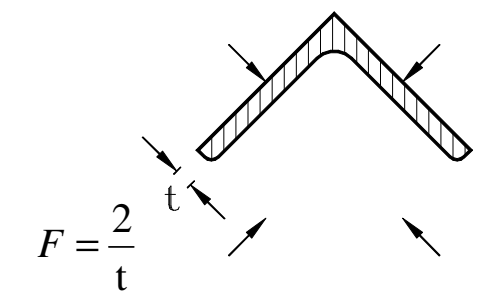

Seção I com reforço em caixão exposta ao incêndio por todos os lados:

$$
F=\frac{2(\mathrm{~b}+\mathrm{d})}{\text { área da seção transversal }}
$$

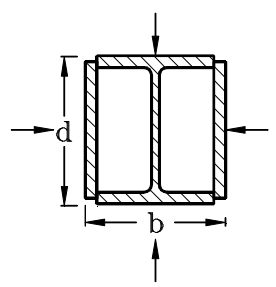

Chapa exposta ao incêndio por três lados:

$$
F=\frac{b+2 t}{b t}
$$




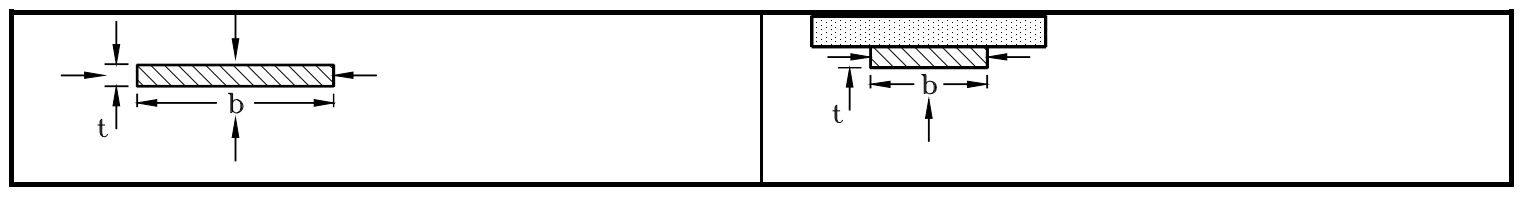

Tabela 3-2 - Fator de massividade de elementos revestidos. Fonte: NBR 14323:1999.

\begin{tabular}{l|l|}
$\begin{array}{l}\text { Proteção tipo contorno de espessura } \\
\text { uniforme exposta ao incêndio por todos } \\
\text { os lados: }\end{array}$ & $\begin{array}{l}\text { Proteção tipo caixa, de espessura uniforme } \\
\text { exposta ao incêndio por todos os lados: }\end{array}$ \\
$F=\frac{\text { perímetro da seção da peça de aço }}{\text { área da seção da peça de aço }}$ & $F=\frac{2(\mathrm{~b}+\mathrm{d})}{\text { área da seção da peça de aço }}$ \\
\hline Proteção tipo contorno, de espessura \\
uniforme exposta ao incêndio por três \\
lados:
\end{tabular}




\subsection{DISTRIBUIÇÃO DE TEMPERATURA EM ELEMENTOS SEM PROTEÇÃO}

Para garantir a segurança da estrutura pela exposição à ação térmica, recomenda-se utilizar mecanismos que retardem o aquecimento até as temperaturas críticas, entretanto, as normas técnicas permitem a exclusão da proteção térmica em determinados casos como contraventamentos e elementos voltados para o exterior da edificação.

A exp. 3.2 é iterativa e utilizada para exprimir o incremento de temperatura durante um intervalo de tempo $\Delta t$ de elementos de aço sem revestimento de proteção ao incêndio.

$$
\Delta \theta_{a, t}=\frac{F}{c_{a} \rho_{a}} \dot{h} \cdot \Delta t
$$

Onde:

$\Delta \theta_{a, t}$ é a elevação de temperatura no elemento estrutural de aço em ${ }^{\circ} \mathrm{C}$;

$F$ é o fator de massividade para elementos estruturais de aço sem proteção contra incêndio em $\mathrm{m}^{-1}$. O EC3 (2003) recomenda que para efeito de cálculo, o valor de massividade $F$, não seja inferior a $10 \mathrm{~m}^{-1}$. Consultar exp. 3.1;

$\rho_{a}$ é a massa específica do aço. A NBR 14323:1999 indica $\rho_{a}=7850 \mathrm{em} \mathrm{kg} / \mathrm{m}^{3}$;

$c_{a}$ é o calor específico do aço. Para modelos simplificados, cujo calor específico pode ser considerado independente da temperatura, a NBR 14323:1999 sugere $c_{a}$ $=600 \mathrm{~J} \mathrm{~kg} /{ }^{\circ} \mathrm{C}$. Para valores mais precisos, consultar o apêndice A.

$\dot{h}$ é o valor do fluxo de calor por unidade de área $\mathrm{em} \mathrm{W} / \mathrm{m}^{2}$;

$\Delta t$ é o intervalo de tempo, em segundo. A NBR 14323:1999 não recomenda tomar $\Delta t$ superior a 5 segundos, porém "tolera valores de $\Delta t$ até $\frac{25000}{F}$ " (SILVA, 2001). 
O valor de fluxo por unidade de área $(\dot{h})$, é a soma dos fluxos de calor convectivo e radiativo, dada pela exp. 3.3, entretanto, o fluxo radiativo e convectivo são calculados de acordo com a temperatura dos gases do passo anterior e da temperatura do aço do passo atual como visto nas expressões 3.4 e 3.5 .

$$
\dot{h}=\dot{h}_{c}+\dot{h}_{r}
$$

$$
\dot{h}_{c}=\alpha_{c}\left(\theta_{g}(t)-\theta_{a}(t-\Delta t)\right)
$$

Onde:

$\dot{h}_{c}$ é o componente do fluxo de calor devido à convecção, $\mathrm{W} / \mathrm{m}^{2}$;

$\alpha_{c}$ é o coeficiente de transferência de calor por convecção, igual a $25 \mathrm{~W} / \mathrm{m}^{2}{ }^{\circ} \mathrm{C}$;

$\theta_{g}$ é a temperatura dos gases em ${ }^{\circ} \mathrm{C}$;

$\theta_{a}$ é a temperatura na superfície do aço em ${ }^{\circ} \mathrm{C}$.

$$
\dot{h}_{r}=5,67.10^{-8} \varepsilon_{r}\left[\left(\theta_{g}(t)+273,15\right)^{4}-\left(\theta_{a}(t-\Delta t)+273,15\right)^{4}\right]
$$

Onde:

$\dot{h}_{r}$ é o componente do fluxo de calor devido à radiação em $\mathrm{W} / \mathrm{m}^{2}$;

$\varepsilon_{r}$ é a emissividade resultante. A NBR 14323:1999 permite a título de simplificação adotar $\varepsilon_{r}=0,5$.

$\theta_{g}$ é a temperatura dos gases em ${ }^{\circ} \mathrm{C}$;

$\theta_{a}$ é a temperatura na superfície do aço em ${ }^{\circ} \mathrm{C}$. 


\subsection{DISTRIBUIÇÃO DE TEMPERATURA EM ELEMENTOS COM REVESTIMENTO CONTRA FOGO}

$\mathrm{Na}$ avaliação de temperatura para um elemento estrutural linear com revestimento contra fogo, deve considerar o "equilíbrio térmico envolvendo: calor emitido por gases quentes, calor absorvido pelo material de revestimento e calor absorvido pelo elemento estrutural. O calor é transferido ao elemento estrutural através do material de proteção por condução". (SILVA, 2001)

A 14323:1999 e o EC3 (2003) recomendam a exp. 3.6 para o cálculo da temperatura em estruturas revestidas por material de proteção contra fogo. Observe que a exp. 3.6 é uma "estimativa aproximada de um mecanismo unidimensional de transmissão de calor" (KRUPPA, 2000), e assim com a exp. 3.2 é iterativa e incremental.

$$
\begin{aligned}
& \Delta \theta_{a}=\frac{F\left(\theta_{g}(t)-\theta_{a}(t)\right)}{\frac{t_{m}}{\lambda m} \cdot \rho_{a} \cdot c_{a}\left(1+\frac{\Phi}{3}\right)} \cdot \Delta t-\left(e^{\frac{\Phi}{10}}-1\right) \cdot\left[\theta_{g}(t+\Delta t)-\theta_{g}(t)\right] \\
& \mathrm{e} \\
& \Phi=\frac{\rho_{m} c_{m}}{\rho_{a} c_{a}} t_{m} F
\end{aligned}
$$

Onde:

$\Delta \theta_{a}$ é o incremento de temperatura ${ }^{21}$ no elemento estrutural de aço em ${ }^{\circ} \mathrm{C}$; $\theta_{g}$ é a temperatura dos gases no instante $t$ em ${ }^{\circ} \mathrm{C}$;

\footnotetext{
${ }^{21}$ Por não se tratar de uma equação exata, o incremento de temperatura dado na equação pode ser negativo $\left(\Delta \theta_{a}<0\right)$, nestes casos, adota-se $\Delta \theta_{a}=0$ para o trecho ascendente da curva.
} 
$\theta_{a}$ é a temperatura na superfície do aço no instante $t$ em ${ }^{\circ} \mathrm{C}$;

$\lambda_{m}$ é a condutividade térmica do material de revestimento contra fogo em função da temperatura, $\lambda_{m}=\lambda_{m}(\theta) \mathrm{em} \mathrm{W} / \mathrm{m}^{\circ} \mathrm{C}$;

$\rho_{a}$ é a massa específica do aço. A NBR 14323:1999 indica $\rho_{a}=7850 \mathrm{em} \mathrm{kg} / \mathrm{m}^{3}$;

$\rho_{m}$ é a massa específica do material de revestimento contra fogo em $\mathrm{kg} / \mathrm{m}^{3}$;

$c_{a}$ é o calor específico do aço de acordo com a temperatura. $c_{a}=c_{a}(\theta) \mathrm{em} \mathrm{J} \mathrm{kg} /{ }^{\circ} \mathrm{C}$;

$c_{m}$ é o calor específico do material de revestimento contra fogo de acordo com a temperatura $c_{m}=c_{m}(\theta) \mathrm{em} \mathrm{J} \mathrm{kg} /{ }^{\circ} \mathrm{C}$;

$t_{m}$ é a espessura do material de revestimento contra fogo em metros;

$\Delta t$ é o intervalo considerado. O EC3 (2003) recomenda utilizar valores de $\Delta t$ inferiores a 30 segundos.

$F$ é o fator de massividade para elementos estruturais de aço com revestimento contra fogo, calculado de acordo com a exp. 3.1.

As principais normas incluem expressões formuladas a partir de métodos analíticos. Petterson (et al, 1976) deduziu a exp. 3.8 de incremento de temperatura em estruturas revestidas por material de revestimento contra fogo em determinado intervalo $\Delta t$.

$$
\Delta \theta_{a}=\frac{F\left(\theta_{g}(t)-\theta_{a}(t)\right)}{\frac{1}{\alpha}+\frac{t_{m}}{\lambda m} \cdot \rho_{a} \cdot c_{a}\left(1+\frac{\Phi}{2}\right)} \cdot \Delta t-\left(\frac{1}{1+\frac{2}{\Phi}}\right) \cdot\left[\theta_{g}(t+\Delta t)-\theta_{g}(t)\right]
$$

Onde: 
$\alpha$ é o somatório do coeficiente de transferência de calor radiativo e convectivo ${ }^{22}$ $\mathrm{em} \mathrm{W} / \mathrm{m}^{2}{ }^{\circ} \mathrm{C}$.

Assim como Petterson, Silva (1999) deduziu a exp. 3.9 de incremento de temperatura em estruturas revestidas por material contra fogo em determinado intervalo $\Delta t$, e uma expressão desconsiderando a absorção de calor pelo material de revestimento, como visto na exp. 3.10.

$$
\begin{aligned}
& \Delta \theta_{a}=\frac{F\left(\theta_{g}(t)-\theta_{a}(t)\right)}{\frac{t_{m}}{\lambda m} \cdot \rho_{a} \cdot c_{a}\left(1+\frac{\Phi}{4}\right)} \cdot \Delta t-\left(\frac{1}{1+\frac{4}{\Phi}}\right) \cdot\left[\theta_{g}(t+\Delta t)-\theta_{g}(t)\right] \\
& \Delta \theta_{a}=\frac{F\left(\theta_{g}(t)-\theta_{a}(t)\right)}{\frac{t_{m}}{\lambda m} \cdot \rho_{a} \cdot c_{a}} \cdot \Delta t
\end{aligned}
$$

\subsection{MATERIAIS DE REVESTIMENTO CONTRA FOGO}

Neste item serão abordados métodos de proteção por meio de revestimento contra fogo, que visam atenuar o aumento de temperatura nos elementos estruturais em situação de incêndio. De acordo com Vargas e Silva (2003) os materiais de revestimento contra fogo devem apresentar:

- baixa massa específica aparente;

\footnotetext{
22 Dada a pequena contribuição do coeficiente $\alpha$, este será desprezado no código do programa STRESFIRE (ver item 5)
} 
- baixa condutividade térmica;

- alto calor específico;

- adequada resistência mecânica (quando expostos a impactos);

- garantia de integridade durante a evolução do incêndio;

- custo compatível.

Os materiais de revestimento contra fogo podem ser classificados como não-reativos (placas e argamassas) ou reativos (tintas intumescentes). Os materiais de revestimento contra fogo mais empregados na construção civil listados por Lamont (et al, 2001), Pannoni (2002) e Kaefer e Silva (2003) são apresentados nos itens 3.4.1 a 3.4.3.

\subsubsection{MATERIAIS PROJETADOS}

A argamassa de vermiculita é composta de argamassa à base de vermiculita expandida, cimento hidráulico e aglomerantes minerais. Possui acabamento rústico além de ser sistema caro, porém possui as vantagens de ter grande resistência mecânica, suportar intemperismos e atmosferas quimicamente agressivas. A sua aplicação é feita por spray ou com uso de espátula e para melhor aderência empregam-se telas;

Os revestimentos projetados são produtos de fácil e rápida aplicação e os mais econômicos, apesar do desperdício de material na aplicação. Dependendo da composição apresentam densidades variadas e conseqüentemente resistências mecânicas diferentes, desta forma para cada tipo de aplicação há um produto mais indicado. Estão divididos em dois grupos: argamassas e fibras.

As argamassas projetadas (Cimenticious), possuem alto índice de material aglomerante (mínimo de $80 \%$ de gesso ou cimento), o que lhes conferem boas características mecânicas, tais como resistência à erosão sob corrente de ar; alta aderência ao substrato; alta resistência à compressão e à abrasão. Quando a temperatura dos gases atinge o intervalo de $90^{\circ} \mathrm{C}$ a $150^{\circ} \mathrm{C}$, as ligações químicas existentes no gesso hidratado começam 
a se romper, liberando água de hidratação. Este mecanismo inibe o aumento de temperatura por 20 a 30 minutos.

As fibras projetadas apresentam características mecânicas muito inferiores as dos Cimenticious. São compostas geralmente por lã de rocha, com baixo teor de aglomerante (20 a 30\% de escória de alto-forno). A aplicação é feita por jateamento e são muito utilizados atualmente;

\subsubsection{MATERIAIS RÍGIDOS}

Placas de gesso são boas alternativas para o revestimento de estruturas de edificações em uso, uma vez que esses sistemas são de aplicação mais limpa do que os materiais projetados. Esses sistemas são fixados em pinos previamente soldados à estrutura e possuem acabamento rústico, devendo ficar ocultos sobre forros ou envolvidos por materiais específicos de acabamento. A placa de gesso perde moléculas de água de hidratação durante o aquecimento, mantendo baixa a temperatura do aço. Estes materiais têm, internamente, uma malha de fibra de vidro, que mantém o conjunto estruturado quando exposto às elevadas temperaturas do incêndio.

A proteção com concreto ou alvenaria consiste no revestimento ou encapsulamento da estrutura metálica por esses materiais. Até o fim da década de 70, o concreto era a forma mais comum de proteção ao fogo para estruturas em aço (DOWLING; ROBINSON, 1998 apud LAMONT et al, 2002), porém, apresenta desvantagens como o aumento do peso da estrutura, custo e tempo para execução.

As chapas ou painéis compostos de materiais fibrossilicatos autoclavados são placas rígidas de grande resistência a impactos e a abrasão. Os painéis são instalados de forma limpa, mesmo em edificações já em funcionamento, por meio de travamentos por parafusos ou grampos, sem a necessidade de soldagem da estrutura. Esse material possui acabamento similar a placas de gesso acartonado, podendo receber massas e pinturas posteriormente; 


\subsubsection{TINTAS INTUMESCENTES}

Tintas intumescentes são revestimentos com pequena espessura, estáveis a baixas temperaturas, contudo sofrem grande expansão volumétrica ao redor de $200^{\circ} \mathrm{C}$, assumindo a aparência de uma espuma. São produtos de melhor acabamento estético, todavia são materiais caros e deve ser utilizado com cautela para não inviabilizarem economicamente o empreendimento. Atingem normalmente de 30 a 60 minutos de proteção contra o incêndio, sendo muito caras acima destes valores. Como as tintas não apresentam grande resistência química e física, devem ser recobertas por uma película acrílica ou poliuretânica. As tintas apresentam a vantagem dos revestimentos serem executados off-site. 


\section{MÉTODO SIMPLIFICADO DE DIMENSIONAMENTO}

O método simplificado de dimensionamento descrito neste capítulo se aplica às barras prismáticas de aço constituídas por perfis laminados e soldados não-híbridos ${ }^{23}$ sob tração, compressão ou flexão normal simples constantes na NBR 14323 (em revisão). São hipóteses do modelo simplificado:

- distribuição uniforme de temperatura na seção transversal e ao longo do comprimento dos elementos estruturais de aço;

- elementos isolados da estrutura;

- dimensionamento por meio de cálculos deve ser feito usando-se o método dos estados limites.

"Os incêndios, ao invés de serem tratados como causa de ações excepcionais ${ }^{24}$, também podem ser levados em conta por meio de uma redução da resistência dos materiais constitutivos da estrutura" (NBR 8681:2003), ou seja, as propriedades mecânicas do aço, debilitam-se progressivamente com o aumento de temperatura. As normas NBR 14323:1999 e o EC3(2003) apresentam tabelas de fatores de minoração para limites de escoamento $\left(k_{y, \theta}\right)$ e módulo de elasticidade $\left(k_{E, \theta}\right)$ de acordo com a temperatura para dimensionamento aplicando-se o modelo simplificado.

${ }^{23}$ Perfil não-híbrido é o perfil cujos elementos componentes são formados pelo mesmo aço.

24 "Os carregamentos excepcionais somente devem ser considerados no projeto de estrutura de determinados tipos de construção, para os quais a ocorrência de ações excepcionais não possa ser desprezada e que, além disso, na concepção estrutural, não possam ser tomadas medidas que anulem ou atenuem a gravidade das conseqüências dos efeitos dessas ações. O carregamento excepcional é transitório, com duração extremamente curta. Com um carregamento do tipo excepcional, considera-se apenas a verificação da segurança em relação a estados limites últimos, por meio de uma única combinação última excepcional de ações”. (NBR 8681:2003) 
Tabela 4-1-Fatores de redução da resistência ao escoamento para aços submetidos a ação térmica. FONTE: NBR 14323:1999

\begin{tabular}{|l|l|l|l|}
\hline \multirow{2}{*}{$\begin{array}{l}\text { Temperatura } \\
\left.\text { do aço } \theta_{a}{ }^{\circ} \mathrm{C}\right)\end{array}$} & \multicolumn{2}{|c|}{$\begin{array}{l}\text { Fator de redução para o limite de } \\
\text { escoamento dos aços }\end{array}$} & $\begin{array}{l}\text { Fator de redução para } \\
\text { o módulo de } \\
\text { elasticidade de todos } \\
\text { os tipos de aço }\left(k_{E, \theta}\right)\end{array}$ \\
\cline { 2 - 4 } & $\begin{array}{l}\text { laminados a } \\
\text { quente }\left(k_{y, \theta}\right)\end{array}$ & $\begin{array}{c}\text { trefilados } \\
\left(k_{y o}, \theta\right)\end{array}$ & 1,000 \\
\hline 20 & 1,000 & 1,000 & 1,000 \\
\hline 100 & 1,000 & 1,000 & 0,900 \\
\hline 200 & 1,000 & 1,000 & 0,800 \\
\hline 300 & 1,000 & 1,000 & 0,700 \\
\hline 400 & 1,000 & 0,940 & 0,600 \\
\hline 500 & 0,780 & 0,670 & 0,310 \\
\hline 600 & 0,470 & 0,400 & 0,130 \\
\hline 700 & 0,230 & 0,120 & 0,090 \\
\hline 800 & 0,110 & 0,110 & 0,0675 \\
\hline 900 & 0,060 & 0,080 & 0,0450 \\
\hline 1000 & 0,040 & 0,050 & 0,0225 \\
\hline 1100 & 0,020 & 0,030 & 0,0000 \\
\hline 1200 & 0,000 & 0,000 & per feita interpolação \\
\hline Nota: Para valores intermediários da temperatura do aço, pode & & & \\
\hline linear. & & & 0 \\
\hline
\end{tabular}

Quando a segurança é verificada isoladamente em relação a cada um dos esforços atuantes, as condições de segurança tomam a forma simplificada, expressa pela equação 4.1 .

$S_{\mathrm{fi}, \mathrm{d}} \geq R_{\mathrm{fi}, \mathrm{d}}$

Onde: 
$S_{f i d}$ é a solicitação de cálculo em situação de incêndio. As combinações de ações para os estados limites últimos em situação de incêndio devem ser consideradas como combinações últimas excepcionais e obtidas de acordo com a NBR 8681:2003;

$R_{\mathrm{fi}, \mathrm{d}}$ é a resistência de cálculo correspondente do elemento estrutural para o estado limite último em consideração, em situação de incêndio.

\subsection{BARRAS TRACIONADAS}

A resistência de cálculo de uma barra axialmente tracionada com distribuição uniforme de temperatura na seção transversal e ao longo do comprimento, para o estado limite último de escoamento da seção bruta, é dado pela expressão 4.2 .

$$
N_{f i, R d}=k_{y, \theta} A_{g} f_{y}
$$

Onde:

$N_{f i, R d}$ é resistência de cálculo de uma barra axialmente tracionada em situação de incêndio em kN;

$k_{y, \theta}$ é o fator de redução do limite de escoamento do aço à temperatura $\theta_{a}$, conforme Tabela 4-1.

$A_{g}$ é a área bruta da seção transversal da barra em $\mathrm{m}^{2}$;

$f_{y}$ é o valor característico de resistência de escoamento do aço em $\mathrm{kN} / \mathrm{m}^{2}$;

\subsection{BARRAS COMPRIMIDAS}

A resistência de cálculo de uma barra axialmente comprimida com distribuição uniforme de temperatura na seção transversal e ao longo do comprimento, para o estado limite último de instabilidade é dado pela expressão 4.3 . 


$$
N_{f i, R d}=\chi_{f i} k_{y, \theta} A_{g} f_{y}
$$

Onde:

$N_{f i, R d}$ é resistência de cálculo de uma barra axialmente comprimida em situação de incêndio em $\mathrm{kN}$;

$\chi_{f i}$ é o fator de redução da resistência à compressão em situação de incêndio, obtido de acordo com a NBR 8800 (em revisão), utilizando a curva "c" de resistência, independentemente do tipo de seção transversal, do modo de instabilidade e do eixo em relação ao qual esta instabilidade ocorre;

$k_{\mathrm{y}, \theta}$ é o fator de redução do limite de escoamento do aço à temperatura $\theta_{a}$, conforme tabela 4.1;

$A_{g}$ é a área bruta da seção transversal da barra $\mathrm{em} \mathrm{m}^{2}$;

$f_{y}$ é o valor característico de resistência de escoamento do aço em $\mathrm{kN} / \mathrm{m}^{2}$;

$\chi_{f i}=\frac{1}{\beta_{\theta}+\sqrt{\beta_{\theta}^{2}-\lambda_{o, \theta}^{2}}} \leq 1$

$\beta_{\theta}=\frac{1}{2}\left(1+\alpha_{\theta} \cdot \lambda_{o, \theta}+\lambda_{o, \theta}^{2}\right)$

$\alpha_{\theta}=0,022 \sqrt{\frac{E}{f_{y}}}$ 


$$
\lambda_{0, \theta}=\frac{l_{f l} / r}{\sqrt{\frac{\pi^{2} \cdot k_{E, \theta} \cdot E}{k_{y, \theta} \cdot f_{y}}}}
$$

Onde:

$\alpha$ é um coeficiente relacionado à curva de dimensionamento a compressão;

$\chi_{f i}$ é o fator de redução da resistência à compressão em situação de incêndio;

$\lambda_{o, \theta}$ é o parâmetro de esbeltez para barras comprimidas à temperatura $\theta_{a}$;

$l_{f l}$ é o comprimento de flambagem determinado à temperatura ambiente em metros (eixo x ou eixo y);

$r$ é o raio de giração (eixo x ou eixo y) em metros;

$E$ é o módulo de elasticidade do aço em $\mathrm{kN} / \mathrm{m}^{2}$;

$f_{y}$ é o valor característico de resistência de escoamento do aço em $\mathrm{kN} / \mathrm{m}^{2}$;

$k_{y, \theta}$ é o fator de redução do limite de escoamento do aço à temperatura $\theta_{a}$ conforme tabela 4.1 ;

$k_{E, \theta}$ é o fator de redução do módulo de elasticidade do aço à temperatura $\theta_{a}$ conforme tabela 4.1 .

\subsection{BARRAS FLETIDAS}

Este item se aplica às barras fletidas, cujos elementos componentes da seção transversal não possam sofrer flambagem local em regime elástico em decorrência da atuação do momento fletor.

$\mathrm{O}$ valor do parâmetro de esbeltez $\lambda, \lambda_{p}$ (correspondente à plastificação), $\lambda_{r}$ (correspondente ao início do escoamento) para os estados limites últimos de flambagem 
local da mesa comprimida (FLM), flambagem local da alma (FLA) e flambagem lateral com torção (FLT), deve ser determinado como no Anexo D da NBR 8800 (em revisão).

Tabela 4-2 - Expressões para cálculo dos parâmetros $\lambda, \lambda_{p}, \lambda_{r}$ de acordo o caso de flambagem. Expressões válidas para perfis com seção transversal em forma de "I" ou "H" com dois eixos de simetria fletidos em torno do eixo de maior inércia Fonte: NBR 8800 (em revisão)

\begin{tabular}{|c|c|c|c|c|c|}
\hline $\begin{array}{l}\text { Estados } \\
\text { limites } \\
\text { aplicáveis }\end{array}$ & $\begin{array}{l}\text { Momento } \\
\text { fletor } \\
\text { limite de } \\
\text { flambagem } \\
\text { elástica } \\
\left(M_{r}\right)\end{array}$ & $\begin{array}{l}\text { Momento } \\
\text { fletor de } \\
\text { flambagem } \\
\text { elástica } \\
\left(M_{c r}\right)\end{array}$ & $\begin{array}{l}\text { Parâmetro } \\
\text { de esbeltez } \\
(\lambda)\end{array}$ & $\lambda_{p}$ & $\lambda_{r}$ \\
\hline FLT & $\left(f_{y}-\sigma_{r}\right) W$ & exp.4.20 & $\frac{\ell_{b}}{r_{y}}$ & $1,76 \sqrt{\frac{E}{f_{y}}}$ & $\begin{array}{l}\text { Valor de } \lambda \text { para o } \\
\text { qual } M_{c r}=M_{r}\end{array}$ \\
\hline FLM & $\left(f_{y}-\sigma_{r}\right) W$ & $\begin{array}{l}\text { Laminados: } \\
\frac{0,69 E}{\lambda^{2}} W \\
\text { Soldados: } \\
\frac{0,90 E \cdot k_{c}}{\lambda^{2}} W\end{array}$ & $\frac{b_{f}}{2 t}$ & $0,38 \sqrt{\frac{E}{f_{y}}}$ & $\begin{array}{l}\text { Laminados: } \\
0,83 \sqrt{\frac{E}{f_{y}-\sigma_{r}}} \\
\text { Soldados: } \\
0,95 \sqrt{\frac{E \cdot k_{c}}{f_{y}-\sigma_{r}}}\end{array}$ \\
\hline FLA & $f_{y} W$ & - & $\frac{h}{t_{w}}$ & $3,76 \frac{h_{p}}{h} \sqrt{\frac{E}{f_{y}}}$ & $1,49\left(1+2,83 \frac{h}{h_{c}}\right) \sqrt{\frac{E}{f_{y}}}$ \\
\hline
\end{tabular}

Para converter os parâmetro de esbeltez $\lambda_{p}$ e $\lambda_{r}$ (temperatura ambiente) em parâmetros equivalentes para temperaturas elevadas $\lambda_{p, f i}$ e $\lambda_{r, f i}$, substituir na Tabela 4-2 "E" por “E. $k_{E \theta}$ " , " $f_{y}$ " por " $f_{y} \cdot k_{y, \theta}$ " e " $\left(f_{y}-\sigma_{r}\right)$ " por " $\left(f_{y}-\sigma_{r}\right) \cdot k_{y}, \theta$ " 
Onde:

$h$ é a altura da alma, tomada igual à distância entre faces internas das mesas nos perfis soldados e igual a esse valor menos os dois raios de concordância entre mesa e alma nos perfis laminados;

$h_{c}$ é duas vezes a distância do centro geométrico da seção transversal à face interna da mesa comprimida nos perfis soldados e igual a esse valor menos o raio de concordância entre mesa e alma nos perfis laminados;

$h_{\mathrm{p}}$ é duas vezes a distância da linha neutra plástica da seção transversal para a atuação apenas de momento fletor à face interna da mesa comprimida nos perfis soldados e igual a este valor menos o raio de concordância entre mesa e alma nos perfis laminado;

$\lambda_{p f i}$ é o parâmetro de esbeltez, à temperatura $\theta_{a}$, correspondente à plastificação;

$\lambda_{r, f i}$ é o parâmetro de esbeltez, à temperatura $\theta_{a}$, correspondente ao início do escoamento;

$k_{y, \theta}$ é o fator de redução da resistência ao escoamento do aço à temperatura $\theta_{a}$ conforme tabela 4.1 ;

$k_{E, \theta}$ é o fator de redução do módulo de elasticidade do aço à temperatura $\theta_{a}$ conforme tabela 4.1 ;

$M_{r}$ é o momento fletor correspondente ao início do escoamento da seção transversal para projeto em temperatura ambiente;

$M_{c r}$ é o momento fletor de flambagem elástica em temperatura ambiente;

$$
k_{c}=\frac{4}{\sqrt{h / t_{w}}} \quad 0,350 \leq k_{c} \leq 0,763
$$


Onde:

$h$ é a altura interna do perfil de aço em metros;

$t_{w}$ é a espessura da alma do perfil de aço em metros;

$M_{f i, R d}$ é o menor dos três valores obtidos, considerando-se os estados limites de flambagem lateral (FLT), flambagem local de mesa (FLM) e flambagem local de alma (FLA). A expressão que rege cada um dos estados limites é definida de acordo com o parâmetro de esbeltez $(\lambda)$ em relação à $\lambda_{p, f i}$ e $\lambda_{r, f i}$.

Para o estado limite último de flambagem local da mesa comprimida (FLM) utilizar as expressões de 4.9 a 4.11 .

$M_{f i, R d}=\kappa_{1} \kappa_{2} k_{y, \theta} M_{p l}$ para $\lambda \leq \lambda_{p, f i}$

$M_{f i, R d}=\kappa_{1} \kappa_{2} k_{y, \theta}\left[M_{p l}-\left(M_{p l}-M_{r}\right) \frac{\lambda-\lambda_{p, f i}}{\lambda_{r, f i}-\lambda_{p, f i}}\right]$ para $\lambda_{p, f i}<\lambda \leq \lambda_{r, f i}$

$M_{f i, R d}=k_{E, \theta} \cdot M_{c r}$ para $\lambda>\lambda_{r, f i}$

Para o estado limite último de flambagem lateral (FLT), utilizar as expressões de 4.12 a 4.14 .

$M_{f i, R d}=\kappa_{1} \kappa_{2} k_{y, \theta} M_{p \ell}$ para $\lambda \leq \lambda_{p, f i}$ 


$$
\begin{aligned}
& M_{f i, R d}=\frac{k_{y, \theta}}{1,2} C_{b}\left[M_{p \ell}-\left(M_{p \ell}-M_{r}\right) \frac{\lambda-\lambda_{p, f i}}{\lambda_{r, f i}-\lambda_{p, f i}}\right] \text { para } \lambda_{p, f i}<\lambda \leq \lambda_{r, f i} \\
& M_{f i, R d}=\frac{k_{E, \theta} M_{c r}}{1,2} \text { para } \lambda>\lambda_{r, f i}
\end{aligned}
$$

Para o estado limite último de flambagem local da alma (FLA), utilizar as expressões de 4.15 e 4.16 .

$$
\begin{aligned}
& M_{f i, R d}=\kappa_{1} \kappa_{2} k_{y, \theta} M_{p l} \text { para } \lambda \leq \lambda_{p, f i} \\
& M_{f i, R d}=\kappa_{1} \kappa_{2} k_{y, \theta}\left[M_{p l}-\left(M_{p l}-M_{r}\right) \frac{\lambda-\lambda_{p, f i}}{\lambda_{r, f i}-\lambda_{p, f i}}\right] \operatorname{para} \lambda_{p, f i}<\lambda \leq \lambda_{r, f i}
\end{aligned}
$$

Onde:

$M_{f i R d}$ é o momento resistente de cálculo de uma barra em situação de incêndio em kN.m;

$\lambda$ é o parâmetro de esbeltez;

$\lambda_{p, f i}$ é o parâmetro de esbeltez, à temperatura $\theta_{a}$, correspondente à plastificação;

$\lambda_{r, f i}$ é o parâmetro de esbeltez, à temperatura $\theta_{a}$, correspondente ao início do escoamento;

$k_{y, \theta}$ é o fator de redução da resistência ao escoamento do aço à temperatura $\theta_{a}$ conforme tabela 4.1 ;

$k_{E, \theta}$ é o fator de redução do módulo de elasticidade do aço à temperatura $\theta_{a}$ conforme tabela 4.1; 
$M_{c r}$ é o momento fletor de flambagem elástica em temperatura ambiente, conforme expressão 4.19;

$M_{p l}$ é o momento de plastificação da seção transversal para projeto em temperatura ambiente, conforme expressão 4.17;

$M_{r}$ é o momento fletor correspondente ao início do escoamento da seção transversal para projeto em temperatura ambiente, conforme expressão 4.18;

$\kappa_{l}$ é um fator de correção para temperatura não-uniforme na seção transversal:

- para uma viga com todos os quatro lados expostos: $\kappa_{1}=1,00$;

- para uma viga envolvida por material de proteção contra incêndio, com três lados expostos, com uma laje de concreto ou laje com fôrma de aço incorporada no quarto lado: $\kappa_{1}=1,40$;

- para uma viga sem proteção contra incêndio, com três lados expostos, com uma laje de concreto ou laje com fôrma de aço incorporada no quarto lado: $\kappa_{1}=1,15$;

$\kappa_{2}$ é um fator de correção para temperatura não-uniforme ao longo do comprimento da barra:

- nos apoios de uma viga estaticamente indeterminada: $\kappa_{2}=1,15$;

- em todos os outros casos: $\kappa_{2}=1,00$;

1,2 é um fator de correção empírica da resistência da barra em temperatura elevada.

$M_{p l}=Z \cdot f_{y}$

Onde:

$M_{p l}$ é o momento de plastificação da seção transversal para projeto em temperatura ambiente; 
$Z$ é o módulo resistente plástico em $\mathrm{m}^{3}$;

$f_{y}$ é o valor característico de resistência de escoamento do aço em $\mathrm{kN} / \mathrm{m}^{2}$;

$$
M_{r}=W\left(f_{y}-\sigma_{r}\right)
$$

Onde:

$M_{r}$ é o valor característico do momento fletor resistente correspondente ao início de escoamento em kN.m;

$W$ é o módulo resistente elástico em $\mathrm{m}^{3}$;

$\sigma_{r}$ é a tensão residual do aço em $\mathrm{kN} / \mathrm{m}^{2}$;

$f_{y}$ é o valor característico de resistência de escoamento do aço em $\mathrm{kN} / \mathrm{m}^{2}$.

$$
M_{c r}=C_{b} \frac{\pi^{2} E I_{y}}{\left(\ell_{b}\right)^{2}} \sqrt{\frac{C_{w}}{I_{y}}\left(1+\frac{G I_{t}}{E C_{w}} \frac{\left(\ell_{b}\right)^{2}}{\pi^{2}}\right)}
$$

Onde:

$M_{c r}$ é o momento fletor de flambagem elástica em temperatura ambiente em kN.m;

$C_{b}$ é o fator de equivalência de momentos na flexão;

$E$ é o módulo de elasticidade do aço em $\mathrm{kN} / \mathrm{m}^{2}$;

$\ell_{b}$ é a distância entre travamentos em metros;

$I_{y}$ é o momento de inércia à flexão em relação ao eixo de menor inércia $\mathrm{em} \mathrm{m}^{4}$;

$C_{w}$ é a constante de empenamento da seção em $\mathrm{m}^{6}$;

$I_{t}$ é o momento de inércia à torção $\mathrm{em}^{4}$;

$G$ é o módulo de deformação transversal do aço em kN/m². 


\subsection{VERIFICAÇÃO DE FORÇA CORTANTE EM INCÊNDIO}

O valor do parâmetro de esbeltez $\lambda, \lambda_{p}$ (correspondente a plastificação), $\lambda_{r}$ (correspondente ao início do escoamento) para os estados limites últimos de força cortante devem ser determinados como no Anexo D da NBR 8800 (em revisão).

Tabela 4-3. Expressões para cálculo do parâmetros $\lambda, \lambda_{\mathrm{p}}, \lambda_{\mathrm{r}}$ para força cortante. Fonte: NBR 8800 (em revisão)

\begin{tabular}{|l|l|l|}
\hline Parâmetro de esbeltez $(\lambda)$ & $\lambda_{p}$ & $\lambda_{r}$ \\
\hline$\frac{h}{t_{w}}$ & $1,10 \sqrt{\frac{E \cdot k_{y}}{f_{y}}}$ & $1,37 \sqrt{\frac{E \cdot k_{y}}{f_{y}}}$ \\
\hline
\end{tabular}

Para converter os parâmetro de esbeltez $\lambda_{p}$ e $\lambda_{r}$ (temperatura ambiente) em parâmetros equivalentes para temperaturas elevadas $\lambda_{p, f i}$ e $\lambda_{r, f i}$, substituir na Tabela 4-3 " $E$ " por "E. $k_{E} \ddot{\theta}$ ", "fy" por " $f_{y} \cdot k_{y}, \theta$ ".

O valor de dimensionamento da força cortante resistente em situação de incêndio é dado pelas expressões 4.20 a 4.22 .

$$
\begin{aligned}
& V_{f i, R d}=k_{y, \theta} \cdot V_{p l} \quad \text { para } \lambda \leq \lambda_{p, f i} \\
& V_{f i, R d}=k_{y, \theta} \frac{\lambda_{p, f i}}{\lambda} \cdot V_{p l} \quad \text { para } \lambda_{p, f i}<\lambda \leq \lambda_{r, f i} \\
& V_{f i, R d}=1,28 \cdot k_{y, \theta}\left(\frac{\lambda_{p, f i}}{\lambda}\right)^{2} \cdot V_{p l} \quad \text { para } \lambda>\lambda_{r, f i}
\end{aligned}
$$


Onde:

$V_{f i, R d}$ é o valor de cálculo da força cortante resistente em situação de incêndio em $\mathrm{kN}$;

$k_{y, \theta}$ é o fator de redução do limite de escoamento do aço à temperatura $\theta_{a}$ conforme tabela 4.1 ;

$\lambda$ é o parâmetro de esbeltez da alma;

$\lambda_{p, f i}$ é o parâmetro de esbeltez, à temperatura $\theta_{a}$, correspondente à plastificação;

$V_{p l}=0,6 f_{y} A_{w}$

Onde:

$V_{p l}$ é a força cortante correspondente à plastificação da alma por cisalhamento em $\mathrm{kN}$;

$f_{y}$ é o valor característico de resistência de escoamento do aço em $\mathrm{kN} / \mathrm{m}^{2}$;

$A_{w}$ é a área da seção transversal da alma em $\mathrm{m}^{2}$.

\subsection{COMBINAÇÃO DE SOLICITAÇÕES}

Este item é aplicável a barras de aço em situação de incêndio cuja seção transversal possui um ou dois eixos de simetria. A seção transversal deve ter seus elementos componentes atendendo aos requisitos dos itens referentes aos esforços isolados de força normal de compressão e momento fletor, quando cada uma destas solicitações ocorrerem. Para os efeitos combinados de força normal de tração ou compressão e momentos fletores, devem ser atendidas as expressões 4.24 ou 4.25.

Caso $\frac{N_{f i, S d}}{N_{f i, R d}} \geq 0,2$ atender a exp. 4.24, caso contrário, $\frac{N_{f i, S d}}{N_{f i, R d}}<0,2$ atender a exp. 4.25. 


$$
\frac{N_{f i, S d}}{N_{f i, R d}}+\frac{8}{9}\left(\frac{M_{x, f i, S d}}{M_{x, f i, R d}}+\frac{M_{y, f i, S d}}{M_{y, f i, R d}}\right) \leq 1,0
$$

$$
\frac{N_{f i, S d}}{2 N_{f i, R d}}+\frac{M_{x, f i, S d}}{M_{x, f i, R d}}+\frac{M_{y, f i, S d}}{M_{y, f i, R d}} \leq 1,0
$$

Onde:

$N_{f i, S d}$ é a força normal solicitante de cálculo em situação de incêndio, de tração ou compressão, considerada constante ao longo da barra;

$N_{f i, R d}$ é valor de cálculo da força normal resistente, conforme item 4.1 para barras tracionadas ou conforme item 4.2 para barras comprimidas,

$M_{x, f i, S d}$ é valor de cálculo do momento fletor solicitante, em situação de incêndio, na seção considerada, em torno do eixo x;

$M_{y, f i, S d}$ é valor de cálculo do momento fletor solicitante, em situação de incêndio, na seção considerada, em torno do eixo y;

$M_{x, f i R d}$ é valor de cálculo do momento fletor resistente, em torno do eixo $x$, determinado conforme o item 4.3;

$M_{y, f i R d}$ é valor de cálculo do momento fletor resistente, em torno do eixo y, determinado conforme o item 4.3.

Se a força normal solicitante de cálculo em situação de incêndio for de compressão, os momentos fletores solicitantes de cálculo, $M_{x, f i, S d}$ e $M_{y, f i, S d}$, a serem usados nas expressões de interação, devem levar em conta os efeitos locais de segunda ordem (não 
linearidade geométrica), multiplicando-se diretamente o momento obtido da análise estrutural elástica citada em 4.26 por:

$$
B_{1}=\frac{C_{m}}{1-\frac{N_{f i, S d}}{N_{f i, e}}}
$$

Onde:

$C m$ é o coeficiente de equivalência de momentos conforme NBR 8800 (em revisão);

$N_{f i, e}$ é a força que provoca a flambagem elástica da barra em situação de incêndio.

$$
N_{f i, e}=\frac{A_{g} k_{y, \theta} f_{y}}{\lambda_{o, \theta}^{2}}
$$

Onde:

$A_{g}$ é a área bruta da seção transversal em $\mathrm{m}^{2}$;

$\lambda_{o, f i}$ é o parâmetro de esbeltez para barras comprimidas à temperatura $\theta_{a}$;

$f_{y}$ é o valor característico de resistência de escoamento do aço em $\mathrm{kN} / \mathrm{m}^{2}$;

$k_{y, \theta}$ é o fator de redução da resistência ao escoamento do aço à temperatura $\theta_{a}$ conforme tabela 4.1 ;

Dependendo da deslocabilidade dos nós da estrutura em análise, os efeitos da nãolinearidade geométrica global devem ser levados em conta, conforme recomendações da NBR 8800 (em revisão). 


\section{ELABORAÇÃO DO PROGRAMA STRESFIRE}

“Ainda não há um programa de computador que reúna toda tecnologia disponível para se enfrentar o problema de segurança estrutural de forma global. É necessário empregar um conjunto de programas de computador". (SILVA, 2005b) Os modelos numéricos de computador desenvolvidos em centros de pesquisas e universidades normalmente englobam apenas um dos aspectos do incêndio como:

- Determinação do tempo de desocupação;

- Determinação da potência térmica ou do campo de temperaturas atuante sobre as estruturas;

- Determinação do campo de temperaturas nos elementos de aço;

- Análise estrutural.

Para alcançar o objetivo deste trabalho, que é determinar os esforços resistentes em barras de aço isoladas em situação de incêndio natural, foi desenvolvido o programa STRESFIRE capaz de calcular o campo de temperaturas (ação térmica) a qual a barra será exposta, a temperaturas nos elementos de aço (transferência de calor dos gases do compartimento para a peça de aço) e a análise estrutural simplificada (esforço resistente em função do tempo e exposição).

O programa é arquitetado na linguagem Visual Basic ${ }^{25}$. Por se tratar de uma linguagem de programação orientada a objeto, o Visual Basic possui interface amigável, grande quantidade de componentes disponíveis e permite integração com outros programas para exportação dos relatórios de resultados. O Visual Basic tem grande comunidade de desenvolvedores e farta literatura disponível.

${ }^{25}$ O Visual Basic 6.0 é uma marca de propriedade da Microsoft Corporation. 
A biblioteca de materiais de vedação e as listas de perfis utilizadas pelo programa são apresentadas em arquivos texto, portanto, são passíveis de adição, remoção e edição de quaisquer características.

\subsection{MODELOS DE INCÊNDIO COMPARTIMENTADO}

Para Cadorin e Franssen ${ }^{26}$ (2003), os modelos de incêndio compartimentado são aptos a estimar mais de um aspecto do incêndio, como por exemplo, o desenvolvimento da temperatura e a propagação de fumaça. Podem ser classificados em três categorias, do mais simples ao mais complexo.

- Modelos analíticos (natural ou padronizado);

- Modelos por zonas (zone models);

- Modelos por campos (field models).

Modelos analíticos usualmente têm por base desenvolvimentos teóricos e correlações obtidas de resultados experimentais. São classificados como nominais, tempo equivalente, curvas paramétricas de temperatura -tempo.

\footnotetext{
${ }^{26}$ Cadorin, J.F. e Franssen, J.M. são professores da Universidade de Liège (Bélgica) e desenvolvedores do programa acadêmico OZONE V2 que utiliza o modelo por zonas. O modelo proposto no programa Ozone é abrangente, já que, o código inclui os modelos de uma e duas zonas e possui a habilidade de alternar entre os dois modos automaticamente de acordo com os critérios encontrados. Permite a análise de incêndios totalmente desenvolvidos (fase pós-flashover) bem como de incêndios localizados (a análise restringe-se a vigas ao nível do teto do compartimento). Este requer como entradas a geometria do compartimento, as propriedades térmicas dos materiais, a taxa de calor liberada (HRR), a taxa de pirólise e a área do incêndio em função de tempo. As saídas do modelo são: a temperatura dos gases, temperatura das vedações (calculado pelo método dos elementos finitos) e a taxa de energia liberada pelo incêndio. A estimativa do calor liberado é realizada por meio de três sub-modelos de combustão e foram projetados para representar um cenário específico. (BOUNAGUI, BÉNICHOU, 2003) (CADORIN, 2002)
} 
Modelos por zonas é um nome genérico dado a um modelo de incêndio que tem por base a suposição que o compartimento pode ser divido em zonas de temperatura. Em cada zona, é razoável considerar a temperatura uniforme. Neste modelo, as equações de energia e de equilíbrio de massas nas zonas de incêndio são resolvidas numericamente, alguns dos fenômenos do incêndio sendo modelados embasados em princípios fundamentais e outros são modelados por modelos analíticos e correlações.

Enquanto os modelos de uma zona são extensamente usados na análise de incêndios pósflashover, os modelos de duas zonas usados na análise de incêndios pré-flashover (BOUNAGUI; BÉNICHOU, 2003).

No modelo de duas zonas, o compartimento é dividido em uma porção superior com fumaça aquecida e uma porção inferior de ar frio. A pluma do fogo atua como uma bomba de entalpia entre a camada inferior e a camada superior (ver Figura 1-3).

$\mathrm{Na}$ realidade dependendo das dimensões do compartimento e da taxa de calor liberada (HRR) do incêndio, não existe uma 'interface' perfeitamente definida entre a camada superior e a camada inferior e a distribuição da temperatura não é homogênea (temperaturas mais elevadas são observadas próximas às chamas e a pluma). Entretanto, o uso de duas zonas permite aproximações razoáveis do desenvolvimento do incêndio sob muitas condições (OLENICK; CARPENTER, 2003).

Os modelos por campos, assim como os modelos por zonas são usados para modelar o incêndio em um ou em uma série de compartimentos. Os modelos de campos dividem o compartimento em um grande número de volumes de controle (na ordem dos milhares) e resolve as equações de conservação de massa e energia no interior de cada volume de controle. Eles estão implementados em programas ${ }^{27}$ complexos.

\footnotetext{
${ }^{27}$ No site www.firemodelsurvey.com existe amplo catálogo dos modelos computacionais para modelagem de incêndio e propagação de fumaça. Está catalogado por modelo utilizado e inclui informações como: descrição do modelo, organização desenvolvedora, referências, disponibilidade, língua e descrição detalhada, versão do programa e contato com os desenvolvedores. [Acesso em 20/03/05]
} 
Dependendo do tipo de modelo, sua resolução envolve poucos cálculos simples, enquanto outros, como as análises por campos (field model), requerem um grande número (até bilhões) de cálculos e, assim, longo tempo de processamento. "Tais análises complexas são custosas, e não apenas em processamento, mas também pela ocupação do engenheiro devido à dificuldade de definir dados, analisar e utilizar os resultados produzidos pela ferramenta" (CADORIN; FRANSSEN, 2003).

O modelo de incêndio utilizado no programa de computador STRESFIRE é o analítico."É muito comum que a solução dos problemas com base em formulações matemáticas do século 19 serão resolvidas por computadores no século 21 . Ainda, com a mentalidade do século 20, é seguro dizer que a engenharia de segurança contra incêndio é ainda baseada em expressões e correlações. Alguns dizem que o uso das mesmas expressões do século 20, e os atrasos no campo da engenharia de segurança contra incêndio são decorrentes da complexidade e da relativa pequena quantidade de pesquisas" (QUINTIERE, 2000).

\subsection{ENTRADAS E SAÍdAS DO PROGRAMA STRESFIRE}

As telas de entrada de dados fornecidas pelo usuário estão apresentadas nas Figuras de Figura 5-1 a Figura 5-4. 


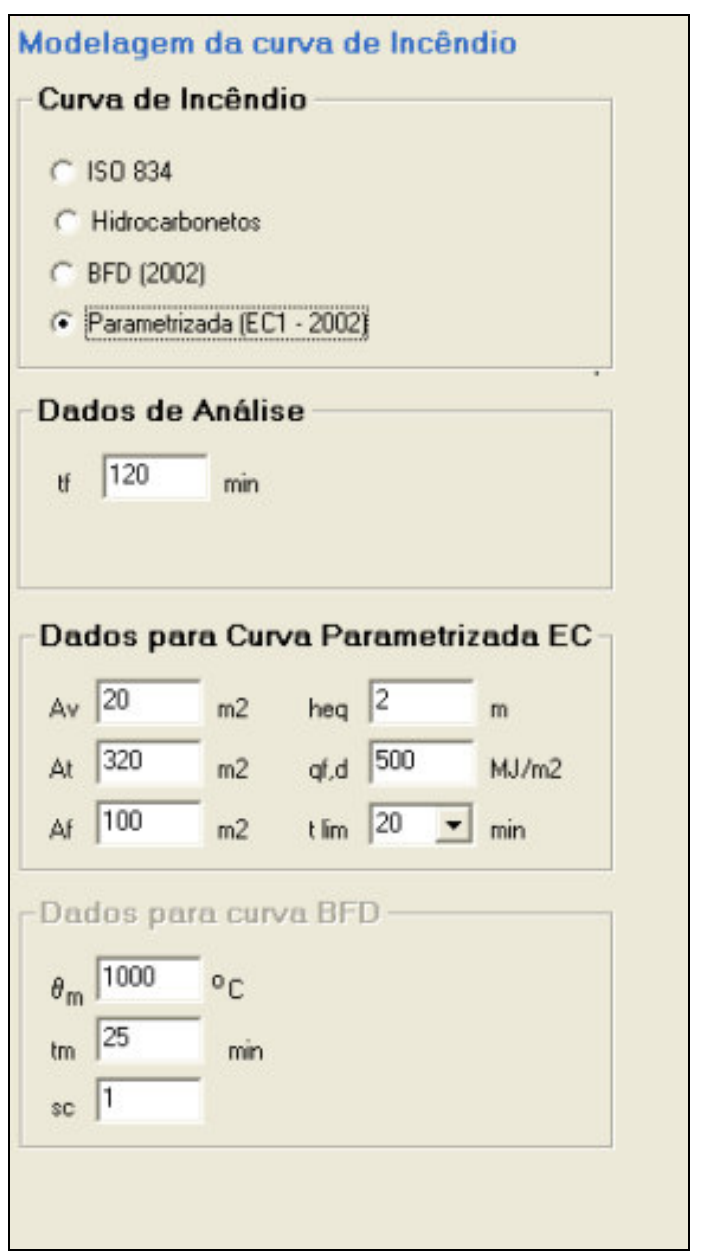

Figura 5-1 - Dados para modelagem da curva de incêndio.

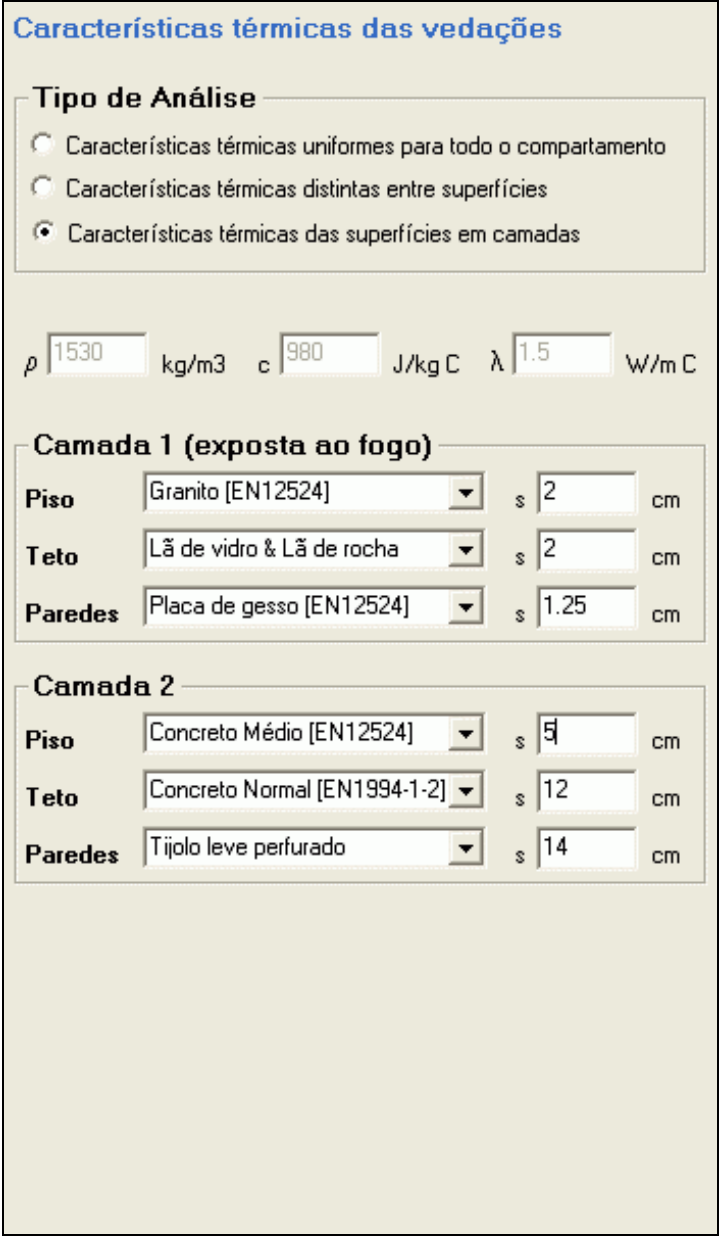

Figura 5-2 - Definição das características térmicas das vedações. 


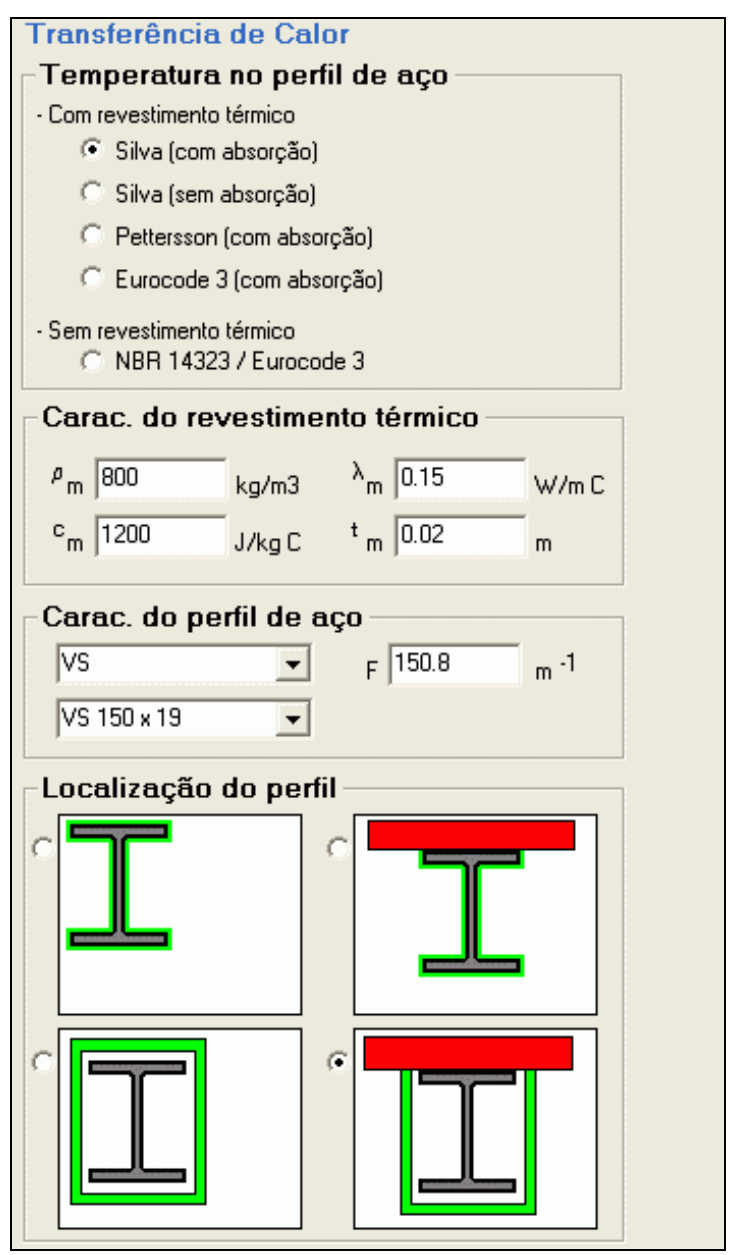

Figura 5-3 - Dados para transferência de calor.

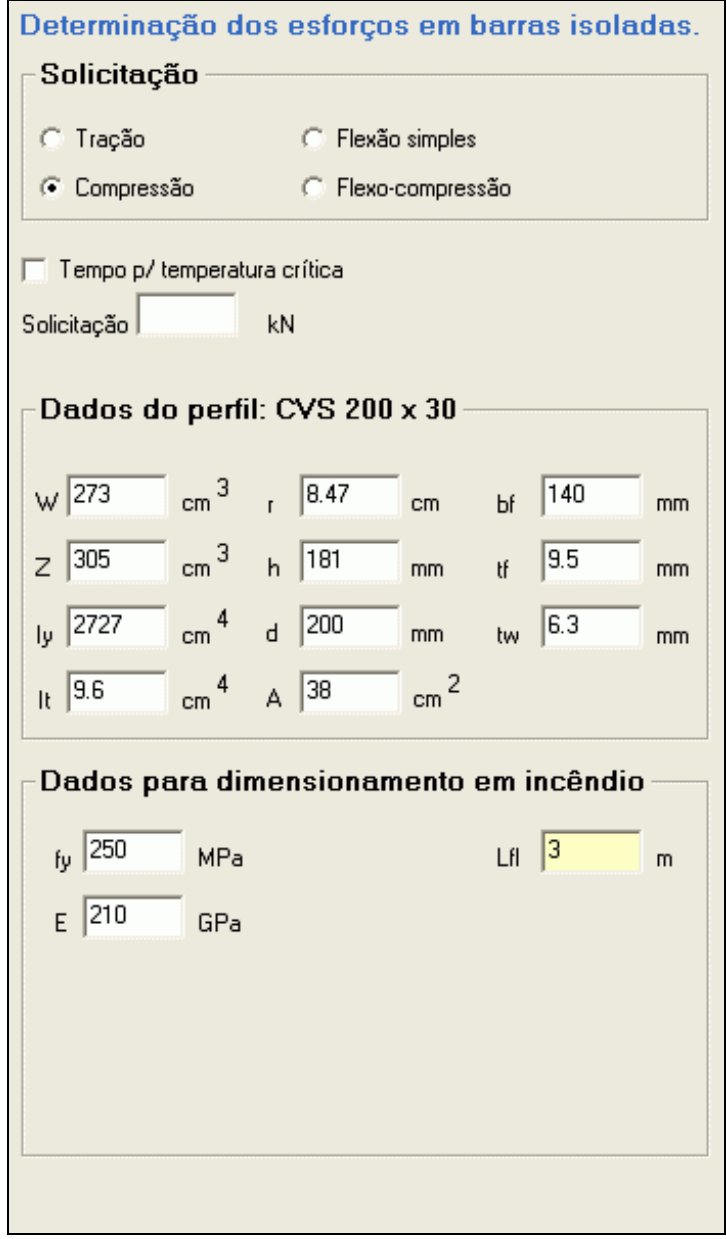

Figura 5-4 - Definições para determinação dos esforços resistentes.

Dados de análise:

- tempo de análise $(t)$;

Para geração das curvas paramétricas são necessários dados como as características geométricas do compartimento, características térmicas das superfícies do compartimento e carga de incêndio:

- Área de ventilação $\left(A_{v}\right)$; 
- Área total das superfícies do compartimento (paredes, piso, teto) $\left(A_{t}\right)$;

- Área de piso $\left(A_{f}\right)$;

- Altura média das aberturas nas paredes $\left(h_{e q}\right)$;

- Densidade da carga de incêndio por área de piso $\left(q_{f, d}\right)$;

- Tempo limite $\left(t_{\text {lim }}\right)$

- Condutividade térmica de cada superfície $(\rho)$;

- Calor específico de cada superfície (c);

- Peso específico de cada superfície $(\lambda)$;

Características do perfil ${ }^{28}$ a ser analisado:

- Área bruta da seção transversal $(A)$, altura interna $(h)$, altura total $(d)$, altura excluindo o raio de concordância $(d)$, largura da aba $\left(b_{f}\right)$, espessura da aba $\left(t_{f}\right)$, espessura da alma $\left(t_{w}\right)$, raio de giração do perfil $\left(r_{y}\right.$ e $\left.r_{x}\right)$, momento de inércia à flexão $\left(I_{y}\right)$, momento de inércia à torção $\left(I_{t}\right)$, módulo resistente elástico $(W)$, módulo resistente plástico $(Z)$, constante de empenamento da seção $\left(C_{w}\right)$;

- Fator de massividade $(F)$;

Propriedades térmicas, geométricas e físicas do material de revestimento (caso a análise trate de perfil revestido):

- Espessura da camada de revestimento contra fogo $\left(t_{m}\right)$;

- Condutividade térmica $\left(\rho_{m}\right)$;

${ }^{28}$ Os perfis soldados e laminados à quente cadastrados no programa de computador STRESFIRE foram extraídos da norma NBR 5884 (atualmente em revisão) e do catálogo da Açominas (2004). 
- Calor específico $\left(c_{m}\right)$;

- Peso específico $\left(\lambda_{m}\right)$;

- Tipo de revestimento (contorno ou caixa)

Escolha do modelo para transferência de calor entre os gases quentes do compartimento e o perfil de aço. Entre as metodologias para perfis revestidos: Silva (com absorção), Silva (sem absorção), Pettersson, EC3/NBR 14323:1999. Para perfis não-revestidos: EC3/NBR 14323:1999.

Dados complementares para o dimensionamento dos esforços resistentes;

- Resistência ao escoamento do aço $\left(f_{y}\right)$;

- Módulo de elasticidade do aço $(E)$;

- Tensão residual $\left(\sigma_{r}\right)$;

- Comprimento de flambagem $\left(l_{f l}\right)$;

- Distância entre travamentos $\left(l_{b}\right)$;

- Fator de correção para distribuição de temperatura não-uniforme na seção transversal $\left(\kappa_{l}\right)$, fator de correção para distribuição de temperatura não-uniforme ao longo do comprimento da barra fletida $\left(\kappa_{2}\right)$;

- Fator de equivalência de momentos na flexão $\left(C_{b}\right)$.

As saídas geradas pelo programa são:

- Gráficos de tempo-temperatura de gases e do aço (Figura 5-5) e gráfico de esforço resistente - tempo do perfil de aço (Figura 5-6);

- Planilha com os resultados do processamento; 


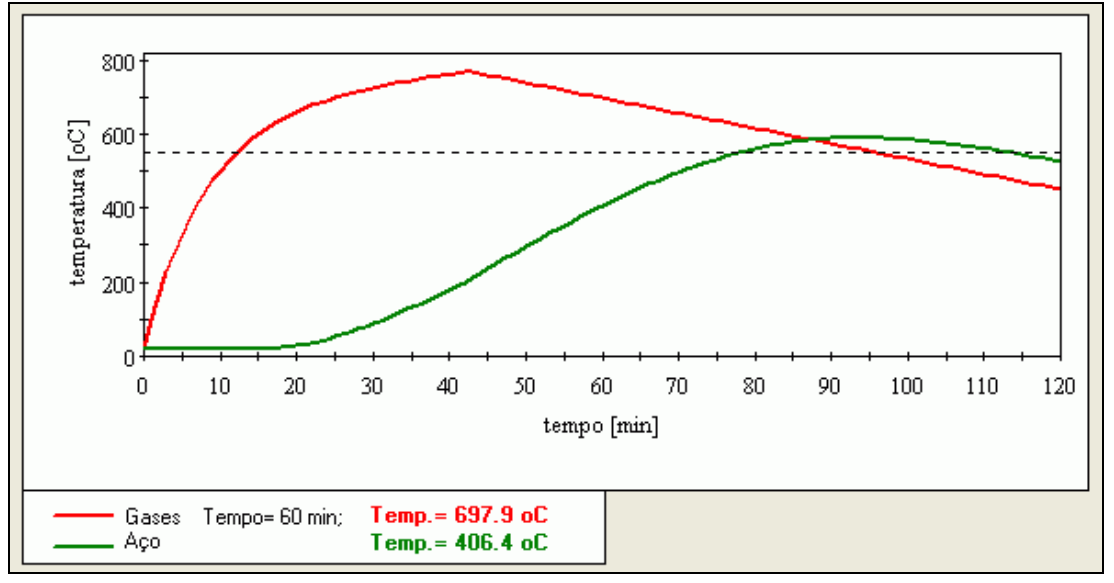

Figura 5-5 - Gráfico da curva tempo-temperatura dos gases quentes e do perfil de aço de curvas nominais ou paramétricas;

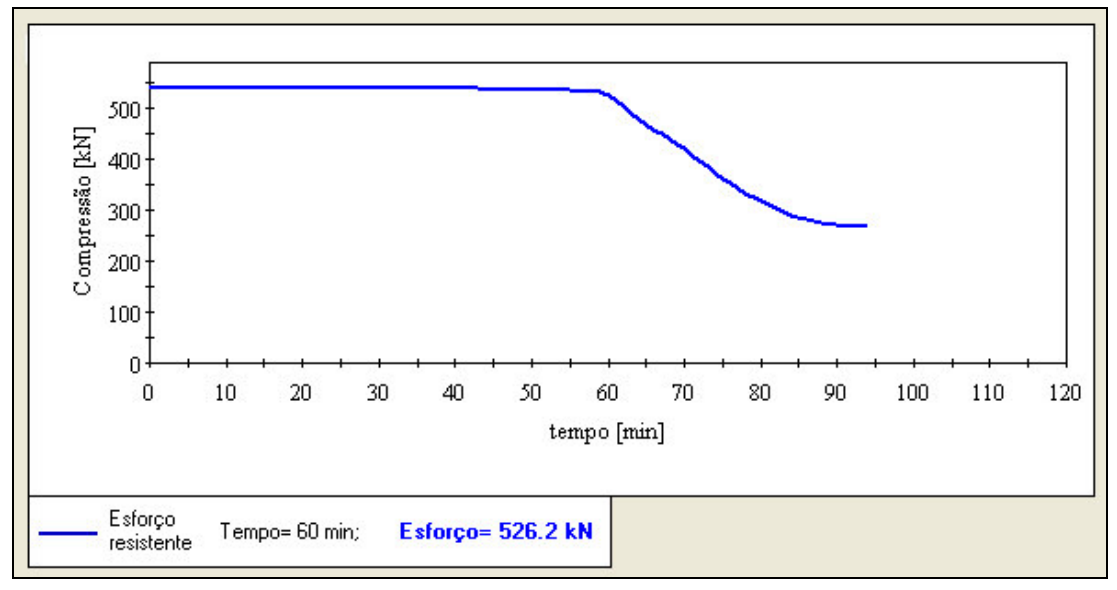

Figura 5-6 - Gráfico da curva de esforço resistente do aço - tempo em incêndio compartimentados para barras tracionadas ou comprimidas ou sob flexão simples;

\subsection{VALIDAÇÃO DOS RESULTADOS}

A validação de resultados do programa STRESFIRE foi realizada por três modalidades distintas: 
- A validação das curvas tempo-temperatura (paramétrica do EC1, curva padrão e curva $\mathrm{H}$ ) foi realizada por meio de estudo comparativo com o programa STEMPFIRE $^{29}$.

- A validação das curvas tempo-temperatura provenientes da transferência de calor do ambiente para ao aço foi realizado por meio de comparação com bibliografia especializada (FRANSSEN, ZAHARIA, 2005) e (SILVA, 2001) tendo por base a curva-padrão.

Tabela 5-1 - Tabela comparativa de temperatura de perfis desprotegidos, conforme a curva ISO. Parâmetros: $\mathrm{F}=\mathbf{1 0 0} \mathrm{m}^{-1} / \varepsilon=0,7$.

\begin{tabular}{|c|c|c|}
\hline & FRANSSEN / ZAHARIA & STRESFIRE \\
\hline Tempo [min] & Temp. do aço [oC] & Temp. do aço [oC] \\
\hline 0 & 20 & 179,9 \\
\hline 5 & 177 & 394,9 \\
\hline 10 & 392 & 566,9 \\
\hline 15 & 565 & 677,7 \\
\hline 20 & 676 & 732,5 \\
\hline 25 & 732 & 768,4 \\
\hline 30 & 767 & 827,6 \\
\hline 35 & 827 & 865,6 \\
\hline 40 & 865 & 889,9 \\
\hline 45 & 890 & \\
\hline
\end{tabular}

Tabela 5-2 - Tabela comparativa de temperatura de perfis desprotegidos, conforme a curva ISO. Parâmetros: $\mathrm{F}=\mathbf{2 0 0} \mathrm{m}^{-1} / \varepsilon=\mathbf{0 , 5}$.

\begin{tabular}{|c|c|c|}
\hline & SILVA & STRESFIRE \\
\hline Tempo [min] & Temp. do aço [oC] & Temp. do aço [oC] \\
\hline 0 & 20 & 508,3 \\
\hline 10 & 505 & 653,2 \\
\hline 15 & 651 & 724,8 \\
\hline 20 & 724 & 20 \\
\hline
\end{tabular}

\footnotetext{
${ }^{29}$ O programa Stempfire foi desenvolvido por Elka Cohen Kaefer e Valdir Pignatta e Silva.
} 


\begin{tabular}{|l|l|l|}
\hline 25 & 756 & 756,5 \\
\hline 30 & 815 & 815,6 \\
\hline 35 & 851 & 851,8 \\
\hline 40 & 875 & 875,8 \\
\hline 45 & 895 & 895,2 \\
\hline
\end{tabular}

Tabela 5-3- Tabela comparativa de temperatura de perfis protegidos, conforme a curva ISO. Parâmetros: $\mathrm{F}=106,67 \mathrm{~m}^{-1}, \lambda_{\mathrm{m}}=0,15 \mathrm{~W} / \mathrm{m}^{0} \mathrm{C}, \mathrm{t}_{\mathrm{m}}=0,02 \mathrm{~m}, \varepsilon=0,7$.

\begin{tabular}{|c|c|c|}
\hline & FRANSSEN / ZAHARIA & STRESFIRE \\
\hline Tempo [min] & Temp. do aço [oC] & Temp. do aço [oC] \\
\hline 0 & 20 & 20 \\
\hline 10 & 85 & 82,9 \\
\hline 20 & 160 & 158,6 \\
\hline 30 & 232 & 230,4 \\
\hline 40 & 298 & 297,0 \\
\hline 50 & 359 & 358,2 \\
\hline 60 & 414 & 414,0 \\
\hline 70 & 465 & 464,6 \\
\hline 80 & 510 & 510,3 \\
\hline 90 & 552 & 551,6 \\
\hline
\end{tabular}

- A validação do cálculo dos esforços resistentes foi realizada por meio de cálculos manuais. Ver APÊNDICE B. 


\section{ANÁLISE PARAMÉTRICA}

O programa STRESFIRE foi empregado para efetuar uma análise paramétrica com as variáveis que compõem o incêndio natural do modelo do EC1 e a transferência de calor do modelo do EC3 e caracterizar com essas variáveis influenciam os esforços resistentes (tração, compressão ou flexão). A análise paramétrica tem por características:

- restrita ao intervalo de 2 horas;

- ação térmica dada pela curva paramétrica do EC1(2002);

- transferência de calor para os elementos de aço por meio da curva do EC3(2003);

Os valores das variáveis utilizadas para a análise paramétrica estão apresentados abaixo, entretanto, os valores em negrito são os padrões.

Área de piso $\left(A_{f}\right) \quad \mathbf{1 0 0}, 300\left[\mathrm{~m}^{2}\right]$;

Área total $\left(A_{t}\right) \quad 304 ; 312 ; 320 ; 328 ; 336 ; 344 ; 782 ; 796 ; 810 ; 824 ; 838 ; 852\left[\mathrm{~m}^{2}\right]$;

Área de ventilação $\left(A_{v}\right) \quad 16 ; 18 ; 20 ; 22 ; 24 ; 26\left[\mathrm{~m}^{2}\right]$;

Altura equivalente das aberturas $\left(h_{e q}\right) \quad 1,25 ; 1,50 ; 1,75 ; \mathbf{2 , 0 0} ; 2,25 ; 2,50[\mathrm{~m}]$;

Carga de incêndio por área de piso $\left(q_{f, d}\right)$ 300; 400; 500; 600; 700; $800\left[\mathrm{MJ} / \mathrm{m}^{2}\right]$;

Tempo limite $\left(t_{\text {lim }}\right) \quad \mathbf{2 0}[\mathrm{min}]$

Inércia térmica das vedações $(b) \quad 500 ; 750 ; 1000 ; 1250 ; 1500 ; 2000\left[\mathrm{~J} / \mathrm{m}^{2} \mathrm{~s}^{1 / 2}{ }^{\mathrm{o}} \mathrm{C}\right]$;

Fator de massividade $(F) \quad 50 ; 100 ; 150 ; 200 ; 250 ; 300\left[\mathrm{~m}^{-1}\right]$;

Espessura do material térmico $\left(t_{m}\right) \quad 0,010 ; 0,015 ; \mathbf{0 , 0 2 0} ; 0,025 ; 0,030 ; 0,035[\mathrm{~m}]$;

Massa específica do revestimento contra fogo $\left(\rho_{m}\right) \quad 100 ; 200 ; \mathbf{2 4 0}{ }^{30} ; 300 ; 500 ; 1000$; $2000\left[\mathrm{~kg} / \mathrm{m}^{3}\right]$;

\footnotetext{
${ }^{30}$ As propriedades térmicas do material de revestimento contra fogo em negrito são as do Blaze Shield II (Isolatek/Refrasol). $\rho_{m}=240 \mathrm{~kg} / \mathrm{m}^{3}, c_{m}=2300 \mathrm{~J} / \mathrm{kg}^{\circ} \mathrm{C}, \lambda_{m}=0,15 \mathrm{~W} / \mathrm{m}^{\circ} \mathrm{C}$. (SILVA, 2005)
} 
Calor específico do revestimento contra fogo $\left(c_{m}\right)$ 1000; $1500 ; 2000 ; 2300 ; 2500 ; 3000$; $3500\left[\mathrm{~J} / \mathrm{kg}^{\circ} \mathrm{C}\right]$;

Condutividade térmica do revestimento contra fogo $\left(\lambda_{m}\right) \quad 0,10 ; \mathbf{0 , 1 5} ; 0,20 ; 0,25 ; 0,30$;

$0,35\left[\mathrm{~W} / \mathrm{m}^{\circ} \mathrm{C}\right]$

Para a determinação dos esforços resistentes, serão empregados os parâmetros abaixo:

Perfil de aço laminado W 310 x 28,3;

$E=205.000 \mathrm{MPa}$;

$f_{y}=250 \mathrm{MPa}$;

$\sigma_{r}=70 \mathrm{MPa}$ (flexão normal simples);

$L_{f l, x}=3,00 \mathrm{~m}$ (compressão);

$L_{f l, y}=2,00 \mathrm{~m}$ (compressão);

$L_{b}=2,00 \mathrm{~m}$ (flexão normal simples);

$C_{b}=1,00$ (flexão normal simples);

$\kappa_{1}=1,40$ (flexão normal simples);

$\kappa_{2}=1,00$ (flexão normal simples);

Os resultados obtidos estão listados nos itens 6.1 a 6.8 .

\section{1.ÁREA DE VENTILAÇÃO}

Neste item, está exposta a análise paramétrica considerando a variação da área de ventilação $\left(A_{v}\right)$. A Tabela 6-1 exibe as temperaturas dos gases do compartimento e as temperaturas transferidas para o aço conforme área de ventilação. 
Tabela 6-1 - Temperaturas máximas dos gases e do aço conforme área de ventilação.

\begin{tabular}{|l|l|l|l|l|l|l|}
\cline { 2 - 7 } \multicolumn{1}{c|}{} & \multicolumn{6}{c|}{$\mathrm{A}_{\mathrm{v}}\left[\mathrm{m}^{2}\right]$} \\
\cline { 2 - 7 } \multicolumn{1}{c|}{} & 16 & 18 & 20 & 22 & 24 & 26 \\
\hline Temp. máxima dos gases $\left[{ }^{\circ} \mathrm{C}\right]$ & 911,7 & 929,1 & 947,6 & 765,5 & 765,5 & 765,5 \\
\hline Tempo p/ temp. máxima dos gases [min] & 26 & 23 & 21 & 20 & 20 & 20 \\
\hline Temp. máxima do aço $\left[{ }^{\circ} \mathrm{C}\right]$ & 452,4 & 432,0 & 414,2 & 299,4 & 292,5 & 287,1 \\
\hline Tempo p/ temp. máxima do aço [min] & 57 & 51 & 47 & 42 & 41 & 39 \\
\hline
\end{tabular}

Para os valores de área de ventilação $\left(A_{v}\right) 16,18$ e $20 \mathrm{~m}^{2}$ o incêndio é controlado pela ventilação, e constatou-se razoável alteração na temperatura dos gases do compartimento. Apesar da elevação da temperatura dos gases ser proporcional ao aumento da área de ventilação, o mesmo não foi observado no elemento de aço. A área de ventilação acelerou a queima do combustível, e portanto, acelerou a fase de resfriamento do compartimento.

Para os valores de área de ventilação $\left(A_{v}\right) 22,24$ e $26 \mathrm{~m}^{2}$, o incêndio é controlado pelo combustível e o modelo do EC1 gera um grande decréscimo nas temperaturas. Dada a grande quantidade de ar que adentra o compartimento via aberturas verticais, a temperatura máxima dos gases estagnou-se em um patamar bem inferior aos incêndios controlados pela ventilação. Neste tipo de modelagem, a ventilação não afeta a temperatura máxima, todas as curvas apresentam a mesma curva de aquecimento. A diferença nas curvas é o coeficiente angular da reta que modela a fase descendente. Uma área de ventilação maior significa um resfriamento mais brusco do ambiente e da temperatura máxima dos elementos de aço. 


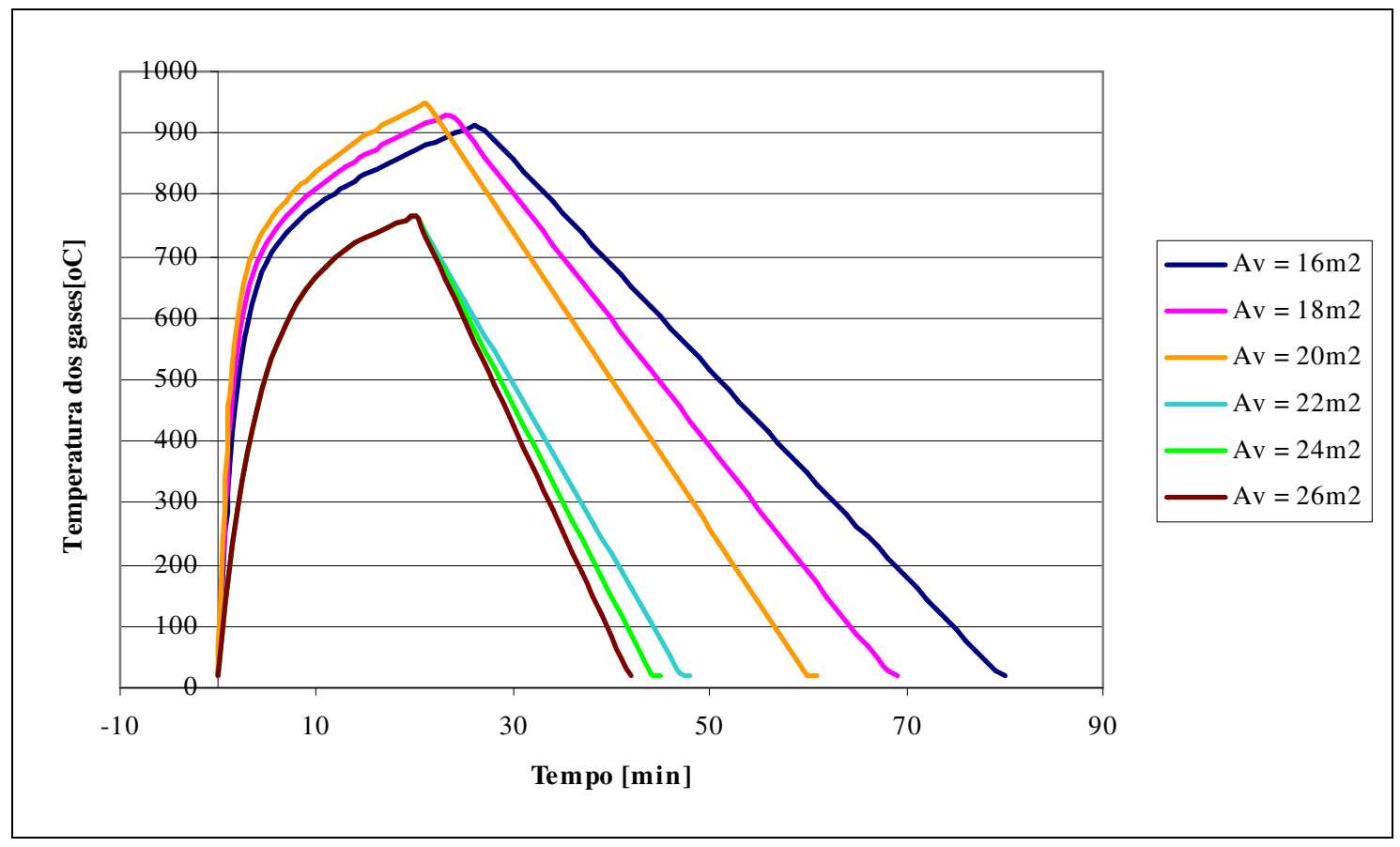

Figura 6-1 - Temperatura dos gases em função do tempo para diversas área de ventilação

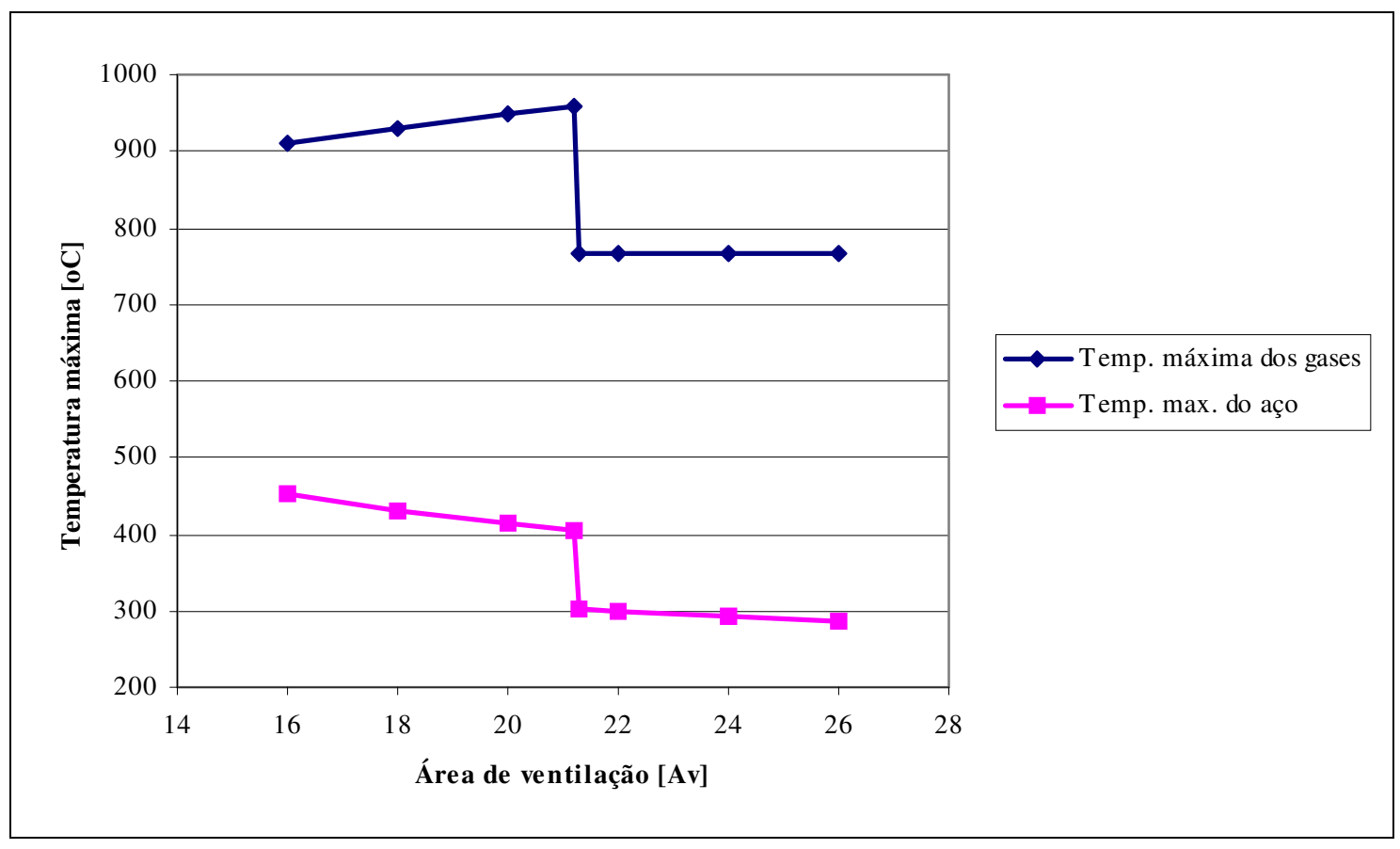

Figura 6-2 - Temperaturas máximas em função do tempo para diversas áreas de ventilação 


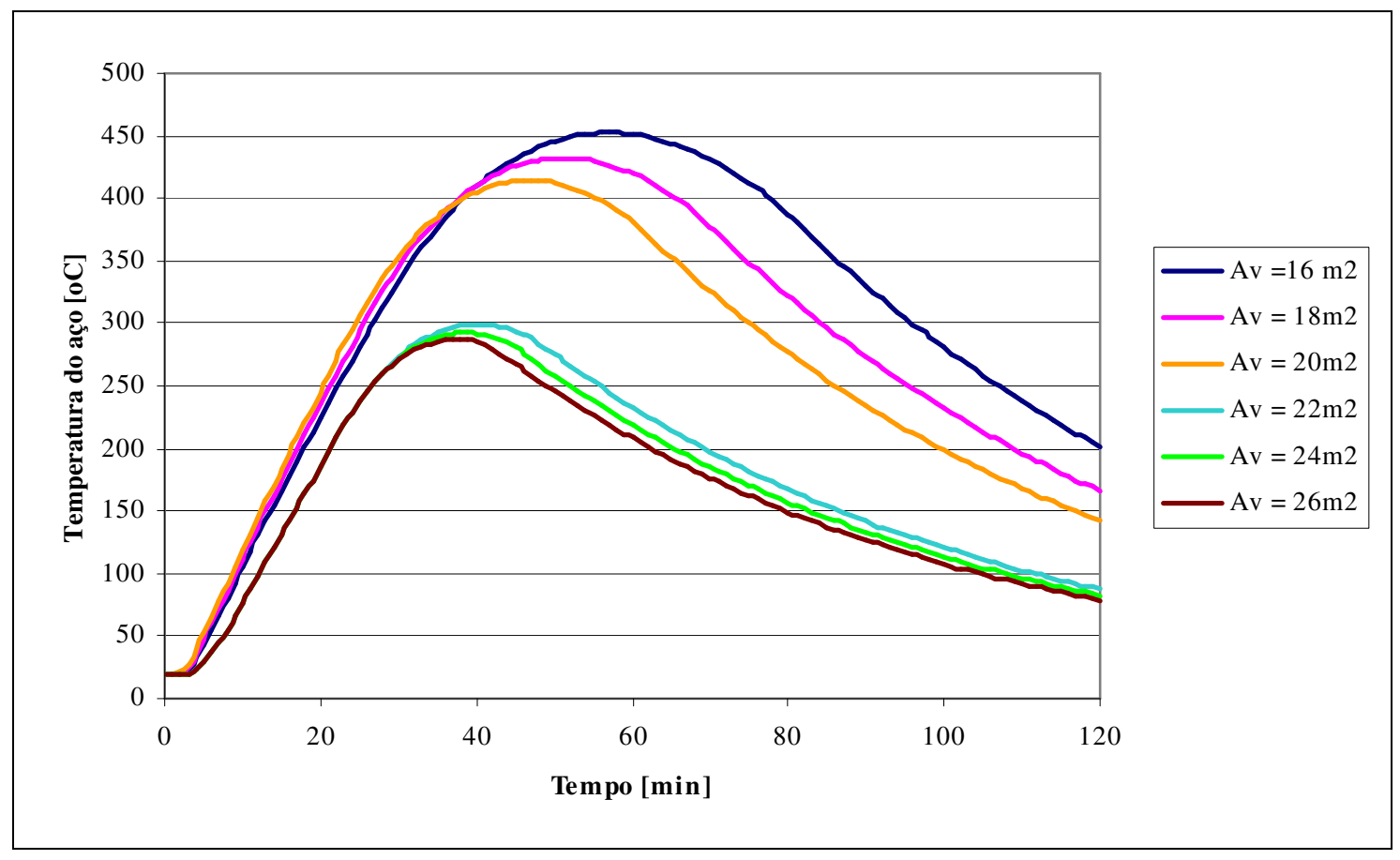

Figura 6-3 - Temperatura do aço em função da área de ventilação

Os esforços resistentes para os incêndios controlados pelo combustível são insensíveis à variação da área de ventilação. Para os incêndios controlados pela ventilação, os esforços são medianamente sensíveis. Os esforços resistentes encontrados para um perfil de aço W 310 x 28,3 estão expostos na Tabela 6-2.

Tabela 6-2 - Esforços resistentes conforme área de ventilação do compartimento.

\begin{tabular}{|l|l|l|l|l|l|l|}
\cline { 2 - 7 } \multicolumn{1}{c|}{} & \multicolumn{6}{c|}{$\mathrm{A}_{\mathrm{v}}\left[\mathrm{m}^{2}\right]$} \\
\cline { 2 - 8 } \multicolumn{1}{c|}{} & 16 & 18 & 20 & 22 & 24 & 26 \\
\hline Esforço resistente de tração [kN] & 807,3 & 848,3 & 884,1 & 912,5 & 912,5 & 912,5 \\
\hline Esforço resistente de compressão [kN] & 289,6 & 300,8 & 310,5 & 345,8 & 347,6 & 349,0 \\
\hline Esforço resistente de flexão simples [kN.m] & 57,8 & 60,3 & 62,6 & 67,3 & 67,5 & 67,6 \\
\hline
\end{tabular}

\subsection{CARGA DE INCÊNDIO}

Neste item, está exposta a análise paramétrica considerando a variação da carga de incêndio. A carga de incêndio pode ser medida por intermédio da pesagem dos materiais 
combustíveis do compartimento e posterior conversão em madeira ou padronizado pelos códigos de segurança e normas técnicas. A carga de incêndio de cálculo é obtida a partir da ponderação do valor característico pelos coeficientes de segurança ${ }^{31}$.

Os vários códigos de edificações não são uniformes em relação à carga de incêndio. Os códigos de edificações da Nova Zelândia recomendam utilizar para residências a carga de incêndio de $400 \mathrm{MJ} / \mathrm{m}^{2}$ (área de piso) e $800 \mathrm{MJ} / \mathrm{m}^{2}$ para escritórios. (PARKINSON; BARNETT, 2001) Já o EC1(2002) recomenda $780 \mathrm{MJ} / \mathrm{m}^{2}$ (valor característico por área de piso) para residências e $420 \mathrm{MJ} / \mathrm{m}^{2}$ (valor característico por área de piso) de escritórios. A NBR 14432:2000 utiliza-se dos valores da SIA81 (Suíça) e da TRVB-126 (Áustria). A carga de incêndio para edificações residenciais é de $300 \mathrm{MJ} / \mathrm{m}^{2}$, para escritórios é de $700 \mathrm{MJ} / \mathrm{m}^{2}$. (SILVA, 1999) A Tabela 6-3 exibe as temperaturas dos gases do compartimento e as temperaturas transferidas para o aço conforme carga de incêndio por área de piso e por área total.

Tabela 6-3 - Temperatura máximas dos gases e do aço conforme carga de incêndio.

\begin{tabular}{|c|c|c|c|c|c|c|}
\hline & \multicolumn{6}{|c|}{$\mathrm{q}_{\mathrm{t}, \mathrm{d}}\left[\mathrm{MJ} / \mathrm{m}^{2}\right]$} \\
\hline & 93,8 & 125 & 156,3 & 187,5 & 218,8 & 250 \\
\hline & \multicolumn{6}{|c|}{$\mathrm{q}_{\mathrm{f}, \mathrm{d}}\left[\mathrm{MJ} / \mathrm{m}^{2}\right]$} \\
\hline & 300 & 400 & 500 & 600 & 700 & 800 \\
\hline Temp. máxima dos gases $\left[{ }^{\circ} \mathrm{C}\right]$ & 599,4 & 707,5 & 947,6 & 974,3 & 996,8 & 1020,5 \\
\hline $\begin{array}{l}\text { Tempo p/ temp. máxima dos gases } \\
\text { [min] }\end{array}$ & 20 & 20 & 21 & 25 & 29 & 34 \\
\hline Temp. máxima do aço $\left[{ }^{\circ} \mathrm{C}\right]$ & 208,3 & 267,5 & 414,2 & 462,0 & 507,2 & 550,3 \\
\hline Tempo p/ temp. máxima do aço [min] & 37 & 40 & 47 & 52 & 59 & 65 \\
\hline
\end{tabular}

Para os valores de carga de incêndio por área de piso $\left(q_{f, d}\right) 300$ e $400 \mathrm{MJ} / \mathrm{m}^{2}$ o incêndio é controlado pelo combustível, e observou-se expressiva sensibilidade no aumento de

\footnotetext{
${ }^{31} \mathrm{O}$ valor característico da carga de incêndio é multiplicado por dois coeficiente de segurança $\left(\gamma_{\mathrm{i}}\right.$ e $\left.\gamma_{\mathrm{s}}\right)$ conforme área do compartimento e risco de colapso e características de detecção de extinção como presença de chuveiros automáticos, brigada de incêndio e detecção automática de fumaça e calor.
} 
temperatura do gases do compartimento, embora a carga de incêndio ainda baixa contribui para a temperatura no elemento de aço seja baixa.

Para os valores 500, 600, 700 e $800 \mathrm{MJ} / \mathrm{m}^{2}$ o incêndio é controlado pela ventilação. Ao aumentar a carga de incêndio nos incêndios controlados pela ventilação o tempo para atingir a temperatura máxima foi postergado, influenciando a curva tempo-temperatura ascendente dos gases quentes. Em todos os casos, as temperaturas dos gases são extremamente altas, e a sensibilidade em relação à carga de incêndio da modelagem do incêndio controlado pela ventilação é elevada.

A temperatura do aço em ambas as modalidades de incêndio sofreu grande variação. $O$ tempo em que o aço atingiu a temperatura máxima também foi postergado, demonstrando proporcionalidade entre a carga de incêndio e a elevação da temperatura no elemento de aço.

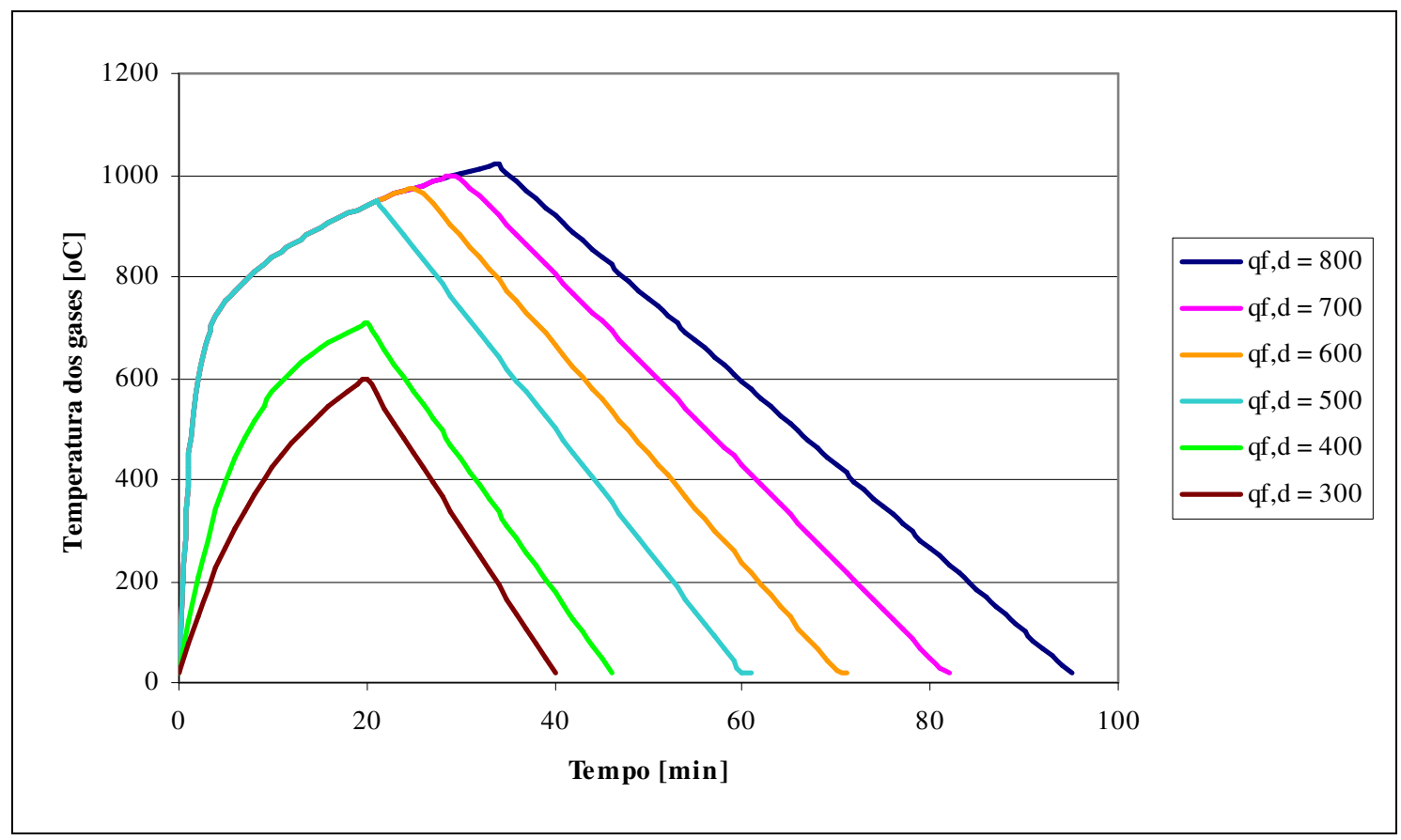

Figura 6-4 - Temperatura dos gases do compartimento conforme carga de incêndio por área de piso. 


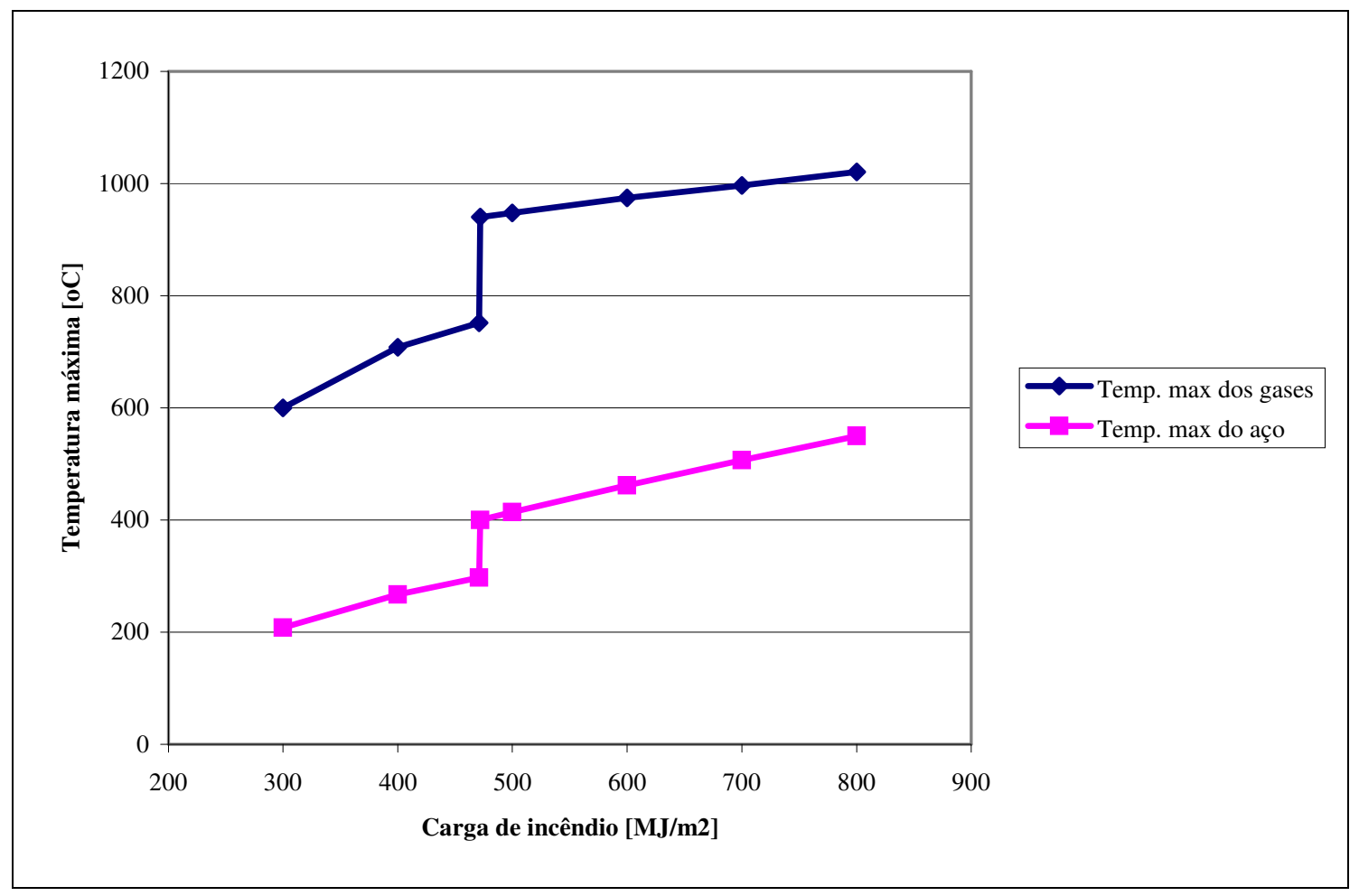

Figura 6-5 - Temperaturas máximas dos gases e do aço conforme carga de incêndio.

Dada a grande variação de temperatura, os esforços resistentes foram rigorosamente afetados e expostos na Tabela 6-4, para um perfil de aço W 310 x 28,3.

Tabela 6-4 - Esforços resistentes conforme carga de incêndio

\begin{tabular}{|l|l|l|l|l|l|l|l|}
\cline { 2 - 7 } \multicolumn{1}{c|}{} & \multicolumn{5}{c|}{$\mathrm{q}_{\mathrm{t}, \mathrm{d}}\left[\mathrm{MJ} / \mathrm{m}^{2}\right]$} \\
\cline { 2 - 7 } \multicolumn{1}{c|}{} & 93,8 & 125 & 156,3 & 187,5 & 218,8 & 250 \\
\cline { 2 - 7 } & \multicolumn{5}{c|}{$\mathrm{q}_{\mathrm{f}, \mathrm{d}}\left[\mathrm{MJ} / \mathrm{m}^{2}\right]$} \\
\cline { 2 - 7 } & 300 & 400 & 500 & 600 & 700 & 800 \\
\hline Esforço resistente de tração [kN] & 912,5 & 912,5 & 884,1 & 788,1 & 691,4 & 569,4 \\
\hline Esforço resistente de compressão [kN] & 368,4 & 354,0 & 310,5 & 284,3 & 254,8 & 203,5 \\
\hline Esforço resistente de flexão simples [kN.m] & 69,5 & 68,1 & 62,6 & 56,6 & 50,2 & 40,7 \\
\hline
\end{tabular}

\subsection{ALTURA MÉDIA DAS ABERTURAS}

Neste item, está exposta a análise paramétrica considerando a variação da altura média das aberturas $\left(h_{e q}\right)$ para uma mesma área de ventilação. A Tabela 6-5 exibe as 
temperaturas dos gases do compartimento e as temperaturas do elemento de aço conforme altura média das aberturas.

Tabela 6-5 - Temperaturas máximas dos gases e do aço conforme altura média das aberturas.

\begin{tabular}{|c|c|c|c|c|c|c|}
\hline & \multicolumn{6}{|c|}{$\mathrm{h}_{\mathrm{eq}}[\mathrm{m}]$} \\
\hline & 1,25 & 1,50 & 1,75 & 2,00 & 2,25 & 2,50 \\
\hline Temp. máxima dos gases $\left[{ }^{\circ} \mathrm{C}\right]$ & 910,1 & 923,8 & 934,1 & 947,6 & 765,5 & 765,5 \\
\hline $\begin{array}{l}\text { Tempo p/ temp. máxima dos gases } \\
\text { [min] }\end{array}$ & 27 & 24 & 22 & 21 & 20 & 20 \\
\hline Temp. máxima do aço $\left[{ }^{\circ} \mathrm{C}\right]$ & 454,4 & 438,6 & 425,4 & 414,2 & 302,6 & 298,0 \\
\hline Tempo p/ temp. máxima do aço [min] & 57 & 53 & 49 & 47 & 43 & 42 \\
\hline
\end{tabular}

Para os valores de altura média das aberturas $\left(h_{e q}\right)$ 1,25, 1,50, 1,75 e 2,00 m o incêndio é controlado pela ventilação. Mostrou-se pouco sensível à variação de temperatura, porém ressaltou que o aumento da altura das aberturas acelerou a queima de combustíveis e resultou em aumento da temperatura máxima dos gases. Contudo, também se observou que acelerou o resfriamento do ambiente e assim, os elementos de aço atingiram temperaturas inferiores.

Para os valores de altura média das aberturas $\left(h_{e q}\right)$ 2,25 e 2,50 m o incêndio é controlado pelo combustível. Da mesma forma que nos itens 6.1 e 6.2 a análise paramétrica revelou um grande salto de temperatura entre os modelos de incêndio controlado pelo combustível (patamar de temperatura inferior) e pela ventilação como visto nas Figura 6-6 e Figura 6-7. 


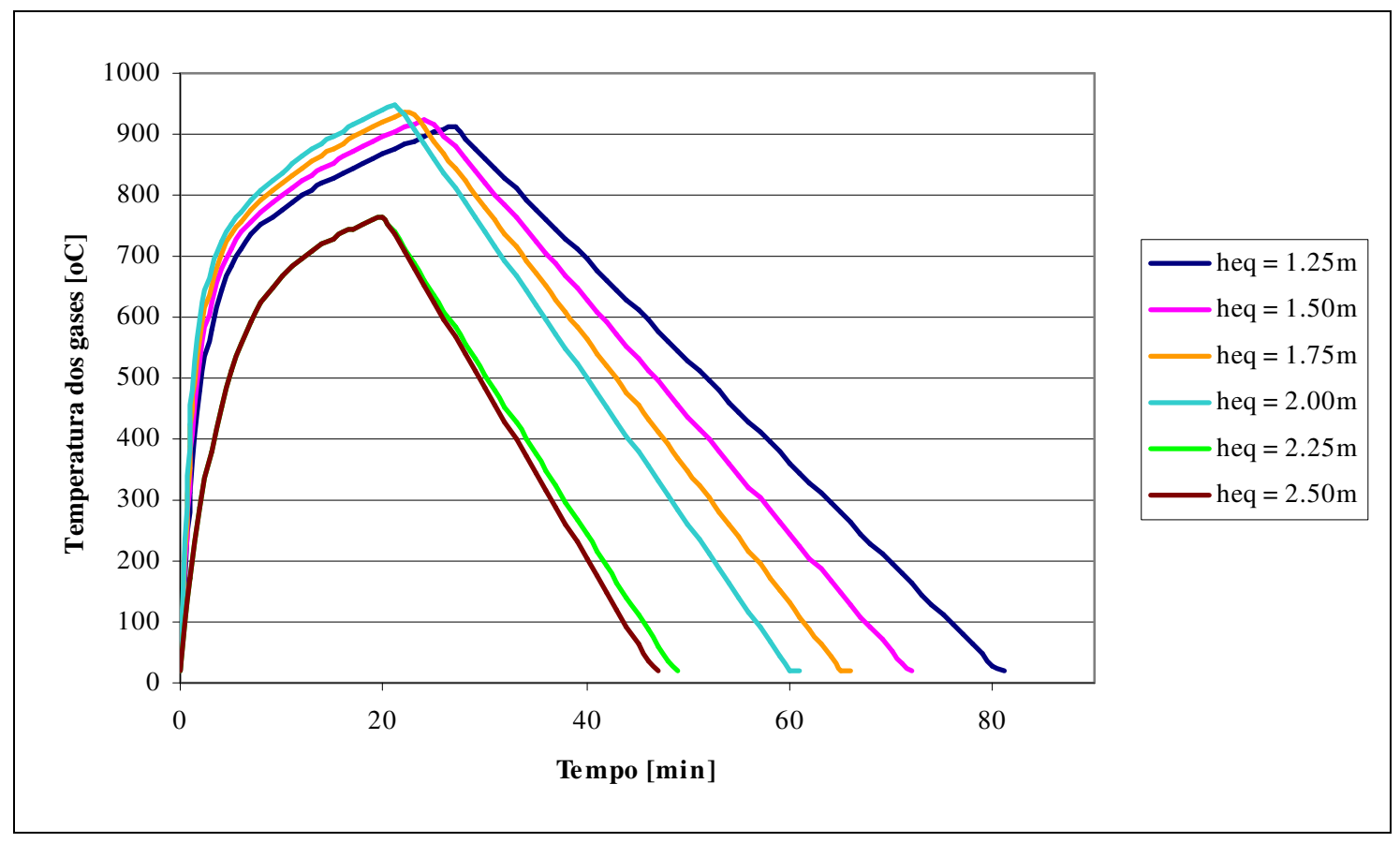

Figura 6-6 - Temperatura dos gases em função da altura média das aberturas

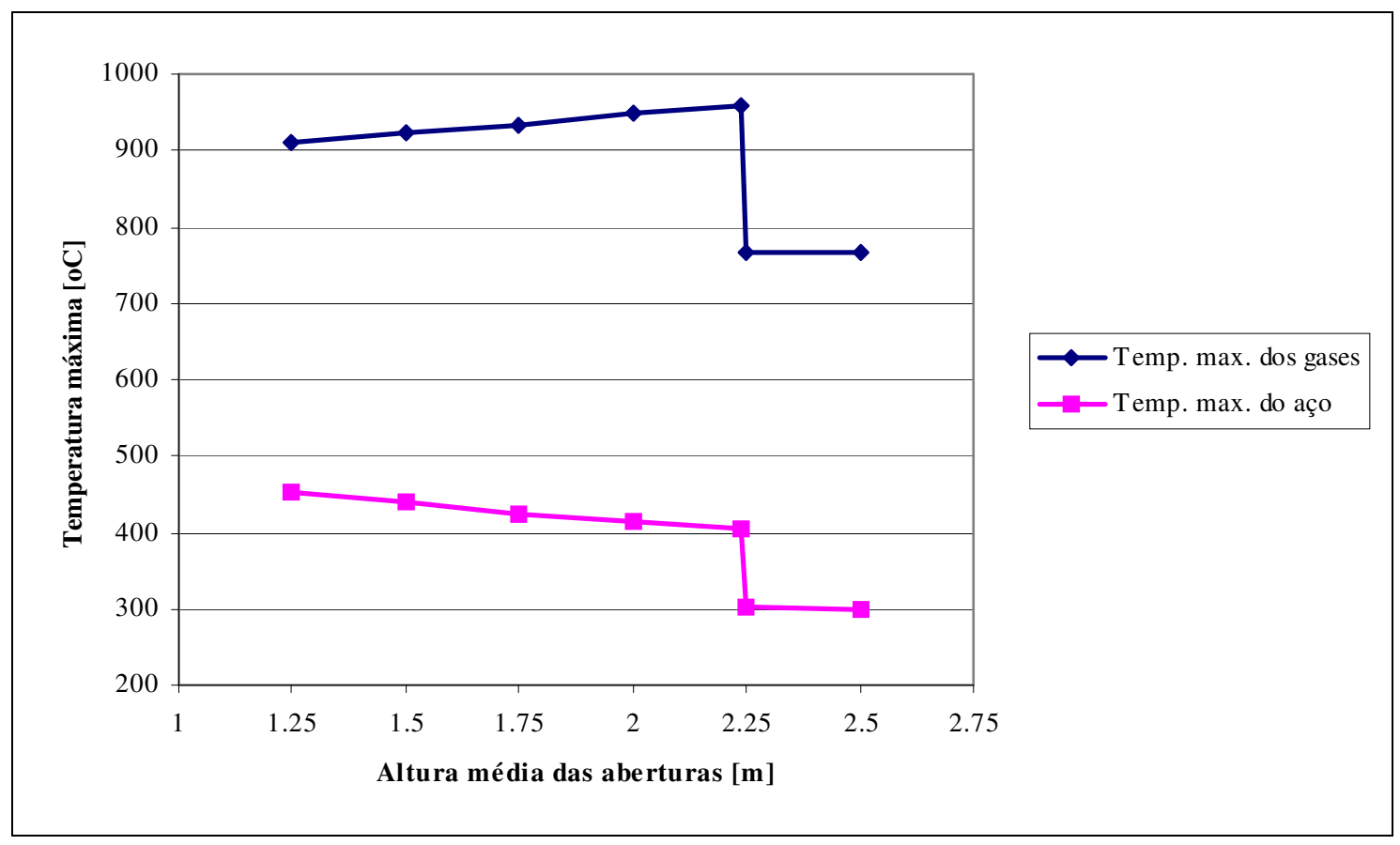

Figura 6-7 - Temperatura máxima doas gases e do aço conforme altura média das aberturas 
Constatou-se que o aumento da altura das aberturas verticais é benéfico ao aço, entretanto seus efeitos são pouco significativos. Para incêndios controlados pelo combustível, seus efeitos são nulos. Os esforços resistentes encontrados para um perfil de aço W 310 x 28,3 estão expostos na Tabela 6-6.

Tabela 6-6 - Esforços resistentes conforme altura média das aberturas.

\begin{tabular}{|l|l|l|l|l|l|l|}
\cline { 2 - 7 } \multicolumn{1}{c|}{} & \multicolumn{5}{c|}{$\mathrm{h}_{\mathrm{eq}}[\mathrm{m}]$} \\
\cline { 2 - 7 } \multicolumn{1}{c|}{} & 1,25 & 1,50 & 1,75 & 2,00 & 2,25 & 2,50 \\
\hline Esforço resistente de tração [kN] & 803,2 & 834,9 & 861,6 & 884,1 & 912,5 & 912,5 \\
\hline Esforço resistente de compressão [kN] & 288,5 & 297,1 & 304,4 & 310,5 & 345,0 & 346,2 \\
\hline Esforço resistente de flexão simples [kN.m] & 57,5 & 59,5 & 61,2 & 62,6 & 67,2 & 67,3 \\
\hline
\end{tabular}

\subsection{INÉRCIA TÉRMICA DAS VEDAÇÕES}

Neste item, está exposta a análise paramétrica considerando a variação da inércia térmica das vedações do compartimento $(b)$. A inércia térmica dos materiais de vedação não está relacionada com o tipo de incêndio e por isso, não impacta no tempo para ocorrência da temperatura máxima dos gases. Dadas às características do combustível e da geometria do compartimento adotados, o incêndio administrado nesta seção é do tipo controlado pela ventilação. A Tabela 6-7 exibe as temperaturas dos gases do compartimento e as temperaturas do elemento de aço conforme inércia térmica das vedações.

Tabela 6-7 - Temperaturas máximas dos gases e do aço conforme inércia térmica das vedações.

\begin{tabular}{|l|l|l|l|l|l|l|}
\cline { 2 - 7 } \multicolumn{1}{c|}{} & \multicolumn{6}{c|}{$\mathrm{b}\left[\mathrm{J} / \mathrm{m}^{2} \mathrm{~s}{ }^{1 / 2} \mathrm{C}\right]$} \\
\cline { 2 - 7 } \multicolumn{1}{c|}{} & 500 & 750 & 1000 & 1250 & 1500 & 2000 \\
\hline Temp. máxima dos gases $\left[{ }^{\circ} \mathrm{C}\right]$ & 1276,8 & 1155,2 & 1068,5 & 1003,0 & 947,5 & 860,6 \\
\hline $\begin{array}{l}\text { Tempo p/ temp. máxima dos gases } \\
{[\mathrm{min}]}\end{array}$ & 21 & 21 & 21 & 21 & 21 & 21 \\
\hline Temp. máxima do aço [ $\left.{ }^{\circ} \mathrm{C}\right]$ & 464,5 & 458,6 & 464,7 & 434,0 & 414,2 & 399,4 \\
\hline Tempo p/ temp. máxima do aço [min] & 32 & 39 & 46 & 46 & 47 & 52 \\
\hline
\end{tabular}

A inércia térmica é variável de grande sensibilidade para a temperatura dos gases quentes do compartimento. Observe que valores menores de "inércia" térmica $(b)$ 
propiciam maior mobilidade da temperatura, traduzida por temperaturas dos gases mais elevadas e resfriamento brusco (Figura 6-8).

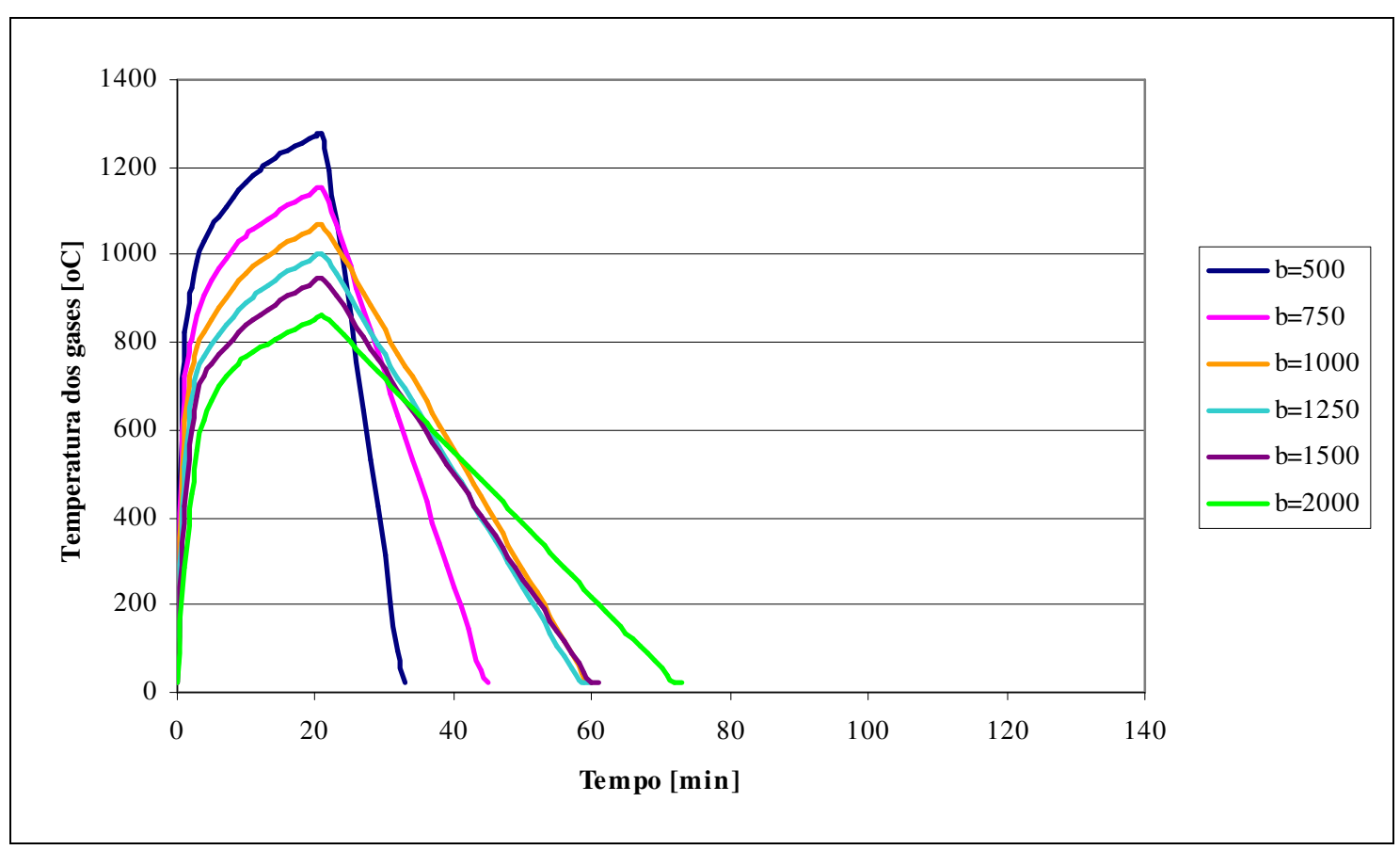

Figura 6-8 - Temperatura dos gases conforme características térmicas das vedações. 


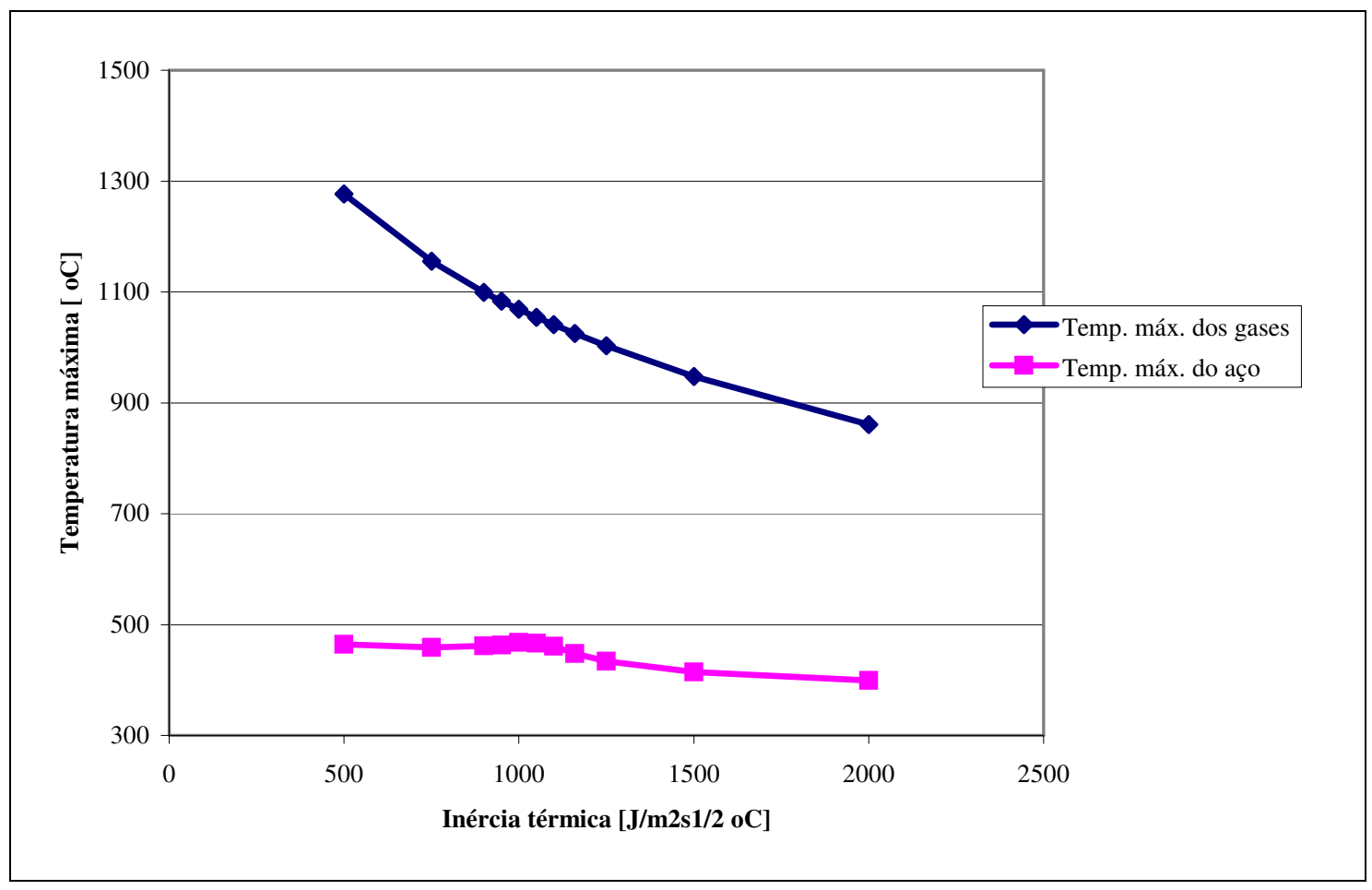

Figura 6-9 - Temperatura máxima dos gases e do aço conforme inércia térmica das vedações.

Já a temperatura do elemento de aço pouco se alterou para variação de inércia térmica das vedações, acusando baixa sensibilidade. Os esforços resistentes encontrados para um perfil de aço W 310 x 28,3 estão expostos na Tabela 6-8.

Tabela 6-8 - Esforços resistentes conforme inércia térmica das vedações

\begin{tabular}{|l|l|l|l|l|l|l|}
\cline { 2 - 7 } \multicolumn{1}{c|}{} & \multicolumn{5}{c|}{$\mathrm{b}\left[\mathrm{J} / \mathrm{m}^{2} \mathrm{~s}^{1 / 2}{ }^{\circ} \mathrm{C}\right]$} \\
\cline { 2 - 7 } \multicolumn{1}{c|}{} & 500 & 750 & 1000 & 1250 & 1500 & 2000 \\
\hline Esforço resistente de tração [kN] & 783,0 & 794,9 & 782,5 & 844,2 & 884,0 & 912,5 \\
\hline Esforço resistente de compressão [kN] & 282,9 & 286,2 & 282,8 & 299,7 & 310,5 & 318,4 \\
\hline Esforço resistente de flexão simples [kN.m] & 56,3 & 57,0 & 56,2 & 60,1 & 62,6 & 64,3 \\
\hline
\end{tabular}

\subsection{ALTURA DO COMPARTIMENTO E ÁREA TOTAL}

Neste item, está exposta a análise paramétrica considerando a variação da altura do compartimento $\left(h_{c}\right)$. A altura livre terá impacto na área das paredes e assim, na área total 
(Tabela 6-9). A área de piso está fixada em $100 \mathrm{~m}^{2}$ (10x10). Dada a pequena variação na área total, todas as análises são para incêndios controlados pela ventilação.

Tabela 6-9 - Correlação entre altura e área total do compartimento

\begin{tabular}{|l|c|c|c|c|c|c|}
\hline Altura livre $[\mathrm{m}]$ & 2,6 & 2,8 & 3,0 & 3,2 & 3,4 & 3,6 \\
\hline Área total $\left[\mathrm{m}^{2}\right]$ & 304 & 312 & 320 & 328 & 336 & 344 \\
\hline
\end{tabular}

A temperatura dos gases foi pouco influenciada pela altura do compartimento, assim como o tempo para atingir à temperatura máxima (Tabela 6-10). Porém foi observado que em compartimentos de altura maior, e assim de maior área total (maior volume de gases), a temperatura tende a ser menor, bem como no aço.

Tabela 6-10 - Temperaturas máximas dos gases e do aço conforme altura do compartimento

\begin{tabular}{|l|l|l|l|l|l|l|}
\cline { 2 - 7 } \multicolumn{1}{c|}{} & \multicolumn{7}{c|}{$\mathrm{h}_{\mathrm{c}}[\mathrm{m}]$} \\
\cline { 2 - 7 } \multicolumn{1}{c|}{} & \multicolumn{1}{c|}{2,6} & \multicolumn{1}{c|}{2,8} & 3,0 & \multicolumn{1}{c|}{3,2} & \multicolumn{1}{c|}{3,4} & \multicolumn{1}{c|}{3,6} \\
\hline Temp. máxima dos gases $\left[{ }^{\circ} \mathrm{C}\right]$ & 963,3 & 955,4 & 947,6 & 939,9 & 932,5 & 925,3 \\
\hline $\begin{array}{l}\text { Tempo p/ temp. máxima dos gases } \\
{[\mathrm{min}]}\end{array}$ & 21 & 21 & 21 & 21 & 21 & 21 \\
\hline Temp. máxima do aço [ $\left.{ }^{\circ} \mathrm{C}\right]$ & 418,6 & 416,3 & 414,2 & 412,3 & 410,6 & 409,0 \\
\hline Tempo p/ temp. máxima do aço [min] & 46 & 46 & 47 & 47 & 47 & 48 \\
\hline
\end{tabular}

A altura do compartimento pouco influencia na temperatura do elemento de aço, sendo irrelevante no dimensionamento de estruturas em situação de incêndio. Os resultados dos esforços resistente em um perfil W 310 x 28,3 estão expostos na Tabela 6-11.

Tabela 6-11 - Esforços resistentes conforme altura do compartimento

\begin{tabular}{|l|c|c|c|c|c|c|}
\cline { 2 - 7 } \multicolumn{1}{c|}{} & \multicolumn{7}{c|}{$\mathrm{h}_{\mathrm{c}}[\mathrm{m}]$} \\
\cline { 2 - 7 } \multicolumn{1}{c|}{} & 2,6 & 2,8 & 3,0 & 3,2 & 3,4 & 3,6 \\
\hline Esforço resistente de tração [kN] & 875,1 & 879,9 & 884,1 & 887,8 & 891,3 & 894,5 \\
\hline Esforço resistente de compressão [kN] & 308,1 & 309,4 & 310,5 & 311,5 & 312,5 & 313,3 \\
\hline Esforço resistente de flexão simples [kN.m] & 62,0 & 62,3 & 62,6 & 62,8 & 63,0 & 63,2 \\
\hline
\end{tabular}

Em outra análise paramétrica, entretanto, com área de piso de $300 \mathrm{~m}^{2}$ (20x15), para reforçar a influência das área de paredes e realizar um estudo comparativo entre as área 
totais (Tabela 6-12), encontrou-se um incêndio controlado pelo ventilação em todas as alturas de compartimentos, com os resultados apresentados na Tabela 6-13.

Tabela 6-12 - Correlação entre altura e área total do compartimento

\begin{tabular}{|l|c|c|c|c|c|c|}
\hline Altura livre $[\mathrm{m}]$ & 2,6 & 2,8 & 3,0 & 3,2 & 3,4 & 3,6 \\
\hline Área total $\left[\mathrm{m}^{2}\right]$ & 782 & 796 & 810 & 824 & 838 & 852 \\
\hline
\end{tabular}

Tabela 6-13 - Temperaturas máximas dos gases e do aço conforme altura do compartimento

\begin{tabular}{|l|l|l|l|l|l|l|}
\cline { 2 - 7 } \multicolumn{1}{c|}{} & \multicolumn{7}{c|}{$\mathrm{h}_{\mathrm{c}}[\mathrm{m}]$} \\
\cline { 2 - 7 } \multicolumn{1}{c|}{} & \multicolumn{1}{c|}{2,6} & \multicolumn{1}{c|}{2,8} & 3,0 & 3,2 & \multicolumn{1}{c|}{3,4} & \multicolumn{1}{c|}{3,6} \\
\hline Temp. máxima dos gases [ $\left.{ }^{\circ} \mathrm{C}\right]$ & 844,7 & 839,8 & 835,0 & 830,4 & 825,9 & 821,6 \\
\hline $\begin{array}{l}\text { Tempo p/ temp. máxima dos gases } \\
{[\mathrm{min}]}\end{array}$ & 63 & 63 & 63 & 63 & 63 & 63 \\
\hline Temp. máxima do aço [ $\left.{ }^{\circ} \mathrm{C}\right]$ & 605,0 & 603,1 & 601,6 & 600,2 & 598,8 & 597,5 \\
\hline Tempo p/ temp. máxima do aço [min] & 114 & 115 & 116 & 116 & 117 & 119 \\
\hline
\end{tabular}

Com relação à área de piso $100 \mathrm{~m}^{2}\left(A_{t}=320 \mathrm{~m}^{2}\right)$ e $300 \mathrm{~m}^{2}\left(A_{t}=810 \mathrm{~m}^{2}\right)$ com altura do compartimento fixada em 3,0m, observou-se que em uma maior área mantendo-se a área de ventilação a temperatura é significativamente menor e o tempo em que se atinge a temperatura máxima é maior, proporcional a área de piso. Já para o aço, ocorre o oposto, em uma área maior a temperatura do aço tende a ser significativamente maior.

Nos itens a seguir, os elementos de aço são submetidos ao mesmo cenário de incêndio, representada pela Figura 6-10 e pela Tabela 6-14. 


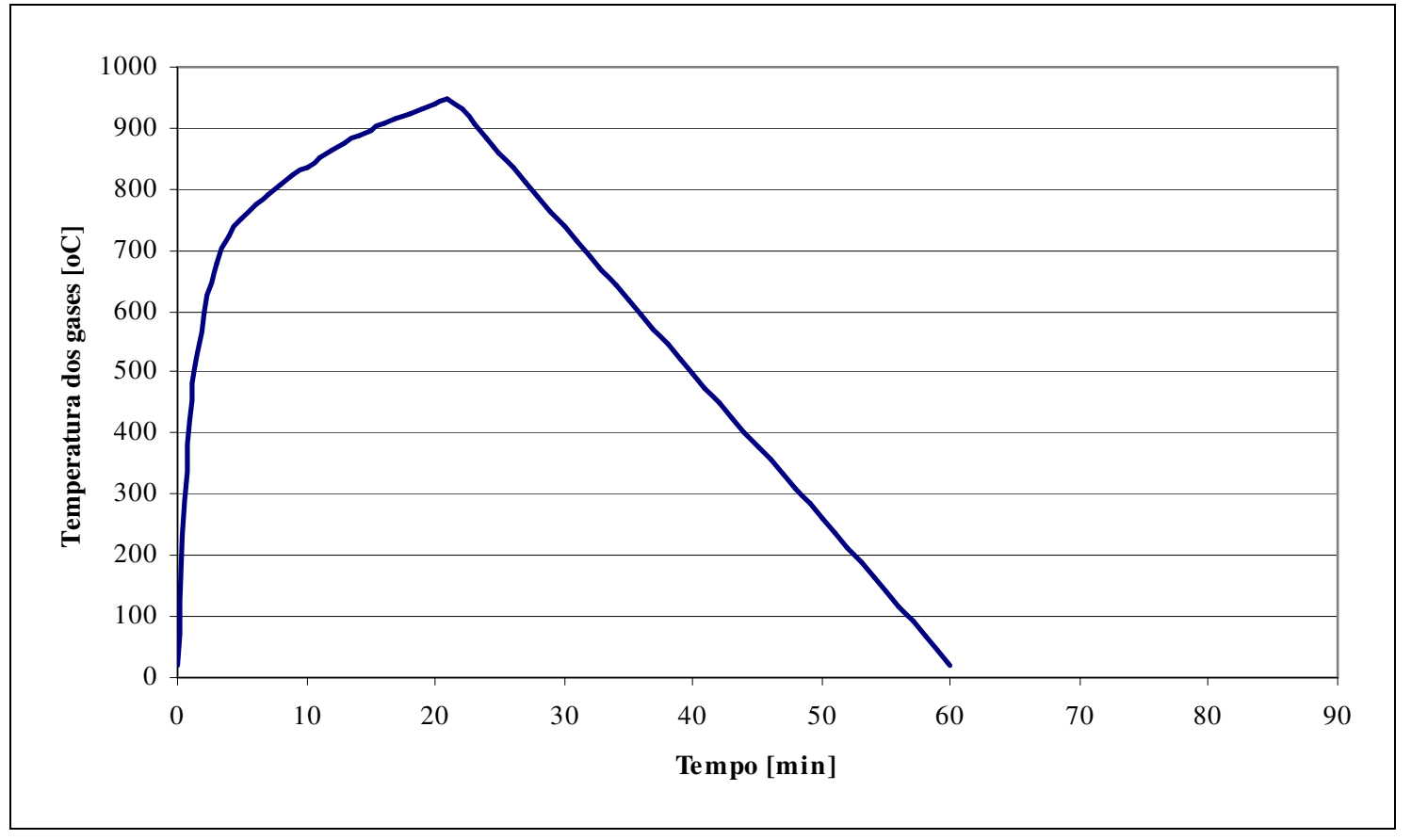

Figura 6-10 - Temperatura dos gases para os itens 6.6 a 6.8

Tabela 6-14- Temperatura dos gases conforme Figura 6-10.

\begin{tabular}{|l|l|l|l|l|l|}
\hline $\begin{array}{l}\text { Tempo } \\
{[\mathrm{min}]}\end{array}$ & $\begin{array}{l}\text { Temperatura } \\
{\left[{ }^{\circ} \mathrm{C}\right]}\end{array}$ & $\begin{array}{l}\text { Tempo } \\
{[\mathrm{min}]}\end{array}$ & $\begin{array}{l}\text { Temperatura } \\
{\left[{ }^{\circ} \mathrm{C}\right]}\end{array}$ & $\begin{array}{l}\text { Tempo } \\
{[\mathrm{min}]}\end{array}$ & $\begin{array}{l}\text { Temperatura } \\
{\left[{ }^{\circ} \mathrm{C}\right]}\end{array}$ \\
\hline 0 & 20 & 21 & 947,6 & 42 & 451,4 \\
\hline 1 & 423,1 & 22 & 930,3 & 43 & 427,4 \\
\hline 2 & 596,6 & 23 & 906,3 & 44 & 403,5 \\
\hline 3 & 678,2 & 24 & 882,4 & 45 & 379,5 \\
\hline 4 & 722,5 & 25 & 858,4 & 46 & 355,6 \\
\hline 5 & 751,3 & 26 & 834,5 & 47 & 331,6 \\
\hline 6 & 773,1 & 27 & 810,5 & 48 & 307,7 \\
\hline 7 & 791,6 & 28 & 786,6 & 49 & 283,8 \\
\hline 8 & 808,1 & 29 & 762,6 & 50 & 259,8 \\
\hline 9 & 823,2 & 30 & 738,7 & 51 & 235,9 \\
\hline 10 & 837,3 & 31 & 714,8 & 52 & 211,9 \\
\hline 11 & 850,5 & 32 & 690,8 & 53 & 188,0 \\
\hline 12 & 862,9 & 33 & 666,9 & 54 & 164,0 \\
\hline 13 & 874,6 & 34 & 642,9 & 55 & 140,1 \\
\hline 14 & 885,6 & 35 & 619,0 & 56 & 116,1 \\
\hline 15 & 895,9 & 36 & 595,0 & 57 & 92,2 \\
\hline 16 & 905,7 & 37 & 571,1 & 58 & 68,3 \\
\hline 17 & 915,0 & 38 & 547,1 & 59 & 44,3 \\
\hline
\end{tabular}




\begin{tabular}{|l|l|l|l|l|l|}
\hline 18 & 923,8 & 39 & 523,2 & 60 & 20,4 \\
\hline 19 & 932,1 & 40 & 499,3 & 61 & 20,0 \\
\hline 20 & 940 & 41 & 475,3 & 62 & 20,0 \\
\hline
\end{tabular}

\subsection{FATOR DE MASSIVIDADE}

Neste item, está exposta a análise paramétrica considerando a variação do fator de massividade $(F)$. Os valores de temperatura e de tempo decorrido para obtenção da temperatura máxima do elemento de aço estão expostos na Tabela 6-15.

A análise mostrou que quanto maior for à área superficial exposta ao calor em relação ao volume do perfil, ou seja, maior o fator de massividade, mais rápido será a elevação da temperatura e maior à temperatura máxima. A maior área superficial exposta em relação ao volume, também aumenta a velocidade de resfriamento do aço como apresentado na Figura 6-11.

Tabela 6-15 - Temperaturas máximas do aço conforme fator de massividade.

\begin{tabular}{|l|c|c|c|c|c|c|}
\cline { 2 - 7 } \multicolumn{1}{c|}{} & \multicolumn{6}{c|}{$\mathrm{F}\left[\mathrm{m}^{-1}\right]$} \\
\cline { 2 - 7 } \multicolumn{1}{c|}{} & 50 & 100 & 150 & 200 & 250 & 300 \\
\hline Temp. máxima do aço $\left[{ }^{\circ} \mathrm{C}\right]$ & 185,8 & 287,5 & 359,7 & 414,2 & 457,0 & 491,7 \\
\hline Tempo p/ temp. máxima do aço [min] & 56 & 51 & 49 & 47 & 45 & 44 \\
\hline
\end{tabular}

O fator de massividade mostrou ser uma variável de grande sensibilidade. Dada a grande eficiência em amortizar a temperatura do elemento de aço, a integração dos elementos de aço com outros elementos da estrutura pode ser extremamente vantajosa e até eximir a proteção da peça com revestimento contra fogo. 


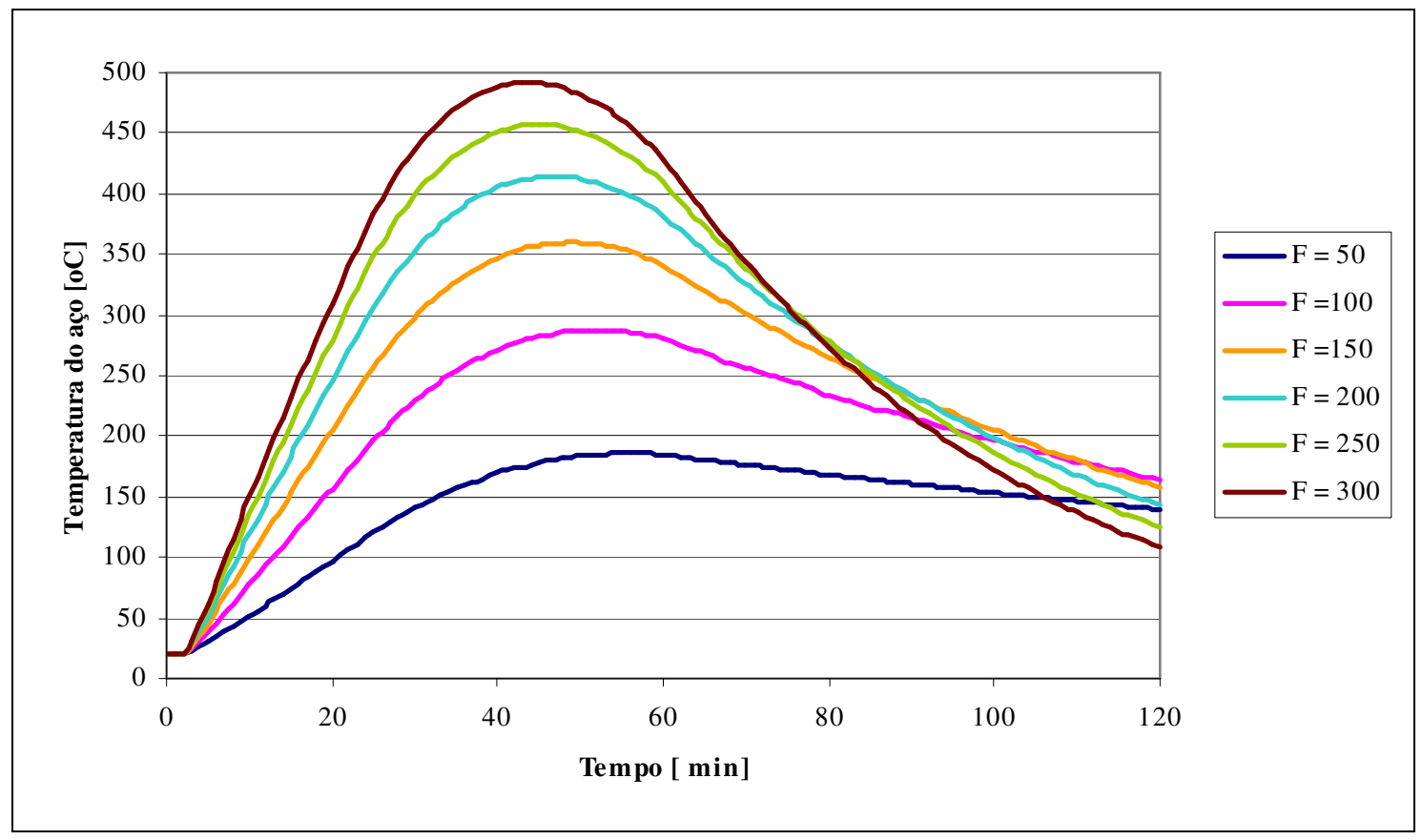

Figura 6-11 - Temperatura do aço conforme fator de massividade

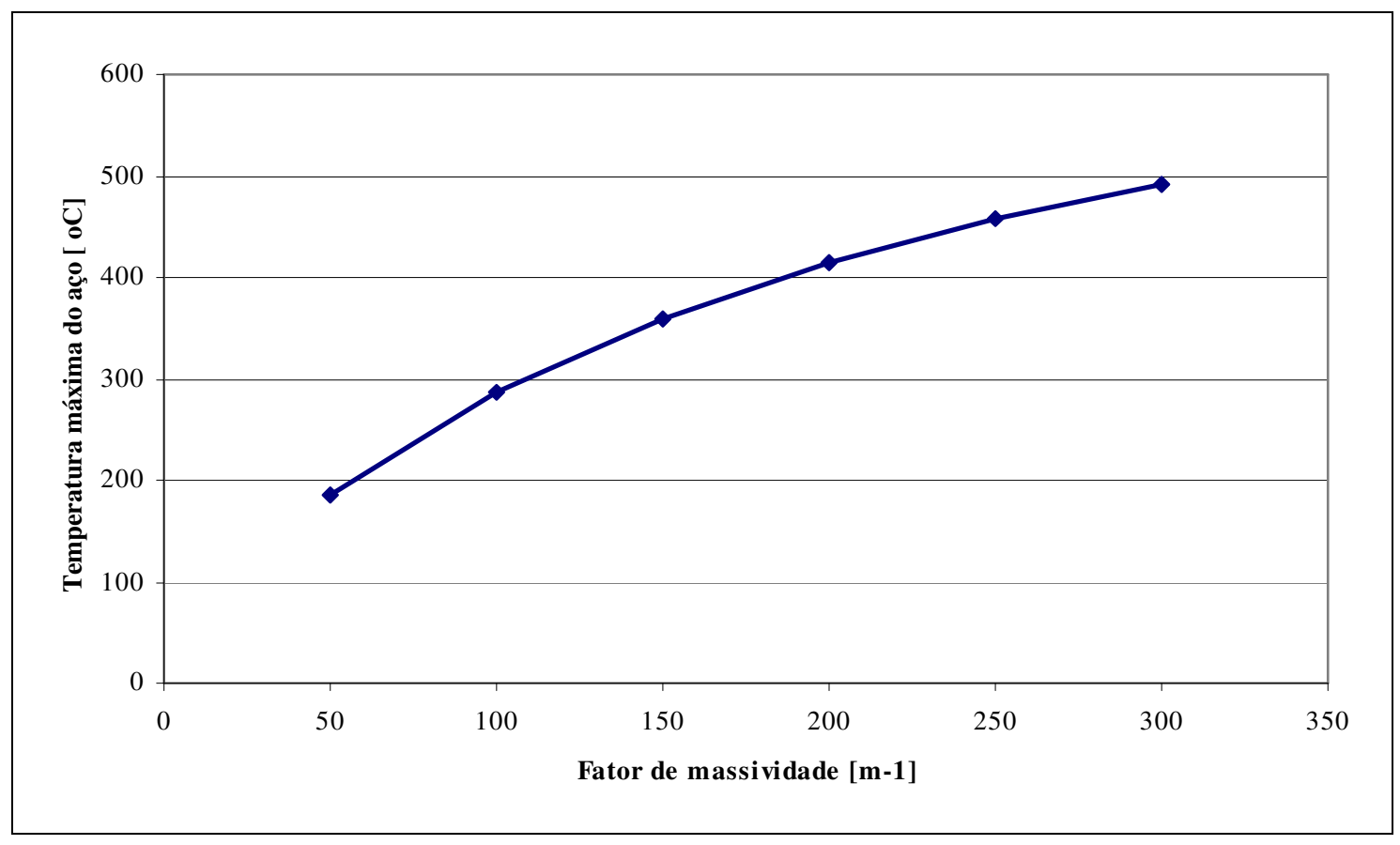

Figura 6-12 - Temperatura máxima do aço conforme fator de massividade 
Para valores baixos do fator de massividade, intervalo em que as temperaturas no elemento de aço não são altas, o fator de massividade mostrou influência menor, entretanto, significativo impacto na determinação dos esforços resistentes, cujos resultados para um perfil W 310 x 28,3 estão expostos na Tabela 6-16.

Tabela 6-16 - Esforços resistentes conforme fator de massividade.

\begin{tabular}{|l|c|c|c|c|c|c|}
\cline { 2 - 7 } \multicolumn{1}{c|}{} & \multicolumn{6}{c|}{$\mathrm{F}\left[\mathrm{m}^{-1}\right]$} \\
\cline { 2 - 7 } \multicolumn{1}{c|}{} & 50 & 100 & 150 & 200 & 250 & 300 \\
\hline Esforço resistente de tração [kN] & 912,5 & 912,5 & 912,5 & 884,1 & 798,0 & 728,5 \\
\hline Esforço resistente de compressão [kN] & 373,7 & 348,9 & 329,6 & 310,5 & 287,0 & 267,9 \\
\hline Esforço resistente de flexão simples [kN.m] & 70,0 & 67,6 & 65,6 & 62,6 & 57,2 & 52,9 \\
\hline
\end{tabular}

\subsection{ESPESSURA DO MATERIAL DE REVESTIMENTO}

Neste item, está exposta a análise paramétrica considerando a variação da espessura do material de revestimento aplicado sobre o elemento de aço. Foi adotado o material de revestimento Blaze Shield II, cujas características térmicas estão descritas na nota de rodapé 30. Os valores de temperatura e de tempo decorrido para obtenção da temperatura máxima estão expostos na Tabela 6-17.

O aço revestido experimentará uma elevação de temperatura muito mais lenta do que o aço sem revestimento. Contudo, a eficiência do material de revestimento na modelagem de transferência de calor dos gases do compartimento para o elemento de aço não é linear como confirmado pela Tabela 6-18 e pela Figura 6-13.

Tabela 6-17 - Temperaturas máximas do aço conforme espessura do material de revestimento.

\begin{tabular}{|l|l|l|l|l|l|l|}
\cline { 2 - 7 } \multicolumn{1}{c|}{} & \multicolumn{6}{c|}{$\mathrm{t}_{\mathrm{m}}[\mathrm{m}]$} \\
\cline { 2 - 7 } \multicolumn{1}{c|}{} & 0,010 & 0,015 & 0,020 & 0,025 & 0,030 & 0,035 \\
\hline Temp. máxima do aço $\left[{ }^{\circ} \mathrm{C}\right]$ & 579,1 & 481,9 & 414,2 & 366,2 & 332,5 & 309,7 \\
\hline Tempo p/ temp. máxima do aço [min] & 37 & 42 & 47 & 50 & 56 & 60 \\
\hline
\end{tabular}




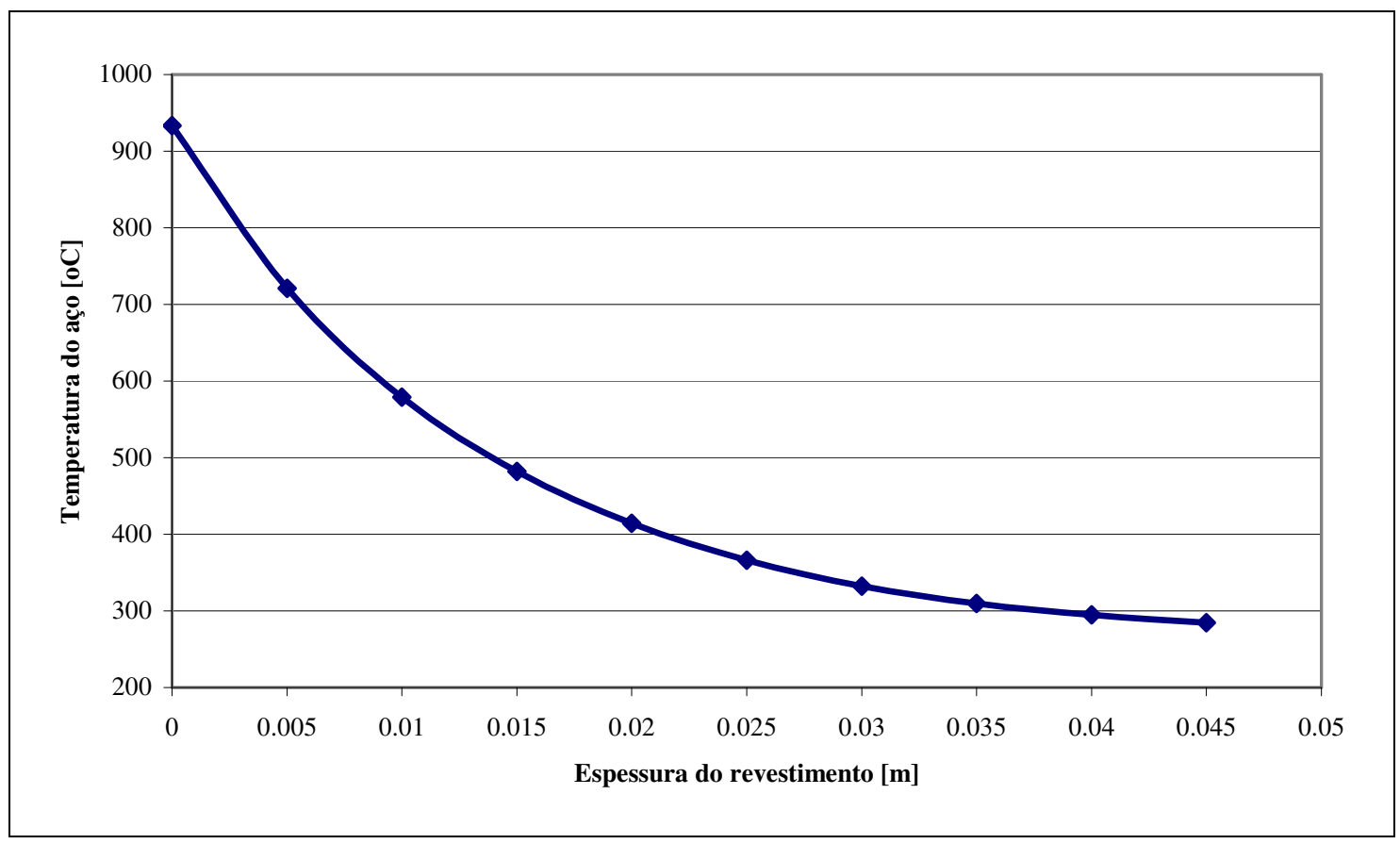

Figura 6-13 - Temperatura do elemento de aço conforme espessura do revestimento contra fogo

Utilizando a modelagem sem revestimento de proteção térmica, a temperatura máxima do aço atingiu $933,4{ }^{\circ} \mathrm{C}$. A Tabela 6-18 mostra a variação de temperatura conforme o aumento da espessura, conseqüentemente, o decréscimo de eficiência na utilização do material de revestimento contra fogo. Também comprova que existe uma espessura de revestimento ideal, ou seja, garante boa proteção sem custo exorbitante. Dada essa característica da modelagem, por vezes, é mais efetivo alterar as características do compartimento do que praticar uma proteção térmica de maior espessura.

Tabela 6-18- Variação de temperatura conforme espessura do revestimento.

\begin{tabular}{|l|c|c|c|c|}
\hline$t_{m}[\mathrm{~cm}]$ & $0 \rightarrow 1$ & $1 \rightarrow 2$ & $2 \rightarrow 3$ & $3 \rightarrow 4$ \\
\hline$\Delta \theta$ & $-354,3$ & $-132,9$ & $-81,7$ & $-37,5$ \\
\hline$\%$ & $-37,95$ & $-22,95$ & $-16,42$ & $-8,15$ \\
\hline
\end{tabular}

A espessura do material de revestimento é uma variável de grande impacto nos casos onde a temperatura é superior aos $400^{\circ} \mathrm{C}$. Os resultados dos esforços resistente em um perfil W 310 x 28,3 estão expostos na Tabela 6-19. 
Tabela 6-19 - Esforços resistentes conforme espessura do revestimento contra fogo.

\begin{tabular}{|l|l|l|l|l|l|l|}
\cline { 2 - 7 } \multicolumn{1}{c|}{} & \multicolumn{6}{c|}{$\mathrm{t}_{\mathrm{m}}[\mathrm{m}]$} \\
\cline { 2 - 7 } \multicolumn{1}{c|}{} & 0,010 & 0,015 & 0,020 & 0,025 & 0,030 & 0,035 \\
\hline Esforço resistente de tração [kN] & 487,9 & 748,0 & 884,1 & 912,5 & 912,5 & 912,5 \\
\hline Esforço resistente de compressão [kN] & 169,0 & 273,3 & 310,5 & 327,9 & 337,1 & 343,1 \\
\hline Esforço resistente de flexão simples [kN.m] & 34,3 & 54,1 & 62,6 & 65,4 & 66,4 & 67,0 \\
\hline
\end{tabular}

\subsection{CARACTERÍSTICAS TÉRMICAS DO MATERIAL DE REVESTIMENTO CONTRA FOGO}

Diferentemente, das características térmicas das vedações (item 1.3.2.2 e 6.4), as características térmicas dos materiais de revestimento contra fogo possuem pesos diferentes na equação de transferência de calor (eq. 3.6). Portanto serão estudadas isoladamente nos itens de 6.8.1 a 6.8.3.

Os valores padrão dos parâmetros não variantes é o do material de revestimento Blaze Shield II, cujas características térmicas estão descritas na nota de rodapé 30.

\subsubsection{MASSA ESPECÍFICA}

Neste item, está exposta a análise paramétrica considerando a variação da massa específica do material de revestimento contra fogo $\left(\rho_{m}\right)$. Para este item foi estudado o comportamento da variação da massa específica do material de revestimento contra fogo entre duas equações, a presente no EC3 (eq. 3.6) e a de Silva (eq. 3.9) como mostrada na Tabela 6-20.

Tabela 6-20 - Temperaturas máximas do aço conforme massa específica do revestimento contra fogo.

\begin{tabular}{|l|c|c|c|c|c|c|}
\cline { 2 - 7 } \multicolumn{1}{c|}{} & \multicolumn{6}{c|}{$\rho_{\mathrm{m}}\left[\mathrm{kg} / \mathrm{m}^{3}\right]$} \\
\cline { 2 - 7 } \multicolumn{1}{c|}{} & 100 & 200 & 300 & 500 & 1000 & 2000 \\
\hline Temp. máxima do aço $\left[{ }^{\circ} \mathrm{C}\right]-$ eq. 3.6 & 427,0 & 417,3 & 410,2 & 403,3 & 424,6 & 548,6 \\
\hline Temp. máxima do aço $\left[{ }^{\circ} \mathrm{C}\right]-$ eq. 3.9 & 436,8 & 439,1 & 444,0 & 458,6 & 507,1 & 576,6 \\
\hline
\end{tabular}


Observou-se que os resultados obtidos pela equação do EC3 não apresentam uma clara tendência, devido à parcela exponencial que proporciona uma inflexão no gráfico (Figura 6-14). Inicia-se com uma tendência de redução de temperatura do aço, porém, após a inflexão mostra forte aumento.

Já a equação de Silva (eq. 3.9) apresenta uma clara relação entre a massa específica do revestimento contra fogo com a temperatura do aço. Quanto maior a massa específica, maior a temperatura do aço, já que, a densidade proporciona uma maior retenção do calor, entretanto, a maior densidade impede a transferência de calor para o elemento de aço nos primeiros instantes do incêndio.

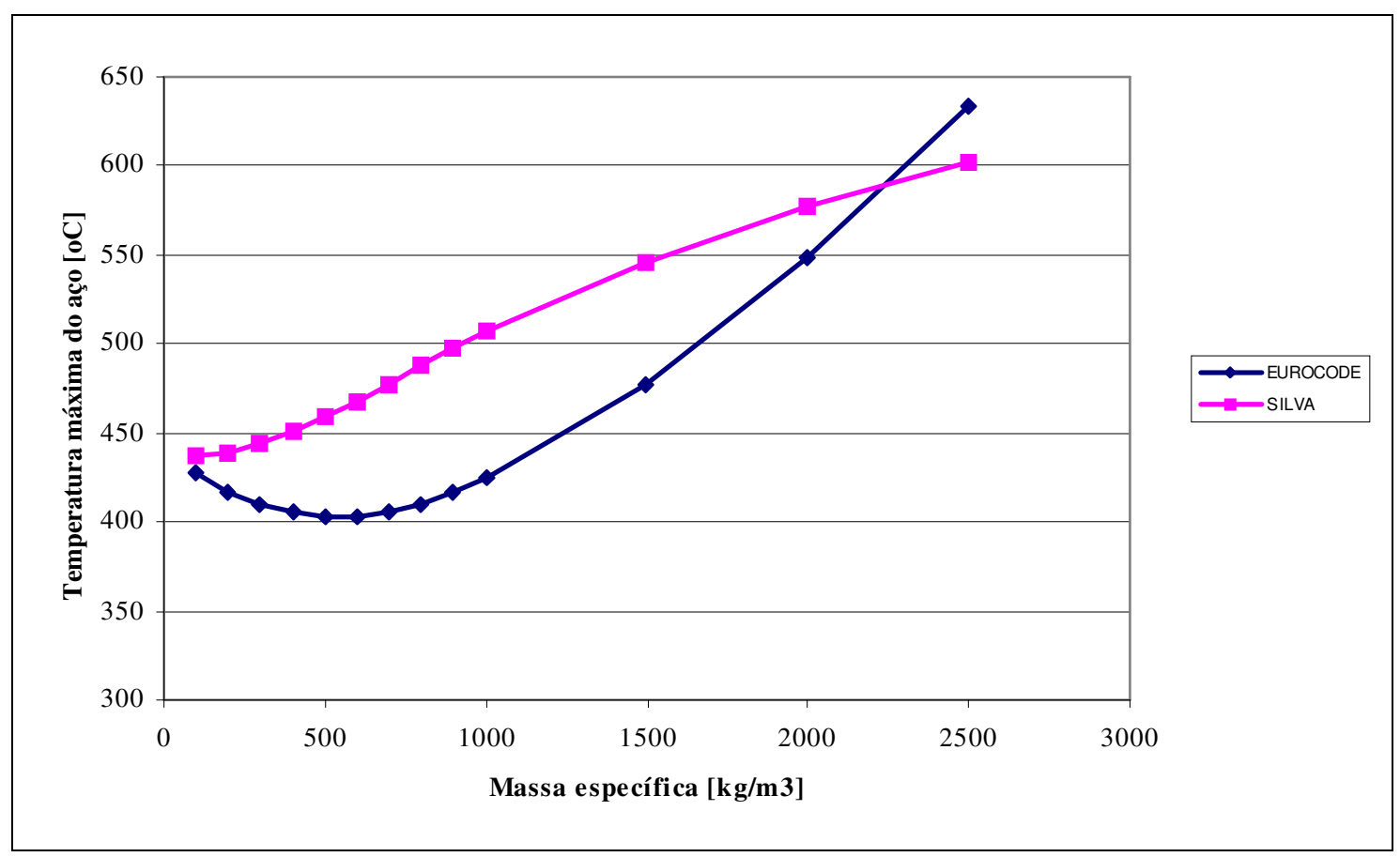

Figura 6-14 - Temperaturas máximas do aço conforme massa específica do revestimento contra fogo

A sensibilidade da temperatura no elemento de aço é classificada conforme o intervalo da massa específica. Representa uma pequena variação para valores menores de massa específica, e aumenta significativamente, conforme se aumenta os valores de massa específica. Os resultados dos esforços resistente em um perfil W 310 x 28,3 estão expostos na Tabela 6-21. 
Tabela 6-21 - Esforços resistentes conforme massa específica do material de revestimento contra fogo.

\begin{tabular}{|l|l|c|c|c|c|c|}
\cline { 2 - 7 } \multicolumn{1}{c|}{} & \multicolumn{6}{c|}{$\rho_{\mathrm{m}}\left[\mathrm{kg} / \mathrm{m}^{3}\right]$} \\
\cline { 2 - 7 } \multicolumn{1}{c|}{} & 100 & 200 & 300 & 500 & 1000 & 2000 \\
\hline Esforço resistente de tração [kN] & 858,3 & 877,7 & 892,0 & 906,0 & 863,1 & 574,3 \\
\hline Esforço resistente de compressão [kN] & 303,5 & 308,8 & 312,7 & 316,4 & 304,8 & 205,6 \\
\hline Esforço resistente de flexão simples [kN.m] & 61,0 & 62,2 & 63,1 & 63,9 & 61,3 & 41,1 \\
\hline
\end{tabular}

\subsubsection{CALOR ESPECÍFICO}

Neste item, está exposta a análise paramétrica considerando a variação do calor específico do material de revestimento contra fogo $\left(c_{m}\right)$. Materiais de maior calor específico transferem menos calor a peça de aço de acordo com a equação de transferência de calor do EC3 e mais calor pela equação de Silva, contudo, possuem pequena influência na temperatura máxima do aço como mostrada na Tabela 6-22.

Tabela 6-22 - Temperaturas máximas do aço conforme calor específico do revestimento contra fogo.

\begin{tabular}{|l|r|r|r|r|r|r|}
\cline { 2 - 7 } \multicolumn{1}{c|}{} & \multicolumn{5}{c|}{$\mathrm{c}_{\mathrm{m}}\left[\mathrm{J} / \mathrm{kg}{ }^{\circ} \mathrm{C}\right]$} \\
\cline { 2 - 7 } \multicolumn{1}{c|}{} & 1000 & 1500 & 2000 & 2500 & 3000 & 3500 \\
\hline Temp. máxima do aço $\left[{ }^{\circ} \mathrm{C}\right]-$ eq. 3.6 & 426,5 & 421,1 & 416,6 & 412,7 & 409,5 & 406,9 \\
\hline Temp. máxima do aço $\left[{ }^{\circ} \mathrm{C}\right]-$ eq. 3.9 & 436,8 & 437,7 & 439,5 & 441,8 & 444,8 & 448,1 \\
\hline
\end{tabular}




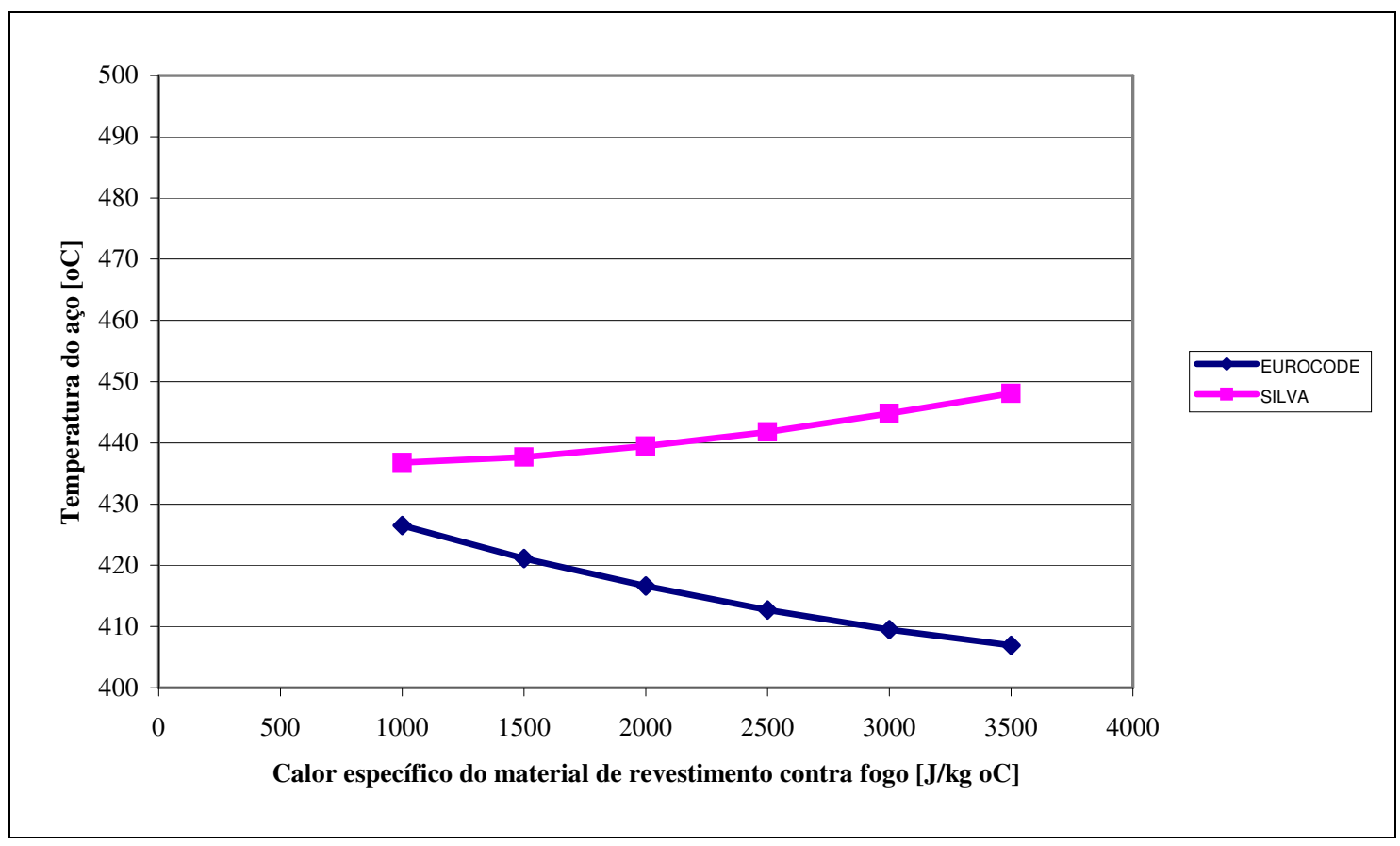

Figura 6-15 - Temperaturas máximas do aço conforme calor específico do revestimento contra fogo

A pequena alteração de temperatura no elemento de aço pela equação 3.6, retrata a pequena variação nos esforços resistentes. Os resultados dos esforços resistente em um perfil W 310 x 28,3 estão expostos na Tabela 6-23.

Tabela 6-23 - Esforços resistentes conforme calor específico do material de revestimento contra fogo

\begin{tabular}{|l|r|r|r|r|r|r|}
\cline { 2 - 7 } \multicolumn{1}{c|}{} & \multicolumn{6}{c|}{$\mathrm{c}_{\mathrm{m}}\left[\mathrm{J} / \mathrm{kg} .{ }^{\circ} \mathrm{C}\right]$} \\
\cline { 2 - 7 } \multicolumn{1}{c|}{} & 1000 & 1500 & 2000 & 2500 & 3000 & 3500 \\
\hline Esforço resistente de tração [kN] & 859,3 & 870,1 & 879,1 & 887,1 & 893,5 & 898,6 \\
\hline Esforço resistente de compressão [kN] & 303,7 & 306,7 & 309,2 & 311,3 & 313,0 & 314,4 \\
\hline Esforço resistente de flexão simples [kN.m] & 61,0 & 61,7 & 62,3 & 62,7 & 63,1 & 63,5 \\
\hline
\end{tabular}

\subsubsection{CONDUTIVIDADE TÉRMICA}

Neste item, está exposta a análise paramétrica considerando a variação da condutividade térmica do material de revestimento contra fogo $\left(\lambda_{m}\right)$. Materiais de maior condutividade térmica transferem maior fluxo de calor a peça de aço, mostrando-se uma variável determinante para atestar o desempenho do revestimento contra fogo. A alta 
sensibilidade da temperatura em relação à condutividade térmica está expressa na Tabela 6-24.

Tabela 6-24 - Temperaturas máximas do aço conforme condutividade térmica do revestimento contra fogo.

\begin{tabular}{|l|c|c|c|c|c|c|}
\cline { 2 - 6 } \multicolumn{1}{c|}{} & \multicolumn{6}{c|}{$\lambda_{\mathrm{m}}\left[\mathrm{W} / \mathrm{m} .{ }^{\circ} \mathrm{C}\right]$} \\
\cline { 2 - 7 } \multicolumn{1}{c|}{} & 0,10 & 0,15 & 0,20 & 0,25 & 0,30 & 0,35 \\
\hline Temp. máxima do aço $\left[{ }^{\circ} \mathrm{C}\right]-$ eq. 3.6 & 334,3 & 414,2 & 476,1 & 525,5 & 565,9 & 599,6 \\
\hline Temp. máxima do aço $\left[{ }^{\circ} \mathrm{C}\right]$ - eq. 3.9 & 367,9 & 440,7 & 498,4 & 544,5 & 582,7 & 614,6 \\
\hline
\end{tabular}

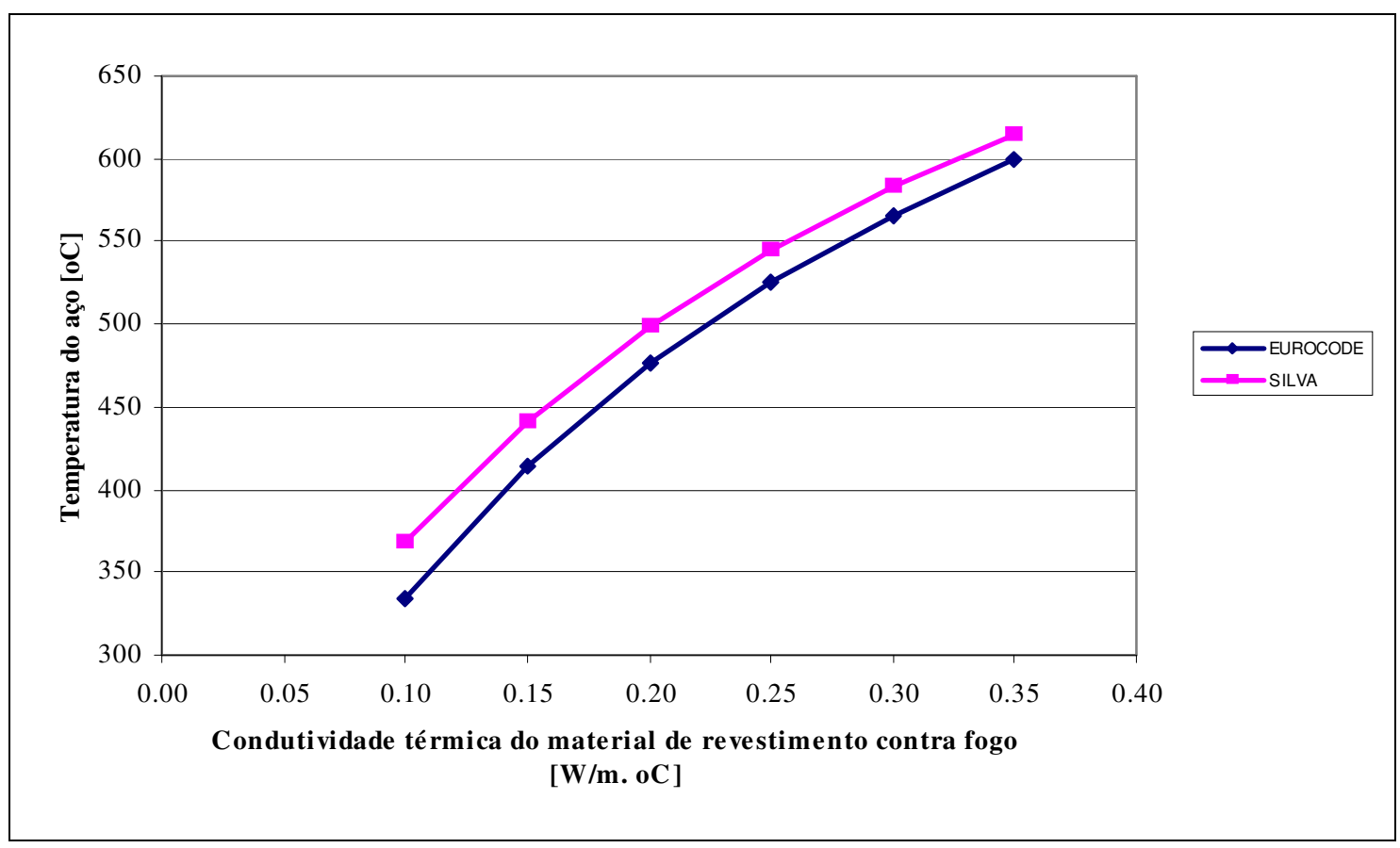

Figura 6-16 - Temperaturas máximas do aço conforme condutividade térmica do revestimento contra fogo

A alta sensibilidade da temperatura do aço em relação à condutividade térmica do revestimento contra o fogo é traduzida em grandes decréscimos na magnitude dos esforços resistentes, ao contrário do calor específico. Os resultados dos esforços resistente em um perfil W 310 x 28,3 estão expostos Tabela 6-25. 
Tabela 6-25 - Esforços resistentes conforme condutividade térmica de revestimento contra fogo

\begin{tabular}{|l|c|c|c|c|c|c|}
\cline { 2 - 7 } \multicolumn{1}{c|}{} & \multicolumn{6}{c|}{$\lambda_{\mathrm{m}}\left[\mathrm{W} / \mathrm{m} .{ }^{\circ} \mathrm{C}\right]$} \\
\cline { 2 - 7 } \multicolumn{1}{c|}{} & 0,10 & 0,15 & 0,20 & 0,25 & 0,30 & 0,35 \\
\hline Esforço resistente de tração [kN] & 912,5 & 884,1 & 759,8 & 639,8 & 525,2 & 429,9 \\
\hline Esforço resistente de compressão [kN] & 336,6 & 310,5 & 276,5 & 233,1 & 184,8 & 144,4 \\
\hline Esforço resistente de flexão simples [kN.m] & 66,3 & 62,6 & 54,8 & 46,2 & 37,2 & 29,7 \\
\hline
\end{tabular}

\section{CONCLUSÕES}

A partir da análise paramétrica apresentada nos itens anteriores, foi possível extrair as seguintes conclusões:

- O modelo atual de curva paramétrica do EC1(2002) atribui a incêndios controlados pelo combustível, valores de temperatura bastante inferiores aos incêndios controlados pela ventilação. Dessa forma, é conveniente ao projetista, na tentativa de reduzir a ação térmica a que será submetida à estrutura buscar por parâmetros que tornem o incêndio controlado pelo combustível;

- Nos casos em que os parâmetros do incêndio natural favoreçam o desenvolvimento do incêndio e por conseqüência propiciem valores maiores de temperatura dos gases, por vezes, não se refletem em aumento de temperatura do aço. Parâmetros favoráveis (exemplo: aumento da área de ventilação) aceleram a queima do combustível, e portanto, aceleram a fase de resfriamento do incêndio;

- Alguns parâmetros do incêndio natural como a inércia térmica das vedações e o pé direito do compartimento não apresenta significativa influência nos esforços resistentes. Outros como a carga de incêndio, afetam rigorosamente os esforços resistentes;

- O fator de massividade mostrou ser uma variável de grande sensibilidade. Dada a grande eficiência em amortizar a temperatura do elemento de aço, a integração dos elementos de aço com outros elementos da estrutura pode ser extremamente vantajosa e até eximir a proteção da peça com revestimento contra fogo; 
- A condutividade térmica é a característica mais importante do revestimento contra fogo. A alta sensibilidade da temperatura do aço em relação à condutividade térmica do revestimento contra o fogo é traduzida em grandes decréscimos na magnitude dos esforços resistentes, ao contrário do calor específico;

- A massa específica e o calor específico têm influência diferenciada de acordo com o método de transferência de calor escolhido;

- A eficiência do material de revestimento contra o fogo não é proporcional à espessura. Dada essa característica da modelagem, por vezes, é mais efetivo alterar as características do compartimento do que praticar uma proteção térmica de maior espessura.

\section{SUGESTÕES PARA FUTUROS TRABALHOS}

\subsection{MELHORIAS AO STRESFIRE}

- Incorporar ao programa de computador a minoração das propriedades mecânicas permanentes do aço ao elevar sua temperatura. Essa benfeitoria é fundamental para averiguar os reais esforços resistentes de uma estrutura atingida por incêndio;

- Incorporar a modelagem do STRESFIRE, o incêndio localizado. O incêndio localizado é o incêndio limitado a uma área do compartimento, ou seja, retrata a fase pré-flashover. Embora a fase pós-flashover seja a mais importante para a engenharia de estruturas, o incêndio localizado pode representar alto risco à estrutura, à medida que afete um elemento estrutural importante, mesmo que isoladamente;

- Inclusão da verificação de perfis submetidos à flexão composta. 


\subsection{OUTROS}

- A partir do STRESFIRE, construir tabelas que permitam a determinação da temperatura crítica para compressão e flexão simples de vigas travadas ou não. 


\section{APÊNDICE A - PROPRIEDADES DO AÇO}

As informações presentes no Anexo A foram extraídas da norma NBR 14323:1999 e do EC3 (2003) e refere-se ao aço carbono, o mais utilizado na construção civil.

\section{A.1.PESO ESPECÍFICO}

O peso específico é uma característica independente da temperatura, cujo valor é $\rho_{a}=$ $7850 \mathrm{~kg} / \mathrm{m}^{3}$;

\section{A.2.CALOR ESPECÍFICO}

A NBR 14323:1999 para cálculos simplificados permite considerar o calor específico independente do tempo $c_{a}=600 \mathrm{~J} / \mathrm{kg} .{ }^{\circ} \mathrm{C}$, porém para cálculos mais precisos utilizar as expressões abaixo também presentes no EC3 (2003).

- $\operatorname{para} 20^{\circ} \mathrm{C} \leq \theta_{a}<600^{\circ} \mathrm{C}$

$c_{a}=425+7,73 \times 10^{-1} \theta_{a}-1,69 \times 10^{-3} \theta_{a}^{2}+2,22 \times 10^{-6} \theta_{a}^{3}$

- $\operatorname{para} 600^{\circ} \mathrm{C} \leq \theta_{a}<735^{\circ} \mathrm{C}$

$c_{a}=666+\frac{13002}{738-\theta_{a}}$

- $\operatorname{para} 735^{\circ} \mathrm{C} \leq \theta_{a}<900^{\circ} \mathrm{C}$

$c_{a}=545+\frac{17820}{\theta_{a}-731}$

- $\operatorname{para} 900^{\circ} \mathrm{C} \leq \theta_{a} \leq 1200^{\circ} \mathrm{C}$

$c_{a}=650$ 


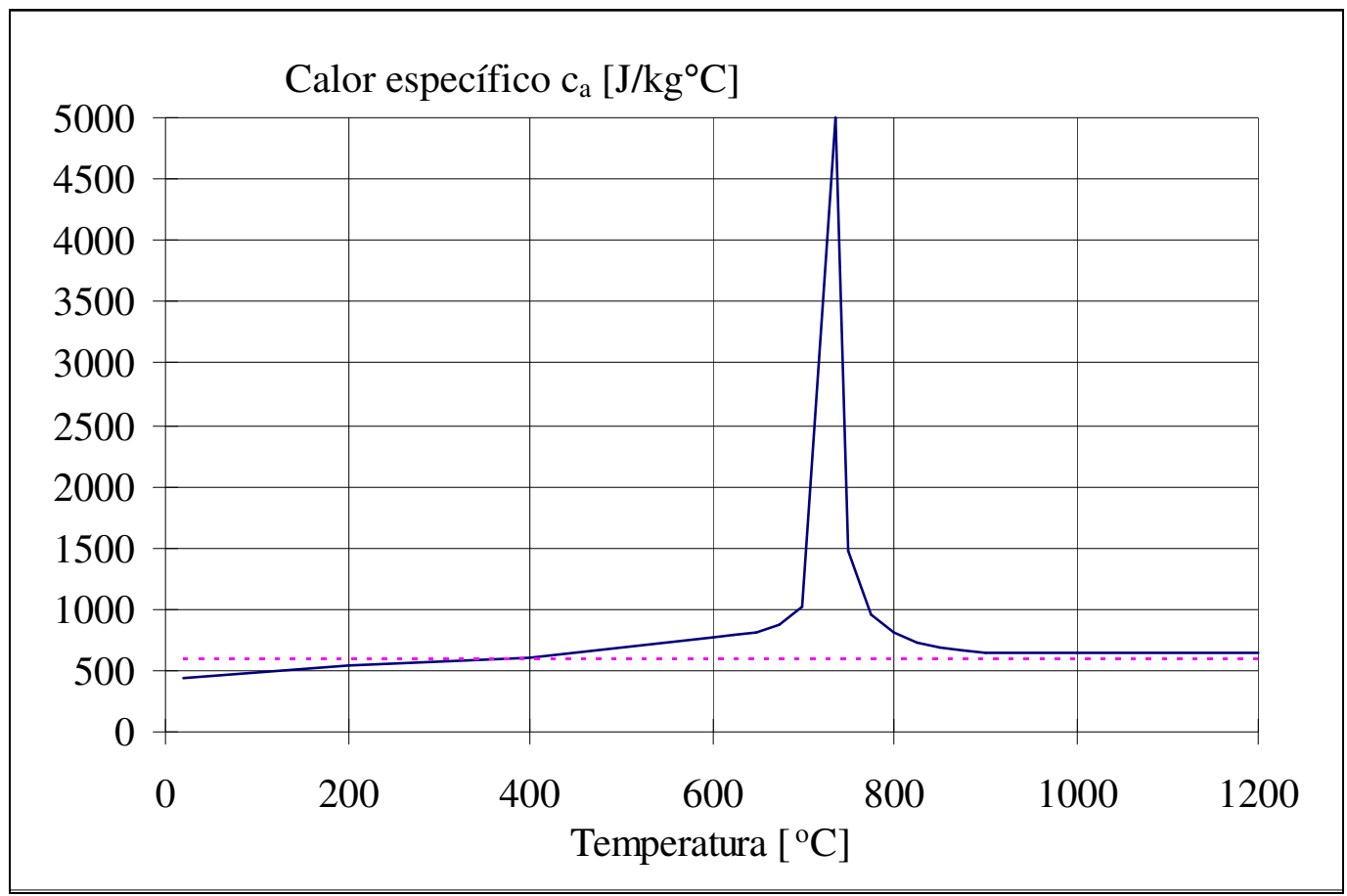

Figura A.1 - Gráfico de calor específico conforme temperatura. Fonte: NBR 14323 (1999).

\section{A.3.CONDUTIVIDADE TÉRMICA}

A norma NBR 14323:1999 recomenda o valor condutividade térmica $\lambda_{a}=45 \mathrm{~W} / \mathrm{m}{ }^{\circ} \mathrm{C}$, em casos simplificados. Para demais casos tanto a NBR 14323:1999 quanto o EC3 (2003) fornecem expressões para o cálculo da condutividade térmica conforme a temperatura:

- $\operatorname{para} 20^{\circ} \mathrm{C} \leq \theta_{a}<800^{\circ} \mathrm{C}$

$\lambda_{a}=54-3,33 \times 10^{-2} \theta_{a}$

- $\operatorname{para} 800^{\circ} \mathrm{C} \leq \theta_{a} \leq 1200^{\circ} \mathrm{C}$

$\lambda_{a}=27,3$

Onde: 
$\theta_{a}$ é a temperatura do aço em ${ }^{\circ} \mathrm{C}$.

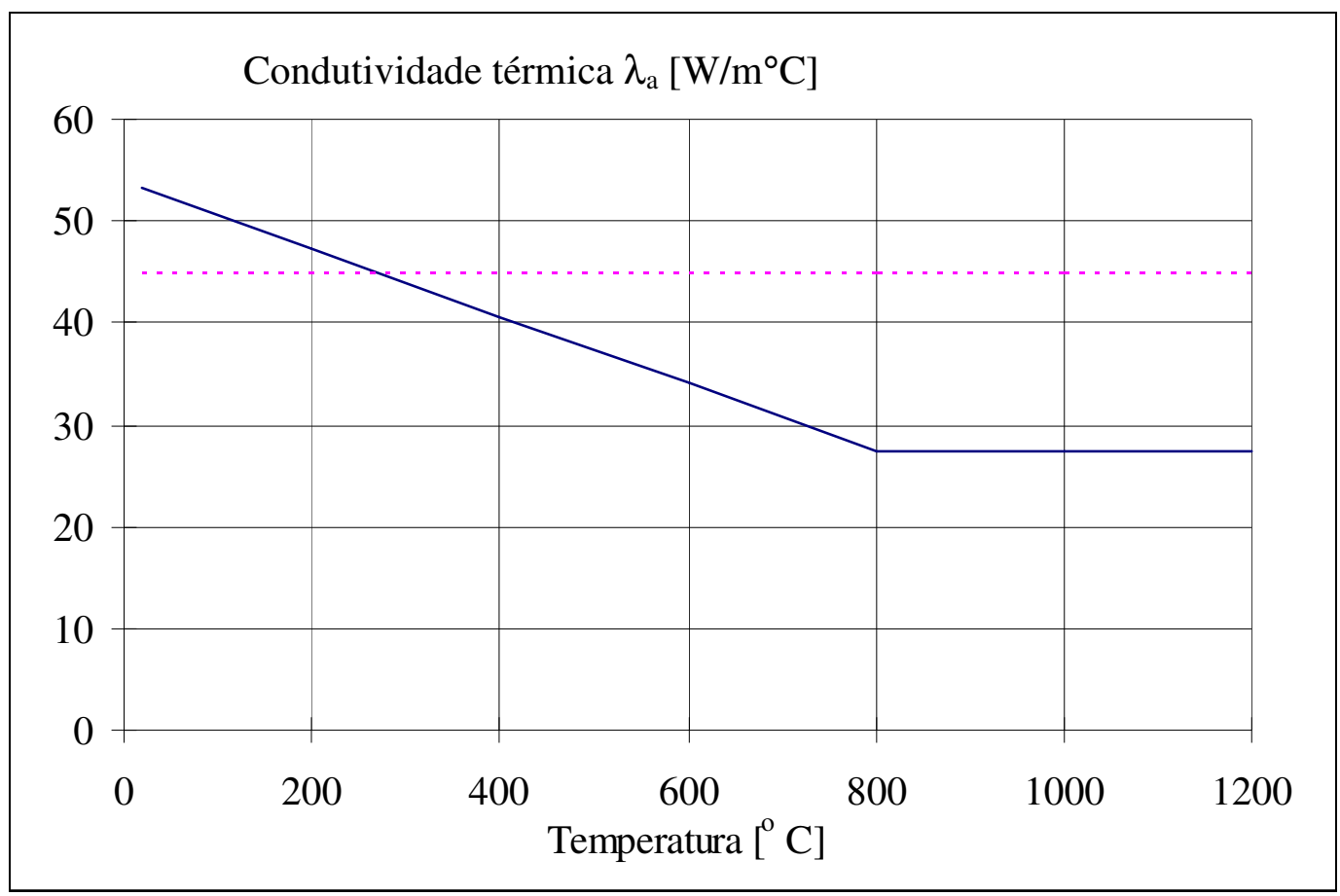

Figura A.2 - Gráfico de condutividade térmica conforme temperatura. Fonte: NBR 14323 (1999).

\section{A.4.ALONGAMENTO DO AÇO}

O EC3(2003) e a NBR 14323:1999 apresentam as equações A.7 a A.9 para cálculo de alongamentos do aço conforme a temperatura:

- $\operatorname{para} 20{ }^{\circ} \mathrm{C} \leq \theta_{a}<750{ }^{\circ} \mathrm{C}$

$\frac{\Delta l}{l}=1,2 \cdot 10^{-5} \theta_{a}+0,4 \cdot 10^{-8} \theta_{a}^{2}-2,416 \cdot 10^{-4}$

- $\quad \operatorname{para} 750{ }^{\circ} \mathrm{C} \leq \theta_{a} \leq 860{ }^{\circ} \mathrm{C}$

$$
\frac{\Delta l}{l}=1,1 \cdot 10^{-2}
$$


- $\operatorname{para} 860{ }^{\circ} \mathrm{C} \leq \theta_{a} \leq 1200{ }^{\circ} \mathrm{C}$

$\frac{\Delta l}{l}=2 \cdot 10^{-5} \theta_{a}-6,2 \cdot 10^{-3}$

Onde:

$l$ é o comprimento a $20^{\circ} \mathrm{C}$ em metros;

$\Delta l$ é expansão térmica em metros;

$\theta_{a}$ é a temperatura do aço em ${ }^{\circ} \mathrm{C}$.

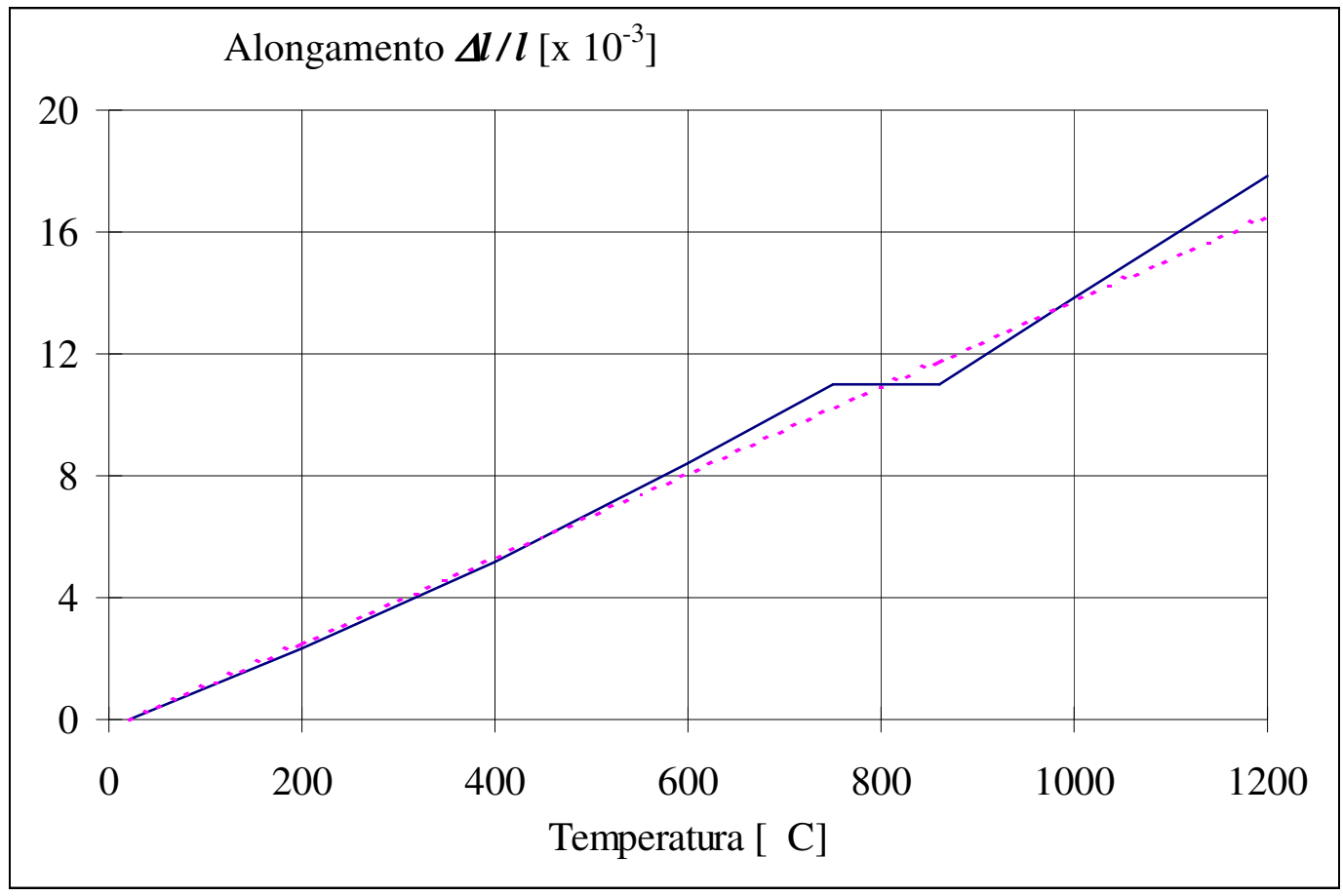

Figura A.3 - Alongamento do aço em função da temperatura. Fonte: NBR 14323 (1999)

A NBR 14323:1999 permite a adoção de simplificação cuja relação entre o alongamento do aço e a temperatura pode ser considerada constante, como mostra a equação A.10. 


$$
\frac{\Delta \ell}{\ell}=14 \times 10^{-6}\left(\theta_{a}-20\right)
$$

Onde:

l é o comprimento a $20{ }^{\circ} \mathrm{C}$ em metros;

$\Delta l$ é expansão térmica em metros;

$\theta_{a}$ é a temperatura do aço em ${ }^{\circ} \mathrm{C}$. 


\section{APÊNDICE B - VALIDAÇÃO DOS ESFORÇOS RESISTENTES (STRESFIRE)}

A validação dos esforços resistentes obtidos pelo programa de computador STRESFIRE foi confrontado pelos dois exemplos abaixo, calculados manualmente.

EXEMPLO B.1. Utilizando um dado cenário de incêndio, a temperatura máxima atingida pelo aço para um fator de massividade de $200 \mathrm{~m}^{-1}$ foi de $414,2^{\circ} \mathrm{C}$. As características mecânicas afetadas pela temperatura apresentam seus respectivos valores são:

$k_{y, \theta}=0,968$

$k_{E, \theta}=0,685$

As características do aço são:

$E=205.000 \mathrm{Mpa}$

$f_{y}=250 \mathrm{MPa}$

$\sigma_{r}=70 \mathrm{MPa}$

Características do perfil escolhido: W 250 x 32,7

$A=0,0042 \mathrm{~m}^{2}$

$d=0,258 \mathrm{~m}$

$h=h_{c}=0,240 \mathrm{~m}$

$h_{p}=d^{\prime}=0,220 \mathrm{~m}$

$t_{f}=0,0091 \mathrm{~m}$

$t_{w}=0,0061 \mathrm{~m}$

$b_{f}=0,146 \mathrm{~m}$ 


$$
\begin{aligned}
& r_{x}=0,1083 \mathrm{~m} \\
& r_{y}=0,0335 \mathrm{~m} \\
& I_{y}=473 \cdot 10^{-8} \mathrm{~m}^{4} \\
& I_{t}=10,44 \cdot 10^{-8} \mathrm{~m}^{4} \\
& W_{x}=382,710^{-6} \mathrm{~m}^{3} \\
& Z_{x}=428,5 \cdot 10^{-6} \mathrm{~m}^{3}
\end{aligned}
$$

\section{B.1.1. TRAÇÃO}

$$
N_{f i, R d}=k_{y, \theta} A_{g} f_{y} \rightarrow N_{f i, R d}=1019,68 \mathrm{kN}
$$

\section{B.1.2. COMPRESSÃO}

$$
\begin{aligned}
& L_{f l, x}=2,00 \mathrm{~m} \\
& L_{f l, y}=2,00 \mathrm{~m} \\
& \lambda_{0, \theta}=\frac{l_{f l} / r}{\sqrt{\frac{\pi^{2} \cdot k_{E, \theta} \cdot E}{k_{y, \theta} \cdot f_{y}}}} \rightarrow \lambda_{0, \theta}=0,789 \text { (em torno do eixo y) } \\
& \lambda_{0, \theta}=\frac{l_{f l} / r}{\sqrt{\frac{\pi^{2} \cdot k_{E, \theta} \cdot E}{k_{y, \theta} \cdot f_{y}}}} \rightarrow \lambda_{0, \theta}=0,244 \text { (em torno do eixo x) }
\end{aligned}
$$

Foi tomado o valor mais desfavorável, ou seja, $\lambda_{0, \theta}=0,789$. 


$$
\begin{aligned}
& \alpha_{\theta}=0,022 \sqrt{\frac{E}{f_{y}}} \rightarrow \alpha_{\theta}=0,63 \\
& \beta_{\theta}=\frac{1}{2}\left(1+\alpha_{\theta} \cdot \lambda_{o, \theta}+\lambda_{o, \theta}^{2}\right) \rightarrow \beta_{\theta}=1,060 \\
& \chi_{f i}=\frac{1}{\beta_{\theta}+\sqrt{\beta_{\theta}{ }^{2}-\lambda_{o, \theta}^{2}}} \leq 1 \rightarrow \chi_{f i}=0,566 \\
& \left.N_{f i, R d}=\chi_{f i} k_{y, \theta} A_{g} f_{y} \rightarrow N_{f i, R d}=576,47 \mathrm{kN}\right)
\end{aligned}
$$

\section{B.1.3. FLEXÃO SIMPLES}

Distância entre travamentos $\left(l_{b}\right)=2,00 \mathrm{~m}$

$$
\begin{aligned}
& C_{b}=1,00 \\
& \kappa_{1}=1,00 \\
& \kappa_{2}=1,00 \\
& M_{p l}=Z \cdot f_{y} \rightarrow M_{p l}=107,13 \mathrm{kN} . \mathrm{m}
\end{aligned}
$$

\section{B.1.3.1. FLAMBAGEM LOCAL DE ALMA (FLA)}

$$
\begin{aligned}
& \lambda=\frac{h}{t_{w}} \rightarrow \lambda=39,34 \\
& \lambda_{p, \theta}=3,76 \frac{h_{p}}{h} \sqrt{\frac{E \cdot k_{E, \theta}}{f_{y} \cdot k_{y, \theta}}} \rightarrow \lambda_{p, \theta}=83,03
\end{aligned}
$$




$$
\lambda_{r, \theta}=1,49\left(1+2,83 \frac{h}{h_{c}}\right) \sqrt{\frac{E \cdot k_{E, \theta}}{f_{y} \cdot k_{y, \theta}}} \rightarrow \lambda_{r, \theta}=146,70
$$

O parâmetro de esbeltez, está no intervalo $\lambda<\lambda_{p, \theta}$ assim, a expressão do momento resistente para flambagem local de alma, está apresentada abaixo:

$$
M_{f i, R d}=\kappa_{1} \kappa_{2} k_{y, \theta} M_{p l} \rightarrow M_{f i, R d}=103,78 \mathrm{kN} . \mathrm{m}
$$

\section{B.1.3.2. FLAMBAGEM LOCAL DE MESA COMPRIMIDA (FLM)}

$$
\begin{aligned}
& \lambda=\frac{b_{f}}{2 \cdot t_{f}} \rightarrow \lambda=8,02 \\
& \lambda_{p, \theta}=0,38 \sqrt{\frac{E \cdot k_{E, \theta}}{f_{y} \cdot k_{y, \theta}}} \rightarrow \lambda_{p, \theta}=9,16 \\
& \lambda_{r, \theta}=0,83 \sqrt{\frac{E \cdot k_{E, \theta}}{\left(f_{y}-\sigma_{r}\right) \cdot k_{y, \theta}}} \rightarrow \lambda_{r, \theta}=23,57
\end{aligned}
$$

O parâmetro de esbeltez, está no intervalo $\lambda<\lambda_{p, \theta}$, assim, a expressão do momento resistente para flambagem local de mesa comprimida, está apresentada abaixo:

$$
M_{f i, R d}=\kappa_{1} \kappa_{2} k_{y, \theta} M_{p l} \rightarrow M_{f i, R d}=103,78 \mathrm{kN} . \mathrm{m}
$$

\section{B.1.3.3. FLAMBAGEM LATERAL COM TORÇÃO (FLT)}

$$
\begin{aligned}
& \lambda=\frac{L_{b}}{r_{y}} \rightarrow \lambda=59,70 \\
& \lambda_{p, \theta}=1,76 \sqrt{\frac{E \cdot k_{E, \theta}}{f_{y} \cdot k_{y, \theta}}} \rightarrow \lambda_{p, \theta}=42,40
\end{aligned}
$$




$$
\begin{aligned}
& C_{w}=I_{y} \frac{\left(d-t_{f}\right)^{2}}{4} \rightarrow C_{w}=7,33.10^{-8} \mathrm{~m}^{6} \\
& G=0,385 E \rightarrow G=78925 \mathrm{MPa} \\
& M_{r}=W\left(f_{y}-\sigma_{r}\right) \rightarrow M_{r}=68,94 \mathrm{kN} . \mathrm{m} \\
& \lambda_{r, \theta}=\frac{\pi \sqrt{2 \cdot G \cdot k_{E, \theta} \cdot E \cdot k_{E, \theta} \cdot A \cdot I_{t}}}{2 \cdot M_{r} \cdot k_{y, \theta}} \sqrt{1+\sqrt{1+\frac{C_{w}}{I_{y}}\left(\frac{2 M_{r} \cdot k_{y, \theta}}{G \cdot k_{E, \theta} \cdot I_{t}}\right)^{2}}} \rightarrow \lambda_{r, \theta}=123,25
\end{aligned}
$$

O parâmetro de esbeltez, está no intervalo $\lambda_{p, \theta}<\lambda<\lambda_{r, \theta}$ assim, a expressão do momento resistente para flambagem lateral com torção, está apresentada abaixo:

$$
M_{f i, R d}=\frac{C_{b}}{1,2} k_{y, \theta}\left[M_{p l}-\left(M_{p l}-M_{r}\right) \frac{\lambda-\lambda_{p, \theta}}{\lambda_{r, \theta}-\lambda_{p, \theta}}\right] \rightarrow M_{f i, R d}=79,68 \mathrm{kN} . \mathrm{m}
$$

O menor momento resistente entre os três, é o momento resistente para flambagem lateral com torção, portanto, $M_{f i, R d}=79,68$ kN.m.

EXEMPLO B.2. Utilizando um dado cenário de incêndio, a temperatura máxima atingida pelo aço para um fator de massividade de $357,8 \mathrm{~m}^{-1}$ foi de $524,5^{\circ} \mathrm{C}$. As características mecânicas afetadas pela temperatura apresentam seus respectivos valores são:

$k_{y, \theta}=0,704$

$k_{E, \theta}=0,529$

As características do aço são:

$E=205.000 \mathrm{Mpa}$ 


$$
\begin{gathered}
f_{y}=250 \mathrm{MPa} \\
\sigma_{r}=70 \mathrm{MPa}
\end{gathered}
$$

Características do perfil escolhido: VS 250 x 21

$$
\begin{aligned}
& A=0,00264 \mathrm{~m}^{2} \\
& d=0,250 \mathrm{~m} \\
& h=h_{c}=h_{p}=d^{\prime}=0,237 \mathrm{~m} \\
& t_{f}=0,0063 \mathrm{~m} \\
& t_{w}=0,00475 \mathrm{~m} \\
& b_{f}=0,120 \mathrm{~m} \\
& r_{x}=0,1037 \mathrm{~m} \\
& r_{y}=0,0263 \mathrm{~m} \\
& I_{y}=182.10^{-8} \mathrm{~m}^{4} \\
& I_{t}=2,9.10^{-8} \mathrm{~m}^{4} \\
& W_{x}=22710^{-6} \mathrm{~m}^{3} \\
& Z_{x}=251.10^{-6} \mathrm{~m}^{3}
\end{aligned}
$$

\section{B.2.1. TRAÇÃO}

$$
N_{f i, R d}=k_{y, \theta} A_{g} f_{y} \rightarrow N_{f i, R d}=464,64 \mathrm{kN}
$$

\section{B.2.2. COMPRESSÃO}

$$
\begin{aligned}
& L_{f l, x}=3,00 \mathrm{~m} \\
& L_{f l, y}=2,00 \mathrm{~m}
\end{aligned}
$$




$$
\begin{aligned}
& \lambda_{0, \theta}=\frac{l_{f l} / r}{\sqrt{\frac{\pi^{2} \cdot k_{E, \theta} \cdot E}{k_{y, \theta} \cdot f_{y}}}} \rightarrow \lambda_{0, \theta}=0,975 \text { (em torno do eixo y) } \\
& \lambda_{0, \theta}=\frac{l_{f l} / r}{\sqrt{\frac{\pi^{2} \cdot k_{E, \theta} \cdot E}{k_{y, \theta} \cdot f_{y}}}} \rightarrow \lambda_{0, \theta}=0,371(\text { em torno do eixo } \mathrm{x})
\end{aligned}
$$

Foi tomado o valor mais desfavorável, ou seja, $\lambda_{0, \theta}=0,975$.

$$
\begin{aligned}
& \alpha_{\theta}=0,022 \sqrt{\frac{E}{f_{y}}} \rightarrow \alpha_{\theta}=0,63 \\
& \beta_{\theta}=\frac{1}{2}\left(1+\alpha_{\theta} \cdot \lambda_{o, \theta}+\lambda_{o, \theta}^{2}\right) \rightarrow \beta_{\theta}=1,282 \\
& \chi_{f i}=\frac{1}{\beta_{\theta}+\sqrt{\beta_{\theta}{ }^{2}-\lambda_{o, \theta}^{2}}} \leq 1 \rightarrow \chi_{f i}=0,473 \\
& N_{f i, R d}=\chi_{f i} k_{y, \theta} A_{g} f_{y} \rightarrow N_{f i, R d}=219,63 \mathrm{kN}
\end{aligned}
$$

\section{B.2.3. FLEXÃO SIMPLES}

Distância entre travamentos $\left(L_{b}\right)=2,00 \mathrm{~m}$

$$
\begin{aligned}
& C_{b}=1,00 \\
& \kappa_{1}=1,40 \\
& \kappa_{2}=1,00 \\
& M_{p l}=Z \cdot f_{y} \rightarrow M_{p l}=62,75 \mathrm{kN} . \mathrm{m}
\end{aligned}
$$




\section{B.2.3.1. FLAMBAGEM LOCAL DE ALMA (FLA)}

$$
\begin{aligned}
& \lambda=\frac{h}{t_{w}} \rightarrow \lambda=49,89 \\
& \lambda_{p, \theta}=3,76 \frac{h_{p}}{h} \sqrt{\frac{E \cdot k_{E, \theta}}{f_{y} \cdot k_{y, \theta}}} \rightarrow \lambda_{p, \theta}=93,33 \\
& \lambda_{r, \theta}=1,49\left(1+2,83 \frac{h}{h_{c}}\right) \sqrt{\frac{E \cdot k_{E, \theta}}{f_{y} \cdot k_{y, \theta}}} \rightarrow \lambda_{r, \theta}=141,66
\end{aligned}
$$

O parâmetro de esbeltez, está no intervalo $\lambda<\lambda_{p, \theta}$ assim, a expressão do momento resistente para flambagem local de alma, está apresentada abaixo:

$$
M_{f i, R d}=\kappa_{1} \kappa_{2} k_{y, \theta} M_{p l} \rightarrow M_{f i, R d}=61,85 \mathrm{kN} . \mathrm{m}
$$

\section{B.2.3.2. FLAMBAGEM LOCAL DE MESA COMPRIMIDA (FLM)}

$$
\begin{aligned}
& \lambda=\frac{b_{f}}{2 \cdot t_{f}} \rightarrow \lambda=9,52 \\
& \lambda_{p, \theta}=0,38 \sqrt{\frac{E \cdot k_{E, \theta}}{f_{y} \cdot k_{y, \theta}}} \rightarrow \lambda_{p, \theta}=9,43 \\
& k_{c}=\frac{4}{\sqrt{\frac{h}{t_{w}}}} \rightarrow k_{c}=0,566\left(0,350 \leq k_{c} \leq 0,763\right) \\
& \lambda_{r, \theta}=0,95 \sqrt{\frac{E \cdot k_{E, \theta}}{\left(f_{y}-\frac{\sigma_{r}}{k_{c}}\right) \cdot k_{y, \theta}}} \rightarrow \lambda_{r, \theta}=33,17
\end{aligned}
$$


O parâmetro de esbeltez, está no intervalo $\lambda_{p, \theta}<\lambda<\lambda_{r, \theta}$, assim, a expressão do momento resistente para flambagem local de mesa comprimida, está apresentada abaixo:

$$
\begin{aligned}
& M_{r}=W\left(f_{y}-\sigma_{r}\right) \rightarrow M_{r}=40,86 \mathrm{kN} . \mathrm{m} \\
& M_{f i, R d}=\kappa_{1} \kappa_{2} k_{y, \theta}\left[M_{p l}-\left(M_{p l}-M_{r}\right) \frac{\lambda-\lambda_{p, f i}}{\lambda_{r, f i}-\lambda_{p, f i}}\right] \rightarrow M_{f i, R d}=61,52 \mathrm{kN} . \mathrm{m}
\end{aligned}
$$

\section{B.2.3.3. FLAMBAGEM LATERAL COM TORÇÃO (FLT)}

$$
\begin{aligned}
& \lambda=\frac{L_{b}}{r_{y}} \rightarrow \lambda=76,05 \\
& \lambda_{p, \theta}=1,76 \sqrt{\frac{E \cdot k_{E, \theta}}{f_{y} \cdot k_{y, \theta}}} \rightarrow \lambda_{p, \theta}=43,69 \\
& C_{w}=I_{y} \frac{\left(d-t_{f}\right)^{2}}{4} \rightarrow C_{w}=2,70.10^{-8} \mathrm{~m}^{6} \\
& G=0,385 E \rightarrow G=78925 \mathrm{MPa} \\
& M_{r}=W\left(f_{y}-\sigma_{r}\right) \rightarrow M_{r}=40,86 \mathrm{kN} \cdot \mathrm{m} \\
& \lambda_{r, \theta}=\frac{\pi \sqrt{2 \cdot G \cdot k_{E, \theta} \cdot E \cdot k_{E, \theta} \cdot A \cdot I_{t}}}{2 \cdot M_{r} \cdot k_{y, \theta}} \sqrt{1+\sqrt{1+\frac{C_{w}}{I_{y}}\left(\frac{2 \cdot M_{r} \cdot k_{y, \theta}}{G \cdot k_{E, \theta} \cdot I_{t}}\right)^{2}}} \rightarrow \lambda_{r, \theta}=119,19
\end{aligned}
$$

O parâmetro de esbeltez, está no intervalo $\lambda_{p, \theta}<\lambda<\lambda_{r, \theta}$ assim, a expressão do momento resistente para flambagem lateral com torção, está apresentada abaixo:

$$
M_{f i, R d}=\frac{C_{b}}{1,2} k_{y, \theta}\left[M_{p l}-\left(M_{p l}-M_{r}\right) \frac{\lambda-\lambda_{p, \theta}}{\lambda_{r, \theta}-\lambda_{p, \theta}}\right] \rightarrow M_{f i, R d}=31,31 \mathrm{kN} . \mathrm{m}
$$

O menor momento resistente entre os três, é o momento resistente para flambagem lateral com torção, portanto, $M_{f i, R d}=31,31$ kN.m. 


\section{LISTA DE REFERÊNCIAS BIBLIOGRÁFICA}

[01] AMERICAN SOCIETY TESTING AND MATERIALS. ASTM E-119-Standard test methods for fire tests of buildings constructions and material. West Conshohocken (USA), 2000.

[02] ASSOCIAÇÃO BRASILEIRA DE NORMAS TÉCNICAS (ABNT). Dimensionamento de estruturas de aço de edifícios em situação de incêndio Procedimento. NBR 14323. Rio de Janeiro, 1999.

[03] ASSOCIAÇÃO BRASILEIRA DE NORMAS TÉCNICAS (ABNT). Exigências de resistência ao fogo de elementos construtivos de edificações - Procedimento. NBR 14423. Rio de Janeiro, 1999.

[04] ASSOCIAÇÃO BRASILEIRA DE NORMAS TÉCNICAS (ABNT). Perfil I estrutural de aço soldado por arco elétrico - Requisitos gerais. NBR 5884. Rio de Janeiro, 2005.

[05] ASSOCIAÇÃO BRASILEIRA DE NORMAS TÉCNICAS (ABNT). Projeto e execução de estruturas de aço e de estruturas mistas de aço e concreto de edifícios Procedimento. NBR 8800. Rio de Janeiro, 1999.

[06] ASSOCIAÇÃO BRASILEIRA DE NORMAS TÉCNICAS (ABNT). Ações e segurança nas estruturas - Procedimento. NBR 8681. Rio de Janeiro, 2003. 
[07] BABRAUSKAS, V.; PEACOCK, R.D. Heat release rate: the single most important variable in fire hazard. Fire Safety Journal (vol.18), 1992. Disponível em http://fire.nist.gov/bfrlpubs/fire92/art019.html [acesso em 25/05/05]

[08] BABRAUSKAS, V. (ed.); GRAYSON, S.J. (ed.) Heat release in fires. New York: Elsevier Applied Sciences, 1992. Chapter 2-5, 7-22p. Disponível em http://fire.nist.gov/bfrlpubs/fire92/PDF/f92027.pdf [acesso em 25/05/05]

[09] BABRAUSKAS,V.; PEACOCK, R.D.; RENEKE, P.A. Defining flashover for fire hazard calculations: Part II. Fire Safety Journal 38, 2003. Disponível em http://fire.nist.gov/bfrlpubs/fire03/art001.html [acesso em 25/05/05]

[10] BARNETT, C. R. Design fires for structural engineers. IPENZ Transactions (vol. 25), 1998.

[11] BEITEL, J.; IWANKIN, N. Analysis of needs and existing capabilities for fullscale fire. Building and Fire Research Laboratory. National Institute of Standards and Technology, 2002.

[12] BOUNAGUI, A.; BÉNICHOU, N. Literature Review on the Modeling of Fire Growth and Smoke Movement. Institute for Research in Construction, 2003. Disponível em http://irc.nrc-cnrc.gc.ca/ircpubs [acesso em 10/04/05]

[13] BUCHANAN, A.; FEASEY, R. Post flashover fires for structural design. Fire Safety Journal, vol. 37/2 p. 83-105, 2002. 
[14] CADORIN, J.F On the application field of OZone V2- Rapport interne NM\&S/2002-003. Département M\&S - Université de Liège, 2002.

[15] CADORIN, J.F.; FRANSSEN, J.M. Compartment fire models for structural enginnering. Tese (Doutorado), Universidade de Liége, Belgium, 2003. 201p. Disponível em http://www.ulg.ac.be/matstruc/en/download.html [acesso em 20/04/05]

[16] COMITÉ EUROPÉEN DE NORMALISATION. Eurocode 1 - Draft prEN 19911-1-2 Actions on structures - Part 1-2: general actions - actions on structures exposed to fire. Brussels, 2002.

[17] COMITÉ EUROPÉEN DE NORMALISATION. Eurocode 3 -Draft ENV 1993-12- Design of steel structures. Part 1.2: general rules structural fire design. Brussels, 2003.

[18] COSTA, C. N.; SILVA, V. P. Estruturas de concreto em situação de incêndio. Dissertação (Mestrado) - Escola Politécnica, Universidade de São Paulo, São Paulo, 2002. 241p.

[19] DRYSDALE, D. An introduction to fire dynamics. $2^{\text {nd }}$ Edition, West Sussex, England: John Wiley and Sons, 1999.

[20] FRANSSEN, J. M. Improvement of the parametric fire of Eurocode 1 based on Experimental Test Results. Fire Safety Science - Procedings of the sixth international symposium, 1999. 927-938p. ISBN 0-925-223-25-5. 
[21] FRANSSEN, J. M. ; ZAHARIA, R. Design of Steel Structures subjected to fire Background and Design Guide to Eurocode. Lés Éditions de 1'Université de Liège, 2005. ISBN 2-930322-99-3

[22] GEWAIN, R. G.; IWANKIW, N. R.; ALFAWAKHIRI F. Facts for Steel Buildings. American Institute of Steel Construction, 2003.

[23] HALL, J.R. Jr. High-rise building fires. NFPA Report, Quincy, MA, 2003.

[24] HAMINS, A.; KASHIWAGI, T.; BURCH, R. Characteristics of pool fire burning. Building and fire research laboratory - National institute of standards and technology, 1996. Disponível em http://fire.nist.gov/bfrlpubs/fire96/art068.html [acesso em $25 / 05 / 05]$

[25] HOLMAN, J.P.; MILANEZ, L.F. (trad.) Transferência de calor. São Paulo: McGraw-Hill, 1983.

[26] INTERNATIONAL IRON AND STEEL INSTITUTE. Fire engineering design for steel structures. Brussels, 1993. Chapter 2 - Principles of fire safety.

[27] JANICAK, C.A. Retrofitting existing high-rise buildings with sprinkler systems. Illinois State University. Disponível em: http://www.firesprinklerassoc.org/ high-rise \%20fire\%20safety-tom\%20lia.doc [acesso em 20/04/05]

[28] JANSSENS, M.L. Heat release rate. 2000 
[29] JEANSSON, S.; ANDERBERG, Y. Multi-storey structures, behavior in case of fire. Dissertação (Mestrado), Fire Safety Design AB, Sweden, 2001. 86p. Disponível em http://www.fsd.se/fou/artiklar/multistorey.pdf [acesso em 16/05/05]

[30] KAEFER, E. C. ; SILVA, V. P. Análise paramétrica de um incêndio conforme o novo Eurocode 1. In anais do XXIV Iberian latin-american congress on computational methods in engeneering - CILAMCE. Ouro Preto. 2003.

[31] KENNEDY, P.M. ; KENNEDY, K.C. Flashover and fire analysis - A discussion of the practical use of flashover in fire investigation, 2003. Disponível em http://ncfs.ucf.edu/twgfex/flashover\%20and\%20fire\%20analysis_patrick\%20kennedy_.p df [acesso em 25/05/05]

[32] KREITH, F. YAMANE E.(trad.); SILVARES, O.M.(trad.); OLIVEIRA, V. R. L.(trad.) Princípios de transmissão de calor. São Paulo: Edgard Blücher, 1977.

[33] KRIEGER, G.C. Notas de aula do curso de especialização em gestão da segurança contra incêndios e explosões. PECEIUSP, São Paulo, 2001.

[34] KRUPPA, J. Characterization of Fire Protection Materials of Steel Elements Sensitivity Study of a Simplified Assessment Method. Fire Safety Science Procedings of the sixth international symposium, 2000. 915-926p.

[35] LAMONT, S.; USMANI, A.S.; DRYSDALE, D.D.; LANE, B.; ROTTER, J.M. The behaviour of multi-storey composite steel framed structures in response to 
compartment fires. Tese (Doutorado) University of Edinburgh, 2001. Disponível em http://guardian.150m.com/fire/slamont.htm [acesso em 25/05/05]

[36] LIE, T.T.(ed.) Fire protection handbook. National Fire Protection Association, Boston, 15th edition.

[37] LIENHARD, J.H. A heat transfer textbook. Phlogiston Press, 2005. Disponível em http://web.mit.edu/lienhard/www/ahtt.html [acesso em 20/12/05]

[38] OLENICK, S.M.; CARPENTER, D. J. An updated international survey of computer models for fire and smoke. Journal of Fire Protection Engineering (vol. 13) Combustion Science \& Engineering Inc., Columbia, USA, 2003. Disponível em http://www.firemodelsurvey.com/pdf/olenick_carpenter_jfpe_87-110.pdf [acesso em 25/05/05]

[39] PANNONI, F.D. Princípios da proteção de estruturas metálicas em situação de corrosão e incêndio. (vol 2), $1^{\mathrm{a}}$. edição, 2002. 1 CD-ROM.

[40] PARKINSON, D.; BARNETT, J. R. Performance based design of structural steel for fire conditions. Dissertação (mestrado) - Worcester Polytechnic Institute, 2001.

[41] PEACOCK, R.D.; REKENE, P.A., BUKOWSKI, R.W.; BABRAUSKAS, V. Defining flashover for fire hazard calculations. Fire Safety Journal (ed. 32),1999. Disponível em http://fire.nist.gov/bfrlpubs/fire03/art001.html [acesso em 25/05/05] 
[42] PETTERSON, O.; MAGNUSSON, S.E.; THOR, J. Fire engineering design of steel structures. Publication 50, Swedish Institute of Steel Construction, Stockholm, 1976.

[43] QUINTIERE, J.G. Some aspects of fire growth. National Institute of Standards and Technology, 2000. Disponível em http://fire.nist.gov/bfrlpubs/fire00/art137.html [acesso em 25/05/05]

[44] RIBEIRO, J.C.L.; FAKURY, R. H. Simulação via método dos elementos finitos da distribuição tridimensional da temperatura em estruturas em situação de incêndio. Dissertação (Mestrado). Universidade Federal de Minas Gerais, 2004. 176.

[45] SILVA, V.P. Estruturas de aço em situação de incêndio. Tese (Doutorado) Escola Politécnica, Universidade de São Paulo, São Paulo, 1997. 170p.

[46] SILVA, V.P. Ação térmica nas estruturas. O modelo do incêndio natural compartimentado. Boletim Técnico PEF 9911, Escola Politécnica, São Paulo, 1999.

[47] SILVA, V.P. Estruturas de aço em situação de incêndio. São Paulo: Zigurate Editora, 2001. 249p.

[48] SILVA, V. P. "Determination of the steel fire protection material thickness by analytical process - A simple derivation". Engineering Structures, ed. 27. ISSN: 01410296. 2005. 
[49] SILVA, V.P. Determination of the temperature of thermally unprotected steel members under fire situations. Considerations on the section factor. Trabalho submetido ao Latin American Journal of Solids \& Structures. ISSN: 1679-7817. 2005b.

[50] SPEARPOINT, M.J.; QUINTIERE, J.G. Predicting the burning of wood using an integral method. University of Maryland, USA, 2000. Disponível em http:// [41] http://fire.nist.gov/bfrlpubs/fire00/art146.html [acesso em 25/05/05]

[51] STECKLER, K.D. Estimation of rate of heat release by means of oxygen consumption measurements. Disponível em http://nvl.nist.gov/pub/nistpubs/sp958lide/280-282.pdf [acesso em 25/05/05]

[52] VARGAS, M.R.; SILVA, V.P. Resistência ao fogo das estruturas de aço. Instituto Brasileiro de Siderurgia - Centro Brasileiro da Construção em Aço. Rio de Janeiro, 2003.

[53] WALTON, W.D.; THOMAS, P.H.; DINENNO, J.P.(ed.); BEYLER, C.L. (ed.); CUSTER, R.L.P. (ed.); WALTON, W.D. (ed.) Estimating temperatures in compartment fires. SPFE Handbook of Fire Protection Engeneering, $2^{\text {nd }}$ edition, 1995. Chapter 6, Section 3. Disponível em http://fire.nist.gov/bfrlpubs/fire95/art044.html [acesso em 25/05/05]

[54] WHITE, R.H.; DIETENBERGER, M.A. Wood handbook - Wood as an engineering material. Forest Products Laboratory, USA, 1999. Chapter 17. Disponível em http://www.fpl.fs.fed.us/documnts/fplgtr/fplgtr113/ch17.pdf [acesso em 16/05/05] 
[55] WICKSTRÖM, U. Temperature analysis of heavily-insulated steel structures exposed to fire. Fire Safety Journal (vol. 9), 1985 